JOINT TRANSPORTATION RESEARCH PROGRAM

FHWA/IN/JTRP-2010/13

Final Report

DETERMINING OF THE BINDER CONTENT OF HOT MIX ASPHALT CONTAINING DOLOMITIC AGGREGATES USING THE IGNITION OVEN

Karol J. Kowalski

Rebecca S. McDaniel

Jan Olek

Ayesha Shah

October 2010 


\section{TECHNICAL Summary}

INDOT Research

Technology Transfer and Project Implementation Information

TRB Subject Code:

Publication No.: FHWA/IN/JTRP-2010/13, SPR-2862

October 2010

Final Report

\section{Determining of the Binder Content of Hot Mix Asphalt Containing Dolomitic Aggregates Using the Ignition Oven}

\section{Introduction}

The binder content of an HMA mix is one of the critical factors affecting the quality of the mix. The ignition oven is one widely used method for determining the binder content, however, its use is problematic with some types of aggregates, including dolomites. With these aggregates, the mass loss continues after the binder is burned off as the aggregates decompose and the test does not terminate at a stable mass. Since dolomites are commonly used in hot mix asphalt in Indiana, the ignition oven cannot be

\section{Findings}

- The research results presented in this report proved that HMA mixtures containing dolomitic aggregate will experience additional mass loss during the ignition oven test above that expected from burning off the binder alone. That additional mass loss is the result of the decomposition of the dolomitic aggregate. Furthermore, research proved that for HMA containing dolomite the mass loss occurring during the ignition oven test is both temperature and time dependent. Additional mass loss may be reduced if the ignition oven test is conducted at a lower temperature or by shortening the length of the testing period. The use of a temperature as low as $427^{\circ} \mathrm{C}$ was shown to adequately remove the binder from the mix.

- The temperature observed during the typical ignition oven test can be significantly (40 to $60^{\circ} \mathrm{C}$ ) higher than the pre-set oven temperature, depending on the type of the used with some mixes or in some parts of the state where they are prevalent.

Research was needed to establish a modified ignition oven test procedure that would allow for the accurate binder content determination for HMA containing dolomite, a common type of aggregate in Indiana. Therefore, this study investigated the factors that affect this mass loss in problematic aggregates and developed a modified ignition oven procedure to limit this mass loss.

mix. This increase in the temperature will lead to additional mass losses in mixes with susceptible aggregate.

- In this study, it was found that the temperature difference between the top and bottom baskets is significant, amounting to around $58^{\circ} \mathrm{C}$. In the vicinity of the dolomite decrepitation temperature, this temperature increase of $58^{\circ} \mathrm{C}$ in the top basket may result in increased mass loss and decomposition of the aggregate. If HMA were placed only in the bottom basket, the sample temperature would be more uniform and decomposition would be limited.

- Based on these findings, a modified ignition oven test procedure was developed. The method involves placing half the total sample mass in the bottom basket only, then running the ignition oven procedure at a temperature of $427^{\circ} \mathrm{C}$. Comparisons 
between the binder content test methods

(solvent extraction and modified ignition oven test run at $427^{\circ} \mathrm{C}$ or $800^{\circ} \mathrm{F}$ ) proved that both test methods yield similar results.

\section{Implementation}

Based on the results of this study, the modified ignition oven test method is therefore recommended for use with problematic aggregates. This method should be used with known problematic aggregates or unfamiliar aggregates when the calibration factor is determined to be greater than or equal to 1.0 or when the standard test does not automatically terminate in less than 90 minutes.

An implementation study is also proposed to apply the modified method on pilot projects in one or two of the districts where ignition ovens are now rarely used. The results may be used to validate the proposed method and also to further refine the criteria for use. The need to run the ignition oven procedure twice to obtain enough aggregate to perform a sieve analysis should also be evaluated.

Materials Management and district testing personnel are recommended to be involved in the implementation of the findings of this study. The equipment is already available within the department and no modifications to the equipment are required to implement the modified test method. Proposed changes to the current Indiana Test Method (ITM No. 586) incorporating the modified method as an alternate have been prepared to facilitate adoption.

\section{Contact}

For more information:

\section{Dr. Rebecca McDaniel}

Principal Investigator

Technical Director

North Central Superpave Center

Purdue University

West Lafayette IN 47907

Phone: (765) 463-2317

E-mail: rsmcdani@.purdue.edu

\author{
Indiana Department of Transportation \\ Division of Research \& Development \\ 1205 Montgomery Street \\ P.O. Box 2279 \\ West Lafayette, IN 47906 \\ Phone: (765) 463-1521 \\ Fax: (765) 497-1665

\section{Purdue University} \\ Joint Transportation Research Program \\ School of Civil Engineering \\ 550 Stadium Mall Drive \\ West Lafayette, IN 47907 \\ Phone: (765) 494-9310 \\ E-mail: jtrp@ecn.purdue.edu \\ http://www.purdue.edu/jtrp
}


Final Report

\title{
Determining the Binder Content of Hot Mix Asphalt Containing Dolomitic Aggregates Using the Ignition Oven
}

\author{
Karol J. Kowalski \\ Assistant Professor and Scholar of Foundation for Polish Science \\ Warsaw University of Technology
}

Rebecca S. McDaniel

Principal Investigator

Jan Olek

Co-Principal Investigator

Ayesha Shah

Research Engineer

School of Civil Engineering

Purdue University

and

Joint Transportation Research Program

Project No. C-36-6TT

File No. 2-4-46

SPR-2862

Prepared in Cooperation with the

Indiana Department of Transportation and the

U.S. Department of Transportation

Federal Highway Administration

The contents of this report reflect the views of the authors who are responsible for the facts and the accuracy of the data presented herein. The contents do not necessarily reflect the official views or polices of the Federal Highway Administration and the Indiana Department of Transportation. This report does not constitute a standard, specification or regulation.

Purdue University

West Lafayette, Indiana 47907

October 2010 
TECHNICAL REPORT STANDARD TITLE PAGE

\begin{tabular}{|c|c|}
\hline $\begin{array}{l}\text { 1. Report No. } \\
\text { FHWA/IN/JTRP-2010/13 }\end{array}$ & 3. Recipient's Catalog No. \\
\hline \multirow{3}{*}{$\begin{array}{l}\text { 4. Title and Subtitle } \\
\text { Determining of the Binder Content of Hot Mix Asphalt Containing Dolomitic } \\
\text { Aggregates Using the Ignition Oven }\end{array}$} & 5. $\quad$ Report Date \\
\hline & October 2010 \\
\hline & 6. Performing Organization Code \\
\hline \multirow{2}{*}{$\begin{array}{l}\text { 6. } \quad \text { Author(s) } \\
\text { Karol J. Kowalski, Rebecca S. McDaniel, Jan Olek, Ayesha Shah }\end{array}$} & 8. Performing Organization Report No. \\
\hline & FHWA/IN/JTRP-2010/13 \\
\hline \multirow[t]{2}{*}{$\begin{array}{l}\text { 9. Performing Organization Name and Address } \\
\text { Joint Transportation Research Program } \\
550 \text { Stadium Mall Drive } \\
\text { Purdue University } \\
\text { West Lafayette, IN } 47907-2051\end{array}$} & 10. Work Unit No. \\
\hline & $\begin{array}{l}\text { 11. Contract or Grant No. } \\
\text { SPR-2862 }\end{array}$ \\
\hline \multirow[t]{2}{*}{$\begin{array}{l}\text { 12. Sponsoring Agency Name and Address } \\
\text { Indiana Department of Transportation } \\
\text { State Office Building } \\
100 \text { North Senate Avenue } \\
\text { Indianapolis, IN } 46204\end{array}$} & $\begin{array}{l}\text { 13. Type of Report and Period Covered } \\
\text { Final Report }\end{array}$ \\
\hline & 14. Sponsoring Agency Code \\
\hline
\end{tabular}

\section{Supplementary Notes}

Prepared in cooperation with the Indiana Department of Transportation and Federal Highway Administration.

16. Abstract

The binder content of an HMA mix is one of the critical factors affecting the quality of the mix. The ignition oven is one widely used method for determining the binder content, however, its use is problematic with some types of aggregates, including dolomites. With these aggregates, the mass loss continues after the binder is burned off as the aggregates decompose and the test does not terminate at a stable mass. This study investigated the factors that affect this mass loss in problematic aggregates and developed a modified ignition oven procedure to limit this mass loss.

The mass loss in the ignition oven was found to be both time and temperature dependent. The mass loss is also related to the binder content in the mixture. When the binder in the mixture ignites, the oven temperature increases and exceeds the pre-set test temperature. Temperature variations inside the ignition oven result in higher temperatures in the vicinity of the upper basket; these temperature differences are even more pronounced when the binder ignites. These higher temperatures can result in increased mass loss with problematic aggregates. A test temperature as low as $427^{\circ} \mathrm{C}$ was found to be effective for removing the binder from a mixture.

Therefore a modified ignition oven procedure was developed to control the temperatures and limit the additional mass loss for problematic aggregates. The method involves placing half the total sample mass in the bottom basket only and running the ignition oven at a temperature of $427^{\circ} \mathrm{C}$. This method was verified by testing six different plant produced mixes containing problematic aggregate and by comparing the results to results of the standard ignition oven method and to solvent extraction. The modified method is recommended for use with problematic aggregates or where the standard test method yields calibration factors greater than 1.0 or the test does not terminate automatically.

\section{Key Words}

Hot Mix Asphalt, ignition oven, binder content, dolomite

\section{Distribution Statement}

No restrictions. This document is available to the public through the National Technical Information Service, Springfield, VA 22161

19. Security Classif. (of this report)
Unclassified

Form DOT F 1700.7 (8-69)
20. Security Classif. (of this page)

Unclassified

\begin{tabular}{|l|l|}
\hline 21. No. of Pages & 22. Price \\
130 & \\
\hline
\end{tabular}




\section{Table of Contents}

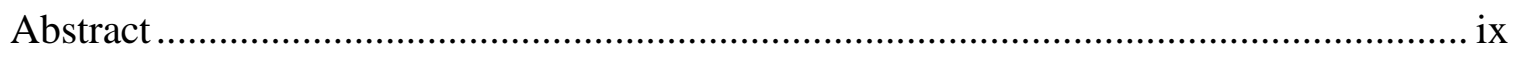

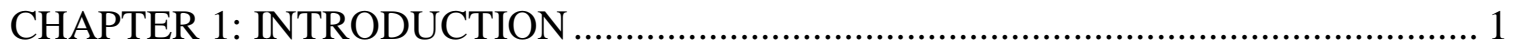

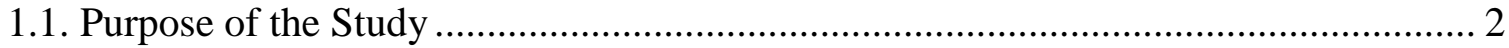

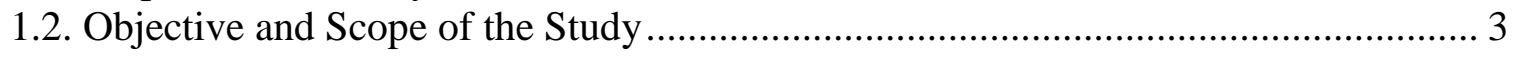

1.3. Organization of the Report................................................................................. 4

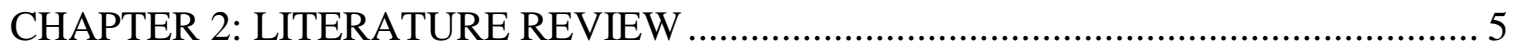

2.1. Binder Content Determination Methods ................................................................ 5

2.2. States' Experiences with HMA Containing Dolomitic Aggregates ............................ 9

2.3. Dolomite Decomposition Study ……………………........................................... 12

2.4. Alternates Explored ....................................................................................... 15

CHAPTER 3: TEST PROGRAM, MATERIALS AND EQUIPMENT ……………....... 17

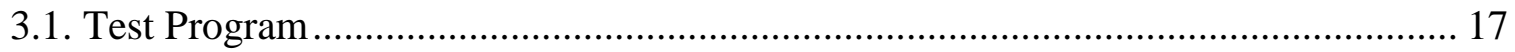

3.2. Material Characterization............................................................................ 22

3.2.1. Phase One Materials ………………………….................................. 23

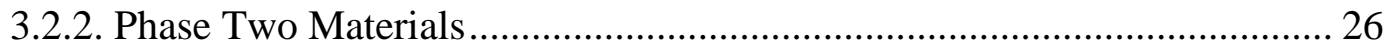

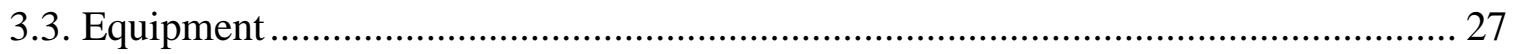

3.3.1. Thermolyne Ignition Oven.......................................................................... 28

3.3.2. Tempyrox Pyro-Clean ${ }^{\circledR}$ Glassware Cleaning Oven ..................................... 33

3.3.3. Compositional Analysis ............................................................................. 36

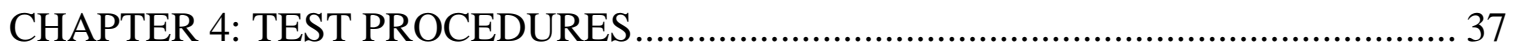

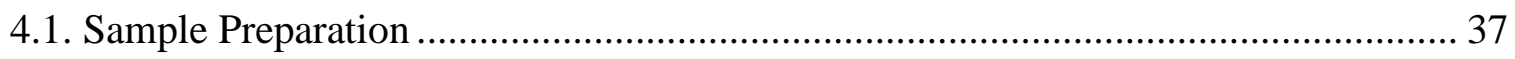

4.2. Tests in the Thermolyne Ignition Oven ............................................................... 38

4.2.1. Thermal Shock Method........................................................................... 40

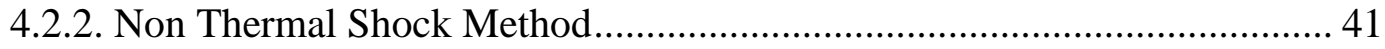

4.2.3. Two-Step Tests ......................................................................................... 42

4.3. Tests in Tempyrox Pyro-Clean ${ }^{\circledR}$ Glassware Cleaning Oven .................................... 44

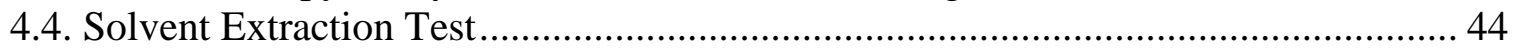

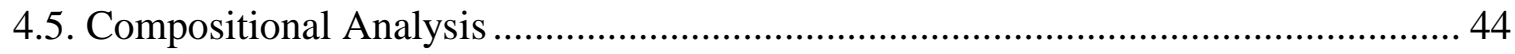

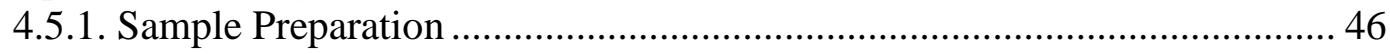

4.5.2. Test Procedure ………………………………….................................. 47

CHAPTER 5: TEST RESULTS AND DISCUSSION - PHASE ONE ............................ 49

5.1. Task 1 - Standard Ignition Oven Results for Non-Problematic Aggregate ................ 49

5.2. Task 2 - Influence of Test Method on HMA with Problematic Aggregate ............... 52 
5.3. Task 3 - Influence of Mix Type on Ignition Test Results ..................................... 56

5.4. Task 4 - Influence of Binder Content on the Ignition Process ................................. 58

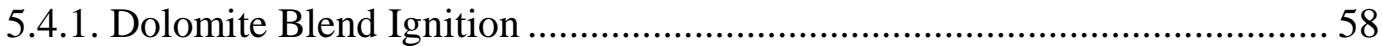

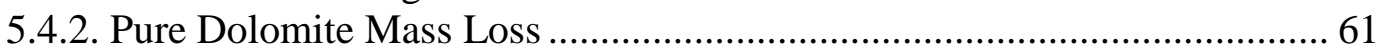

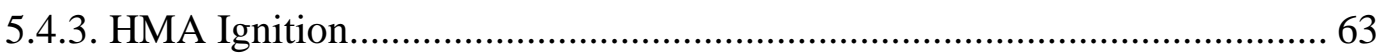

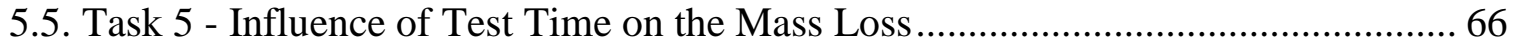

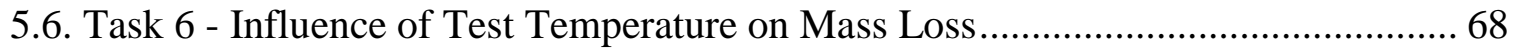

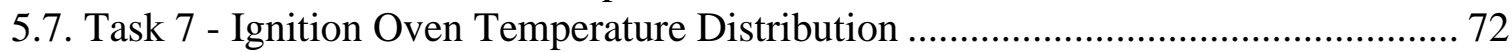

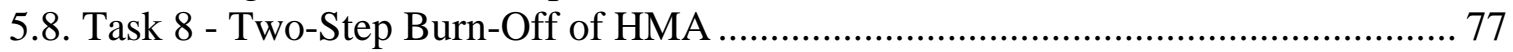

5.9. Task 9 - Changes in Sample Mass Observed after the Ignition Test ........................ 80

5.10. Task 10 - Comparison of Test Results from Ignition and Glass Cleaning Ovens ... 82

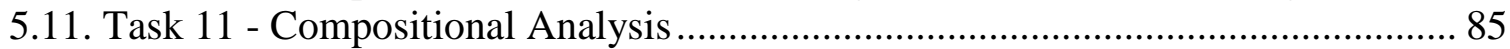

5.11.1. Dolomitic Aggregate Extracted from the HM-1 Mixture....................... 85

5.11.2. Dolomitic Aggregate Blend Tested Alone (No Prior Binder Contact) ..... 87

5.11.2. Comparison of Dolomitic Aggregate Blend with Dolomite from Mix..... 89

5.11.3. Comparison of Pure Dolomite with DB-1 and HM-1 Dolomitic Blends . 92

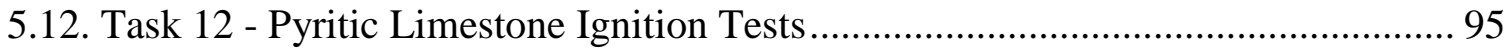

5.13 Phase One Conclusions and Phase Two Plan ...................................................... 96

CHAPTER 6: TEST RESULTS AND DISCUSSIONS - PHASE II........................... 100

6.1. Task 13 - Comparison of Standard and Modified Ignition Oven Methods ............. 100

6.2. Task 14 - Comparison of the Modified IO Method and Solvent Extraction ........... 102

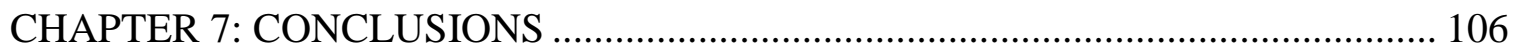

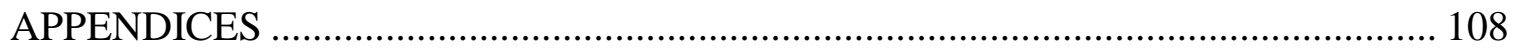

Appendix A: Temperature Distribution and Variation ............................................. 109

Appendix B: Compositional Analysis .................................................................. 112

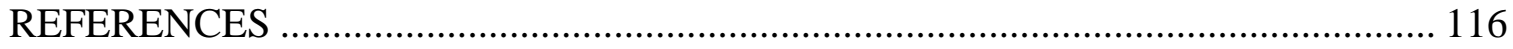

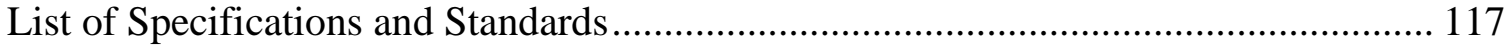

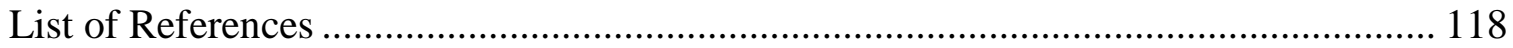




\section{LIST OF FIGURES}

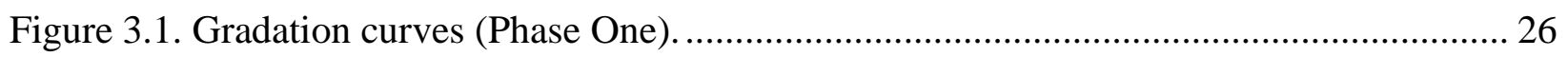

Figure 3.2. Plant-Produced HMA gradation curves (Phase Two) ........................................ 27

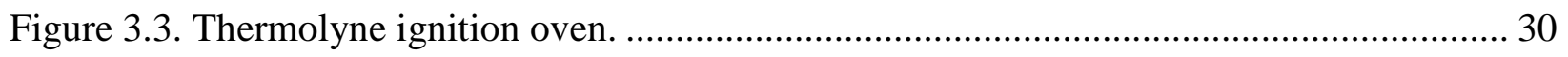

Figure 3.4. Setup of the thermister and thermocouples - front view.................................... 30

Figure 3.5. Setup of the thermister and thermocouples - top view. ...................................... 31

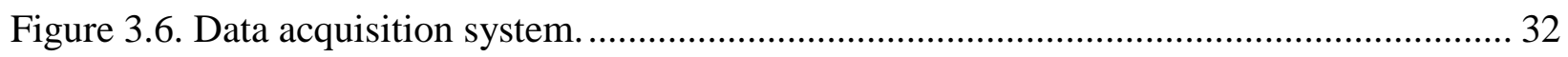

Figure 3.7. Thermocouple attached to a basket (junction not covered by the HMA)................. 32

Figure 3.8. Thermocouple junction embedded in the HMA.................................................. 33

Figure 3.9. Tempyrox Pyro-Clean ${ }^{\circledR}$ Glasware Cleaning Oven .................................................. 34

Figure 4.1. HMA and dolomite blend - sketch of the tests in Thermolyne Ignition Oven (IO) and

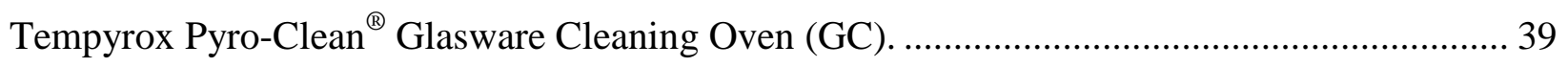

Figure 5.1. Ignition oven temperature and mass loss versus time for non problematic HM-0 at

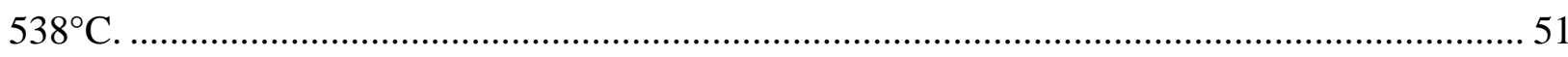

Figure 5.2. Typical TS and nTS ignition test results for HM-1 with $4.6 \%$ binder at $538^{\circ} \mathrm{C} \ldots \ldots . .53$

Figure 5.3. Comparison of aggregate gradation before IO, after nTSand TS tests; HM-1 mix with

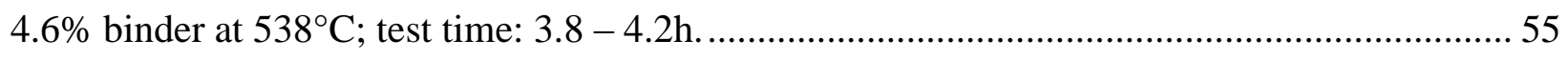

Figure 5.4. Comparison of temperature and mass loss during IO tests at $538^{\circ} \mathrm{C}$ for $\mathrm{HM}-1(4.6 \%$

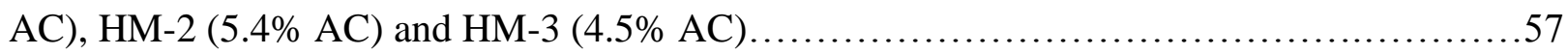

Figure 5.5. Results of typical TS and nTS ignition tests for DB-1; test temperature: $1000^{\circ} \mathrm{F}$ or $538^{\circ} \mathrm{C}$. 
Figure 5.6. Influence of ignition process on gradation; sample without binder at $538^{\circ} \mathrm{C}$. 60

Figure 5.7. Relationship between dolomite oven dried specific gravity measured before and after IO; sample without binder at $538^{\circ} \mathrm{C}$

Figure 5.8. Relationship between dolomite absorption measured before and after IO test; sample without binder at $538^{\circ} \mathrm{C}$ 61

Figure 5.9. Comparison of DB-1 and PD samples mass loss in TS and nTS tests at $538^{\circ} \mathrm{C} \ldots \ldots . .62$ Figure 5.10. Influence of binder content on the nTS ignition oven process for HM-1 with 3 binder contents at $538^{\circ} \mathrm{C}$. 633

Figure 5.11. Effect of binder content on mass loss in nTS ignition test for DB-1 and HM-1 at $538^{\circ} \mathrm{C}$

Figure 5.12. Relationship between mass loss and IO test time; HM-1, 4.6\% binder content at $538^{\circ} \mathrm{C}$

Figure 5.13. Relationship between dolomite blend mass loss and IO test time at $538^{\circ} \mathrm{C}$. 67

Figure 5.14. Influence of target test temperature on mass loss and oven temperature during IO;

$\mathrm{HM}-1$ with $4.6 \%$ binder at $538^{\circ} \mathrm{C}, 483^{\circ} \mathrm{C}, 427^{\circ} \mathrm{C}$.

Figure 5.15. Slope comparison; test time: 240 minutes, TS test method; HM-1 with $4.6 \%$ binder and DB-1; at $538^{\circ} \mathrm{C}, 483^{\circ} \mathrm{C}, 427^{\circ} \mathrm{C}$. 70

Figure 5.16. Relationship between test temperature and mass loss; HM-1 with $4.6 \%$ binder sample; test temperatures: $1000^{\circ} \mathrm{F}$ or $538^{\circ} \mathrm{C}, 900^{\circ} \mathrm{F}$ or $483^{\circ} \mathrm{C}, 800^{\circ} \mathrm{F}$ or $427^{\circ} \mathrm{C}$. 71

Figure 5.17. Relationship between test temperature and mass loss; DB- 1 sample at $538^{\circ} \mathrm{C}, 483^{\circ} \mathrm{C}$, $427^{\circ} \mathrm{C}$. 71

Figure 5.18. Typical temperature distribution plot: a) HM-1, b) DB-1 at $483^{\circ} \mathrm{C}$ 73 
Figure 5.19. Relationship between ignition oven thermsitor, TC1 and TC2 when temperature

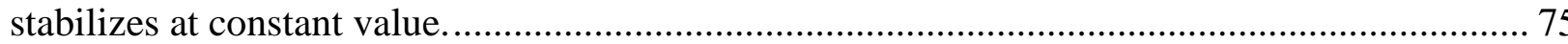

Figure 5.20. Oven thermistor temperature variation during tests with HM-1, 4.6\% binder........ 76

Figure 5.21. Calculated area under the IO thermistor temperature curve for HM-1 with $4.6 \%$

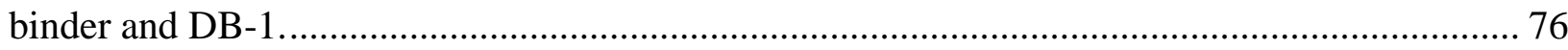

Figure 5.22. Temperature distribution during two step ignition test (HM-1 with $4.6 \%$ binder). . 78

Figure 5.23. Mass loss during the typical two step ignition test (HM-1 with $4.6 \%$ binder)........ 79

Figure 5.24. HM-1 mass loss measured at various times after the end of IO test; TS method..... 81

Figure 5.25. DB-1 mass loss measured at various times after the end of IO test; TS method. .... 81

Figure 5.26. Comparison of the temperature measured during tests with HM-1 (4.6\% of binder) d

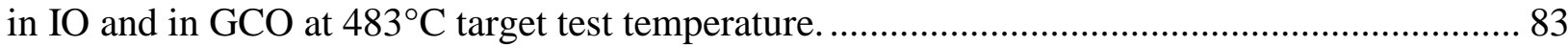

Figure 5.27. Comparison of samples mass losses after tests conducted in IO and GCO. ........... 84

Figure 5.28. Typical TG and DTG plots for dolomitic aggregate from HM-1 mixture tested under non-thermal shock conditions (HM-1-46-nTS). 86

Figure 5.29. Typical XRD pattern for HM-1-46-TS dolomitic aggregate (length of ignition test 10 hours, set test temperature $538^{\circ} \mathrm{C}$ ).

Figure 5.30. TG and DTG plots for DB-1 dolomitic aggregate blend tested before the ignition oven exposure (DB-1_b) and after nTS and TS ignition oven tests. 88 Figure 5.31. XRD pattern for DB-1 dolomitic aggregate blend tested before the ignition oven exposure (DB-1_b) and after nTS and TS ignition oven tests. 89 Figure 5.32. The TG and DTG plots for DB-1 and HM-1 samples, TS and nTS ignition; ignition time: $1.5-10.0 \mathrm{~h}$ 91 
Figure 5.33. Comparison of XRD patterns for DB-1 and HM-1 samples, nTS and TS method;

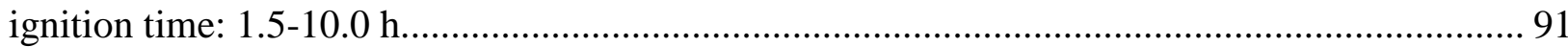

Figure 5.34. TG and DTG plots for pure dolomite (PD), dolomitic aggregate (DB-1) and dolomitic aggregate extracted from mixture (HM-1). 93

Figure 5.35. XRD patterns for pure dolomite (PD), dolomitic aggregate (DB-1) and dolomitic aggregate extracted from the mixture (HM-1).

Figure 5.36. Comparison of the relationship between test temperature and mass loss measured after 4.0 hours ignition test for HM-1 with dolomite and HM-1_P with pyritic limestone 95

Figure 6.1. Comparison of the binder content determination: solvent extraction and corrected modified IO test procedure run at $427^{\circ} \mathrm{C}$.

Figure A-1. Typical temperature distribution plot for HMA with 4.6\% asphalt (HM-1) and DB-1 at $427^{\circ} \mathrm{C}$.

Figure A-2. Typical temperature distribution plot for HMA with 4.6\% asphalt (HM-1) and DB-1

at $483^{\circ} \mathrm{C}$.

Figure A-3. Typical temperature distribution plot for HMA with 4.6\% asphalt (HM-1) and DB-1 at $538^{\circ} \mathrm{C}$.

Figure A-4. Temperature variation during ignition test with HM-1, 4.6\% binder. Top thermocouple reading. 110

Figure A-5. Temperature variation during ignition test with $\mathrm{HM}-1,4.6 \%$ binder. Bottom thermocouple reading. 


\section{LIST OF TABLES}

Table 3.1 Lab produced mix and aggregate blend compositions........................................ 23

Table 3.2. Plant produced mix compositions - Phase Two ................................................. 23

Table 3.3. Average specific gravities of Dolomite A. ........................................................ 24

Table 5.1. Changes in dolomite absorption and specific gravity before and after TS and nTS tests.

Table 5.2. Changes in dolomite absorption and specific gravity before and after IO test........... 60

Table 6. 1. Comparison of the results: mixes HM-A to HM-F........................... 101

Table B-1. XRD test results.................................................. 112

Table B-2. TGA results, $\mathrm{CO}_{2}$ purge gas........................................ 113 


\begin{abstract}
The binder content of an HMA mix is one of the critical factors affecting the quality of the mix. The ignition oven is one widely used method for determining the binder content, however, its use is problematic with some types of aggregates, including dolomites. With these aggregates, the mass loss continues after the binder is burned off as the aggregates decompose and the test does not terminate at a stable mass. This study investigated the factors that affect this mass loss in problematic aggregates and developed a modified ignition oven procedure to limit this mass loss.
\end{abstract}

The mass loss in the ignition oven was found to be both time and temperature dependent. The mass loss is also related to the binder content in the mixture. When the binder in the mixture ignites, the oven temperature increases and exceeds the pre-set test temperature. Temperature variations inside the ignition oven result in higher temperatures in the vicinity of the upper basket; these temperature differences are even more pronounced when the binder ignites. These higher temperatures can result in increased mass loss with problematic aggregates. A test temperature as low as $427^{\circ} \mathrm{C}$ was found to be effective for removing the binder from a mixture. Therefore a modified ignition oven procedure was developed to control the temperatures and limit the additional mass loss for problematic aggregates. The method involves placing half the total sample mass in the bottom basket only and running the ignition oven at a temperature of $427^{\circ} \mathrm{C}$. This method was verified by testing six different plant produced mixes containing problematic aggregate and by comparing the results to results of the standard ignition oven method and to solvent extraction. The modified method is recommended for use with 
problematic aggregates, where the standard test method yields calibration factors greater than 1.0 or where the test does not terminate automatically. 


\section{CHAPTER 1: INTRODUCTION}

The binder content in an asphalt mixture is one of the critical factors determining the quality of the mixture. Using a mixture with too much binder can lead to pavement rutting and bleeding, whereas having a mixture with too little binder can lead to pavement durability problems, including ravelling and cracking. The Indiana Department of Transportation (INDOT) now accepts hot mix asphalts (HMA) based on their volumetric properties (voids in the mineral aggregate (VMA) and percent air voids) and binder content (the mass of binder expressed as a percentage of the total mass of the mix), so accurate determination of the binder content is essential.

Historically, the binder content of a mixture has most commonly been determined by one of several extraction methods in which a solvent is used to remove binder from a known mass of HMA. The main advantages of these methods are as follows: (a) no calibration factor needs to be determined and (b) the properties of the binder and aggregate recovered from the HMA may be tested after extraction. The main limitations associated with solvent extraction methods are related to the length of the test time, possible alteration of binder properties and the hazardous nature of the solvents.

The ignition oven is one alternate to solvent extraction. This oven uses high temperature to burn the asphalt off the aggregate. The procedure terminates when the weight of the sample stabilizes, indicating that there is no more binder to ignite. In 1999, Indiana Department of Transportation (INDOT) began using the ignition oven on a few trial projects; usage increased substantially after that because of the advantages of the 
method. Those advantages include the relatively fast test time and avoidance of the use of hazardous chemicals.

In Indiana, the ignition method has generally worked well on HMAs, except those containing dolomitic aggregates and some limestone sources containing pyrite. These types of aggregates, however, are prevalent in some areas of the state, especially dolomites. With these "problematic aggregates," the high temperatures experienced during ignition cause chemical changes within the aggregates, which result in variable mass loss. In some cases, the sample weight does not stabilize at or below the threshold level, and the ignition test continues for excessive periods of time. This variability in the aggregate mass loss causes difficulties in determining a consistently accurate calibration (or correction) factor and in obtaining consistent and repeatable test results from multiple samples of the same material. Because of this problem, ignition ovens are not used at all in some parts of the state or are only used for those mixes that do not contain dolomite.

\subsection{Purpose of the Study}

Based on INDOT experience with hot mix asphalt (HMA) containing dolomitic aggregates, the determination of the binder content using the ignition oven has been problematic. Research was needed to establish a modified ignition oven test procedure that would allow for the accurate binder content determination for HMA containing dolomite, a common type of aggregate in Indiana. 


\subsection{Objective and Scope of the Study}

This study investigated the use of alternate test protocols using the ignition oven in an attempt to identify a method or methods that would allow the ignition oven to be used consistently and routinely for all HMAs. The primary objective of this research project was to develop revised procedures for using the ignition oven to determine the binder content of HMA containing dolomitic aggregates, pyritic limestone and other aggregates. In order to accomplish this, a better understanding was needed of the changes that occur in dolomitic aggregates and the factors that cause those changes in the ignition oven. Secondary objectives included determining the effects of the modifications to the ignition oven protocols on test time and variability, assessing whether the revised protocols also improve the accuracy when testing limestone containing pyrite, and verification of the efficacy of the modifications.

The National Center for Asphalt Technology (NCAT) Ignition Oven furnace, or more generically the ignition oven (IO), was selected for further investigation. Research was focused on the influence of test conditions (time and temperature) on the sample mass loss. The influence of other factors, such as binder content, was investigated by testing HMA samples with optimum, lower and higher binder contents. The ignition oven procedure was conducted at three temperatures: $427^{\circ} \mathrm{C}, 483^{\circ} \mathrm{C}$ and $538^{\circ} \mathrm{C}\left(800^{\circ} \mathrm{F}\right.$, $900^{\circ} \mathrm{F}$ and $1000^{\circ} \mathrm{F}$, respectively). In addition, a possible correlation between the results obtained using the NCAT ignition oven and Tempyrox Pyro-Clean ${ }^{\circledR}$ Glassware cleaning oven was investigated.

Selected aggregate samples were collected before and after the ignition oven test. In depth compositional analyses, which included thermogravimetric analysis and x-ray 
diffraction analysis, were conducted on those samples to determine the influence of the various test conditions on the aggregate physico-chemical structure and composition.

A proposed modified binder determination protocol was developed based on the findings of this research. The method involves lowering the test temperature to $427^{\circ} \mathrm{C}$ $\left(800^{\circ} \mathrm{F}\right)$ and reducing the sample mass by half. The HMA sample is placed in the bottom basket only. The method was verified using six different plant-produced mixes collected in central Indiana. During the verification testing, the proposed method was compared with the solvent extraction test to evaluate its accuracy.

\subsection{Organization of the Report}

This report is divided into four parts. In the first part, current knowledge about the processes occurring during the ignition oven test and a review of the pertinent literature are presented. In the second part, the materials, equipment and test procedures used in this laboratory study are described. The third part presents the test results and conclusions. In the fourth part, the verification testing of the proposed modified test procedure is discussed. 


\section{CHAPTER 2: LITERATURE REVIEW}

This chapter contains a brief description of binder content determination methods. It also presents the results of a review of states' experiences with using the ignition oven for binder content determination and literature regarding the changes that can occur with HMA containing dolomitic aggregates. Literature relative to decomposition and decrepitation of dolomite at high temperatures is also reviewed. Lastly, this chapter describes some alternate techniques that were considered for use in this study.

\subsection{Binder Content Determination Methods}

Historically, the binder content has most commonly been determined by one of the several extraction methods in which a solvent is used to remove the binder from a known mass of HMA. The solvents used were typically chlorinated solvents such as methylene chloride, trichloroethylene or trichloroethane. The main advantages of these methods are: (a) no calibration factor needs to be determined and (b) the properties of the binder and aggregate extracted from the HMA may be tested after extraction.

Another method for binder content determination is the nuclear gauge method. The nuclear gauge uses radiation to detect the presence of hydrogen in the binder. While relatively quick and easy to conduct, this test does not offer the possibility of testing the binder and aggregate since they are not separated in the process. Another disadvantage of using the nuclear gauge is the requirement for obtaining a Nuclear Regulatory 
Commission license. The nuclear asphalt content gauge requires calibration for each mixture tested, which can be time consuming.

In the 1980s, the conventionally used chlorinated solvents for asphalt extractions began to fall into disfavor. Due to concerns over potential carcinogenicity and environmental impacts, some solvents became difficult to obtain and dispose of after use. Costs also increased greatly. The asphalt industry, which relied heavily on solvent extractions to determine binder contents, needed to find alternatives to chlorinated solvents. In 1990, the National Center for Asphalt Technology (NCAT) began development of an ignition oven to burn off the asphalt from a sample of hot mix. Eventually, this effort led to the development of the NCAT ignition oven. (1)

This developmental effort built on work from the late 1960s by Antrim and Busching (as listed in 1) that showed that the asphalt cement in a mixture could be completely combusted by heating to $843^{\circ} \mathrm{C}\left(1550^{\circ} \mathrm{F}\right)$ with an excess of oxygen. At this high temperature, some aggregate mass was also lost; more mass loss occurred with limestone than with gneiss in the early work.

NCAT built upon this earlier work, but substituted a muffle furnace for the special furnace Antrim and Busching had used. NCAT also used a lower burn temperature $\left(593^{\circ} \mathrm{C}\right.$ or $\left.1100^{\circ} \mathrm{F}\right)$ to reduce the aggregate mass loss. NCAT was motivated to reduce the test time, so they experimented with different ignition temperatures and burn times to optimize the two factors. (1)

Since the method does not use potentially hazardous solvents, it has become quite popular across the country. The oven also does not require nuclear regulatory licensing, so it is easier to implement than the nuclear asphalt content gauge. In addition, the 
aggregate remaining after ignition is generally (but not always) suitable for gradation analysis, which cannot be conducted with the nuclear gauge. At least one study (2) has demonstrated that the ignition oven is potentially far less expensive to operate than the nuclear gauge or various solvent extractions. Many states have adopted the oven for use and find it similar to or less variable than alternate binder content determination methods. $(3,4,5,6,7,8)$

Currently, the ignition oven test is described in both AASHTO T308 and ASTM D 6307 standards. The ignition oven uses high temperature to burn the asphalt off the aggregate; the typical test is conducted at $538^{\circ} \mathrm{C}$ or $1000^{\circ} \mathrm{F}$. (ASTM specifies a test temperature of $540^{\circ} \mathrm{C}$ or $1000^{\circ} \mathrm{F}$ in keeping with their policy of using rationalized unit conversion, so-called "hard conversions.") During a typical ignition test, the sample is heated continuously until three consecutive readings of the mass of the sample, taken at one minute intervals, do not change by more than a specified threshold level, typically $0.01 \%$. To facilitate this determination, many ovens have internal balances to provide continuous readout of the sample weight. All calculations of the asphalt content must account for the calibration factor, which is the difference between the known binder content and ignition oven test result. The calibration factor should be determined independently for each mix. The results of two properly conducted tests by the same operator on the same size samples of HMA should not differ by more than $0.196 \%$.

If the calibration factor is higher than $1.0 \%$, as is the case for some high mass-loss aggregates, the test temperature should be lowered to $482^{\circ} \mathrm{C}\left(900^{\circ} \mathrm{F}\right)$. The calibration factors for most limestone aggregates are typically less than $0.2 \%$. For some dolomitic aggregates, however, the factor can be over 2\%. (According to AASHTO T308, a 
correction factor greater than $1.0 \%$ is considered unusually high.) The correction factor has been observed to decrease when the ignition temperature was decreased from $538^{\circ} \mathrm{C}$ $\left(1000^{\circ} \mathrm{F}\right)$ to $482^{\circ} \mathrm{C}\left(900^{\circ} \mathrm{F}\right) .(9,10,11)$

In a conventional ignition oven, described later in this report, the furnace chamber is heated with a radiant heat source. However, there is an alternate type of ignition oven, called the infrared oven. In this oven, an infrared heating element is used to heat the sample. Hurley and Prowell (12) and Prowell (13) compared the results obtained using both types of ovens. They found the correction factor due to aggregate weight loss for the infrared oven to be generally smaller than that for the conventional oven. They reported the results from the infrared and conventional oven were not statistically different. Research conducted by Williams and Hall (14) reached a similar conclusion that the accuracy of both types of ovens is statistically similar. However, they did not observe that infrared heating limited the over-heating of the aggregate. They discovered that the peak temperature recorded by the infrared oven was often greater than the peak temperature recorded by the conventional oven for the same type and size of sample.

Changes in aggregate properties resulting from binder ignition were observed by Mallick et al. (15). During a study involving different types of aggregate (granite, limerock, gravel and traprock), the authors found that for the same duration of test, the ignition process has a greater effect on the properties of aggregate when an asphalt aggregate mix (rather than an unbound aggregate sample) is placed in a preheated ignition oven.

Similar research was conducted by Prowell and Carter (16). In their study, the impact of the ignition test on the aggregate properties was evaluated. In six of ten cases, 
they noticed significant differences between the bulk specific gravity before and after the test. They also noted that aggregate recovered using the ignition furnace appears to be unsuitable for sand equivalency testing. The results of fine aggregate angularity testing were significantly different between the virgin and burnt samples in three of ten cases. They also observed that accurate results may be obtained for gradation analysis and flat and elongated particle measurements performed on aggregates recovered from the ignition oven test.

During a typical ignition test, the pre-set oven temperature is often exceeded due to the binder ignition. Rogers et al. (17) conducted a study with a modified ignition oven, where a thermo-kinetics infrared thermometer was placed in the oven door. The temperature of the flame created during the ignition process was measured. They noticed up to a $200^{\circ} \mathrm{C}$ difference between the flame and oven temperatures. Temperatures above $565^{\circ} \mathrm{C}$ were consistently measured in the oven, but in no case did the temperature exceed $750^{\circ} \mathrm{C}$. In addition, differences in flame temperature due to differences in binder content were observed.

\subsection{States' Experiences with HMA Containing Dolomitic Aggregates}

Several state Departments of Transportation (DOTs) in the north central region of the country, and elsewhere, have reported some difficulties associated with the use of the ignition oven. For example, in Indiana ignition ovens are not used in some parts of the state because of the prevalence of high mass loss aggregates in those areas. In other areas, they are used only for those mixes that do not contain dolomite or limestone sources 
containing pyrite. With these "problem aggregates," the high temperatures experienced during ignition cause chemical changes within the aggregates resulting in variable mass loss. In some cases, the aggregate weight does not stabilize at or below the threshold level, and the burning continues for excessive periods of time. This variability in the aggregate mass loss causes difficulties in determining a consistently accurate calibration factor and in obtaining consistent and repeatable test results from multiple samples of the same material. Currently, for mixes containing dolomite, INDOT recommends conducting the ignition oven test at a low temperature $\left(427^{\circ} \mathrm{C}\right.$ or $\left.800^{\circ} \mathrm{F}\right) .(18)$

Some other states in the north central region of the country have also reported difficulties, which is logical since they share similar bedrock geology. For example, Wisconsin was an early user of ignition ovens, but discontinued their use due to problems with aggregate breakdown and variability.

The state of Illinois, which has aggregates similar to those of Indiana, routinely utilizes ignition ovens for production control binder content determination and reports satisfactory results, except with aggregates that exhibit high mass loss resulting in a correction factors greater than $1.5 \%$. Illinois identifies aggregates that may exhibit high mass loss during the ignition oven test by using a special procedure, which involves heating the aggregate for one hour at $625^{\circ} \mathrm{C}\left(1157^{\circ} \mathrm{F}\right)$. Aggregates exhibiting differences in mass greater than $4 \%$ (before and after heating) are considered to be high mass loss aggregates. For HMA containing high mass loss aggregate, solvent extraction is conducted instead of the ignition oven test. (19)

Kansas and Nebraska routinely use the ignition oven with no reported problems. 
Missouri and Iowa have also experienced excessive mass loss and have studied the problem. Iowa found that there is a catalyst in some dolomites that promotes a chemical reaction which attacks the carbonate at high temperatures. The catalyst appears to be a chloride compound. The reaction is both time and temperature dependent, which is why the ignition oven test with dolomite has poor repeatability. (20) Missouri conducted a study and found that for "problem aggregates" from the southern part of the state, a low test temperature $\left(427^{\circ} \mathrm{C}, 800^{\circ} \mathrm{F}\right)$ provided the lowest correction factor and lowest variability of results. (9)

A study evaluating four methodologies for determining the asphalt content of mixtures containing high mass loss aggregates (dolomite, basalt and serpentinite/chlorite) was conducted by Prowell and Hurley. (21) In general, they stated that using glasscleaning oven technology may be the best solution for HMAs with high mass loss aggregates. They found that the Pyro-Clean ${ }^{\circledR}$ system, which functions on the basis of pyrolysis, limits the maximum temperature that occurs during the binder combustion. (This type of oven is described in the following chapter.) In addition to the standard AASHTO T308 method with a cut-off point equal to $0.01 \%$, the Ontario Method with a cut-off point equal to mass change of $1 \mathrm{~g}$ (for three consecutive minutes) was also evaluated by Prowell and Hurley. The authors concluded that the Pyro-Clean ${ }^{\circledR}$ furnace produced the lowest aggregate correction factors and found the Ontario Method to produce the smallest bias in measured asphalt content. They reported that the Ontario Method significantly reduced, but did not eliminate, aggregate breakdown on the 0.075 mm sieve. None of the methods reduced aggregate breakdown on the Nominal Maximum Aggregate Size (NMAS) and $4.75 \mathrm{~mm}$ sieves. 
Prowell and Youtcheff (22) investigated other components that may affect the ignition oven correction factor. They found that the amount of sulphur present in the asphalt significantly affects the mass loss occurring during the ignition process. In addition, they observed that variability in the percentage of hydrated lime added to the mixture has a significant effect on the mass loss during the ignition process.

\subsection{Dolomite Decomposition Study}

Dolomite (calcium magnesium carbonate, $\left.\mathrm{CaMg}\left(\mathrm{CO}_{3}\right)_{2}\right)$, is a common rockforming mineral. Pure dolomite contains almost equal amounts of calcium and magnesium, making it intermediate in composition between calcite (calcium carbonate, $\mathrm{CaCO}_{3}$ ) and magnesite (magnesium carbonate, $\mathrm{MgCO}_{3}$ ). The impure dolomitic rock compositions are believed to be the result of incomplete dolomitization, the process by which a deposit of calcite or aragonite reacts with magnesium-rich water to become partially or wholly replaced with dolomite. (23)

In the metamorphic dedolomitization process, part or all of the magnesium in a dolomite or dolomitic limestone is used to form magnesium oxides, hydroxides and silicates (e.g., brucite, forsterite) and calcium-magnesium minerals (e.g., tremoline) thus leaving behind calcite-enriched material. $(24,25,26)$ Dedolomitization reactions are accompanied by an expansive volume change, due to a conversion of dolomite to calcite, which results in the development of micro-cracks in the aggregate. 
Based on X-ray diffraction (XRD), thermogravimetric analysis (TG) and differential thermal analysis (DTA) data, the following factors were determined to be significant during a laboratory accelerated dedolomitization process $(27,28,29)$ :

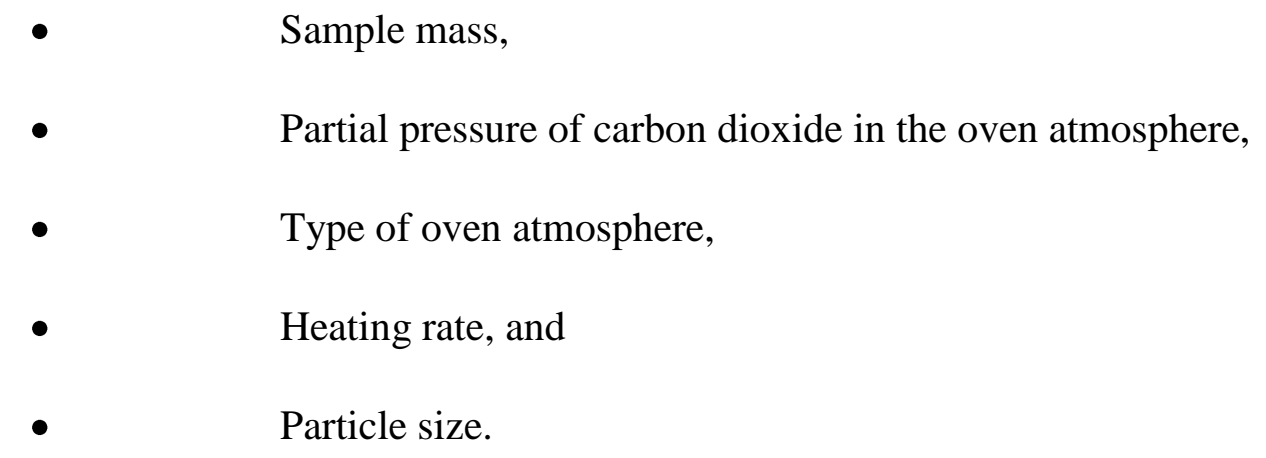

Decomposition is the chemical separation of a material into two or more substances which may differ from each other and from the original material $(25,30)$. It has often been assumed that, when heated, dolomite decomposes in two separate stages: (31)

$$
\begin{aligned}
& \mathrm{CaMg}\left(\mathrm{CO}_{3}\right)_{2} \rightarrow \mathrm{CaCO}_{3}+\mathrm{MgO}+\mathrm{CO}_{2} \\
& \mathrm{CaCO}_{3} \rightarrow \mathrm{CaO}+\mathrm{CO}_{2}
\end{aligned}
$$

The proportion of $\mathrm{MgCO}_{3}$ to $\mathrm{CaCO}_{3}$ varies between many species of dolomite and dolomitic limestone, making the decomposition rate and decomposition temperature hard to predict for a particular sample using only the components' decomposition temperature. (32)

When heated, dolomite particles decrepitate due to the presence of water inclusions in the mineral. (33) Decrepitation means the breaking up of a mineral, usually violently and noisily, when heated. (24) The water trapped in the dolomite structure is converted to steam during heating, and the escape of the steam ruptures the grains. 
Lamar (34) reported that tests of Illinois limestone and dolomites indicate that most of the decrepitation occurs at temperatures between $325^{\circ} \mathrm{C}$ and $425^{\circ} \mathrm{C}\left(617^{\circ} \mathrm{F}\right.$ and $\left.752^{\circ} \mathrm{F}\right)$.

McCauley and Johnson (35) reported that parameters such as furnace atmosphere, total sample mass and heating rate do not affect the temperature of decrepitation, but they do influence the decomposition temperature and the sample mass loss. They reported that the decrepitation temperature was slightly above $400^{\circ} \mathrm{C}\left(750^{\circ} \mathrm{F}\right)$ and was affected by the particle size of the sample.

Dollimore et al. (36) found the decrepitation temperature for most dolomites to be in the vicinity of $500^{\circ} \mathrm{C}\left(930^{\circ} \mathrm{F}\right)$. For limestone they found the decrepitation temperature to be $390^{\circ} \mathrm{C}\left(735^{\circ} \mathrm{F}\right)$ and for some dolomite types that temperature was $400^{\circ} \mathrm{C}\left(752^{\circ} \mathrm{F}\right)$. The same authors also observed that an additional feature that sometimes appears on the thermogravimetric (TG) curve for dolomite is the presence of several irregular weight losses which have been attributed to decrepitation. Using TG analysis (TGA) and the Pilkington method, they proved the dependency between the degree of decrepitation and dolomite particle size. (The Pilkington method is an empirical test adopted by the glass industry as a measure of the degree of decrepitation in limestone and dolomite.)

Samtani et al. (37) observed that decrepitation of dolomite usually occurs in the region of $500^{\circ} \mathrm{C}-700^{\circ} \mathrm{C}\left(930^{\circ} \mathrm{F}-1290^{\circ} \mathrm{F}\right)$, and that there was a relationship between grain size and decrepitation when carbon dioxide was used as a purge gas. In an atmosphere of air and nitrogen, the decomposition and decrepitation processes overlap, and it was difficult to correlate the degree of decrepitation with grain size.

Bandi and Krapf (38) found that carbon dioxide pressure affects different dolomite decomposition mechanisms. They found several rate controlling mechanisms 
involving different types of decomposition at different $\mathrm{CO}_{2}$ pressures. They also identified a possible decomposition of magnesium carbonate to magnesite and calcite formed by the catalytic action of high concentrations of alkali chloride in the dolomite.

McIntosh et al. (39) observed lowering of the first decomposition peak temperature when TGA tests for dolomite were carried out in a carbon dioxide atmosphere rather than in nitrogen or in air (during tests various proportions of $\mathrm{N}_{2}$ and $\mathrm{CO}_{2}$ were used in the purge gas). They reported that the presence of an inorganic salt clearly reduced the decomposition temperature of the first stage. Magnesite was formed as an intermediate compound prior to the formation of magnesium oxide.

In summary, various researchers have reported varying decomposition and decrepitation temperatures for dolomites, ranging from around 325 to $700^{\circ} \mathrm{C}$. These differences are likely caused by differences in the mineralogy of the dolomites tested, variations in the test procedures and ovens used, and other factors. The researchers also identified various mechanisms that cause these changes. For this study, the important conclusion of all of this is that dolomites do undergo chemical and mineralogical changes when heated to high temperatures. These changes can affect the results of the ignition oven test and must be controlled to improve the accuracy and reliability of the test method.

\subsection{Alternates Explored}

It should also be noted that during the course of the present study, the authors searched for alternatives to the standard ignition oven test that could be incorporated, 
both through the literature and web searches and through conversations with various experts. One alternative considered included flooding the oven chamber with some sort of inert atmosphere or flame suppressant. A flame suppressant was deemed unlikely to succeed because flames are necessary to burn off the asphalt; suppressing them would also suppress removal of the binder. The concept of an inert atmosphere was abandoned for two primary reasons. One was that a suitable inert atmosphere was not found that would be safe, reasonably priced, easy to handle in the laboratory and that would not interfere with the materials tested. In addition, the use of an inert atmosphere would likely require modifications to the ignition oven to allow introduction of a gas; these modifications would likely be fairly costly and possibly difficult to implement. Consequently, the study proceeded to explore possible modifications to the test protocols using conventional laboratory equipment (the ignition oven and the glass cleaning oven). 


\section{CHAPTER 3: TEST PROGRAM, MATERIALS AND EQUIPMENT}

In this study, various potential factors influencing problematic aggregate mass loss during binder content determination were investigated. The study involved tests using the NCAT ignition oven, the glass cleaning oven and aggregate compositional analysis.

For brevity, the dolomite source used here that is known to exhibit high mass loss and problems with stabilization of the mass loss is referred to as problematic dolomite; the term "problematic" refers to the behavior of this aggregate in the ignition oven and not to other performance characteristics of the aggregate. It is also occasionally referred to as a high mass loss aggregate. Testing was also conducted on mixes containing a pyritic limestone, which has also been problematic in the ignition oven. Other aggregates that do not display these problems in the ignition oven, tested here for comparison, are referred to as non-problematic; this includes steel slag and some dolomite that does not exhibit problematic behavior.

\subsection{Test Program}

This study was divided into two phases. Phase One was subdivided into 12 tasks (described below) and involved the investigation of the mass and temperature changes that occur during the ignition oven test and the factors influencing those changes. Phase Two focused on verification of the proposed revised test method for determining the binder content of dolomite mixes using the ignition oven. 
Phase One - Investigation of Mass and Temperature Changes during Ignition Oven Tests

- $\quad$ Task 1: Standard Ignition Oven Results for Non-Problematic AggregateIn this task, the influence of test time on mass loss in a plant-produced HMA (HM-0) with a non-problematic aggregate (steel slag) was investigated at the typical test temperature of $538^{\circ} \mathrm{C}\left(1000^{\circ} \mathrm{F}\right)$. This task was intended to establish a baseline showing how non-decomposing aggregates behave in the standard ignition oven test. It also explored the effects of increased burn time on non-decomposing aggregates.

- $\quad$ Task 2: Influence of Test Method on HMA with Problematic Aggregate - Task 2 looked at the behavior of an asphalt mixture (HM-1) containing dolomitic aggregates when tested using the standard ignition oven procedure. In addition, this task explored the possibility that the rapid change in temperature that occurs when room temperature mix is placed into a very hot ignition oven contributes to the mass loss problems noted with dolomites. This was evaluated by comparing the results of the standard test protocol (called the thermal shock (TS) method) to the results when the mix and the oven are gradually heated together from room temperature to the test temperature (called the non thermal shock (nTS) method).

- $\quad$ Task 3: Influence of Mix Size on Ignition Test Results - Three different mix sizes, all incorporating a problematic dolomite, were tested to observe the effects of mix size on the test results under standard conditions (thermal shock test at $538^{\circ} \mathrm{C}$ ). These lab produced mixes included a 25mm mix (HM-1), a 9.5mm mix (HM-2) and a 19mm mix (HM-3) all produced with the same problematic dolomite. 
- $\quad$ Task 4: Influence of Binder Content on Ignition Process - The effect of the amount of asphalt binder in a mixture on the ignition oven process and results was explored by testing samples of a hot mix asphalt (HM-1) containing a problematic dolomite aggregate and varying binder contents. In addition, a companion sample of dolomite only (no binder, called DB-1) was also tested.

- $\quad$ Task 5: Effect of Test Time on Mass Loss - Ignition oven procedures lasting from 90 to 240 minutes (1.25 to 4 hours) were conducted to observe the effects of time on mass loss with a problematic dolomite mix (HM-1). Samples of dolomite aggregate only (DB-1) were also tested for as long as 8 hours for comparison.

- $\quad$ Task 6: Effect of Test Temperature on Mass Loss of HMAs with Problematic Aggregate - Based on the results obtained in the first two tasks, the same three labproduced mixtures containing a problematic or high mass loss aggregate used in Task 3 were tested at $427^{\circ} \mathrm{C}, 483^{\circ} \mathrm{C}$ and $538^{\circ} \mathrm{C}\left(800^{\circ} \mathrm{F}, 900^{\circ} \mathrm{F}\right.$ and $\left.1000^{\circ} \mathrm{F}\right)$ to study the influence of temperature on mass loss.

- $\quad$ Task 7: Evaluation of Ignition Oven Temperature Distribution - In this task, the temperatures occurring at various locations inside the ignition oven chamber were monitored while testing with either the previously mentioned lab-produced mix (HM-1) with high mass loss aggregate or the corresponding dolomitic aggregate blend without binder (DB-1). The purpose of testing the aggregate blend alone was to distinguish the relative proportions of mass loss that could be attributed to the breakdown of aggregate and to the ignition of asphalt in the mix. In addition, this test provided the base-line information for subsequent investigations of temperature differences throughout the 
chamber caused by the ignition of the binder in the HMA. Both groups of tests (HM-1 and DB-1) were conducted at three different temperatures $\left(427^{\circ} \mathrm{C}, 483^{\circ} \mathrm{C}\right.$ and $\left.538^{\circ} \mathrm{C}\right)$.

- $\quad$ Task 8: Two-Step Burn-off of HMA - The focus of this task was to determine the effectiveness of the ignition oven in complete removal of binder at a lower set temperature of $427^{\circ} \mathrm{C}\left(800^{\circ} \mathrm{F}\right)$. Previous experience suggested that some binder or soot could remain on the aggregate after ignition at such a low temperature. So, the purpose of this task was to explore the possibility of controlling the mass loss by burning off most of the binder at a fairly low temperature then removing the remaining soot or ash by increasing the temperature for a short time. Samples of a plant-produced mix (HM-0) composed of non-problematic aggregate were tested in two steps, described in more depth in the following "Procedure" section. Samples of a lab-produced mix with a problematic dolomite (HM-1) was similarly tested. Mass loss before and after the twostep burn-off was studied to investigate whether the reduced time at high temperature would help limit the excessive mass loss with dolomitic aggregate.

- $\quad$ Task 9: Changes in Sample Mass after Ignition Oven Test - In another attempt to understand the changes that occur in dolomitic aggregates in the ignition oven process, the sample mass was monitored for extended periods of time after completion of the ignition oven procedure.

- $\quad$ Task 10: Comparison of Test Results from Ignition and Glass-Cleaning Ovens In addition to the tests conducted using the standard NCAT ignition oven, the HM-1 and DB-1 samples were tested using the Pyro-Clean ${ }^{\circledR}$ glassware cleaning oven (GCO). Because the glass cleaning oven operates in an oxygen deprived condition, the effects of temperature spikes caused by binder ignition may be reduced. This task was conducted 
to determine whether the glass cleaning oven is a readily implementable option to the ignition oven.

- $\quad$ Task 11: Compositional Analysis - Compositional analyses before and after burnoff were conducted to evaluate the influence of the ignition oven test procedure and sample preparation on the chemical changes in dolomite aggregates. Such changes in the chemical composition, if properly characterized, could suggest modification to the ignition oven procedure to reduce variable mass loss problems. To characterize the mineral properties of dolomite, thermogravimetric (TG) analysis and x-ray diffraction (XRD) techniques were used. In order to compare the properties of the dolomitic aggregate used in this study with pure dolomite, a sample of this mineral was obtained. This specimen will be referred to in the text as PD.

- $\quad$ Task 12: Testing of Problematic Limestone Containing Pyrite - In this task, HMA containing pyritic aggregates were tested. Though less widespread in Indiana than dolomitic aggregates, limestones with pyrite do occur and do exhibit high mass losses.

Phase Two - Evaluation of the Modified Ignition Oven Test Procedure

Based on the observations made in first phase of the study, modifications to the ignition oven test procedure were suggested and verified in Phase Two of the study. Phase Two involved testing various HMA mixtures and was subdivided into two tasks.

- $\quad$ Task 13: Comparison of Test Results from Standard and Modified Ignition Oven Methods - Eight different plant-produced mixes (HMA-A to HMA-F) containing the same problematic dolomite as tested in Phase One (Dolomite A) and less problematic, or non-problematic, aggregates (Dolomite B, natural sand, RAP and steel slag) were tested 
at all three temperatures, using the standard and modified ignition test procedures. In addition, the mix binder contents were determined using a solvent extraction method. Ignition oven data from the different protocols were compared (after normalizing using solvent extraction tests results). The oven thermocouple was used to monitor the temperatures generated in the oven in both procedures.

- $\quad$ Task 14: Comparison of the Modified Ignition Oven Test and Solvent Extraction Methods - The same mixes that were tested in Task 13 (HMA-A to HMA-F) were duplicated in the laboratory and tested using the proposed modified test procedure at $427^{\circ} \mathrm{C}$ to obtain a calibration factor. This calibration factor was then applied to the ignition oven results for the plant-produced mixes. These corrected results were compared with the binder content determined using the solvent extraction method to verify the applicability of the modified test procedure for binder content determination of mixtures with high mass loss aggregates.

Throughout this research project, replicate samples were tested. Two replicate samples were typically used unless otherwise stated.

\subsection{Material Characterization}

In this section, the properties of the materials tested are described separately for each phase of the study. For ease of reference, the lab-produced mixes and aggregate blend are summarized in Table 3.1 and the plant-produced mixes are summarized in Table 3.2. 
Table 3.1 Lab produced mix and aggregate blend compositions

\begin{tabular}{|c|c|c|c|c|c|}
\hline & HM-0 & HM-1 & HM-2 & HM-3 & DB-1 \\
\hline Used in Task(s) & $1 \& 8$ & $2-12^{*}$ & 3 & 3 & $4,5-7,9-11$ \\
\hline NMAS, mm & 9.5 & 25 & 9.5 & 19 & 25 \\
\hline Binder Grade & PG 76-22 & PG 64-22 & PG 64-22 & PG 64-22 & None \\
\hline $\begin{array}{c}\text { Design Binder } \\
\text { Content, \% }\end{array}$ & 5.7 & 4.6 & 5.4 & 4.5 & 0 \\
\hline Dolomite A, \% & 0 & 100 & 100 & 100 & 100 \\
\hline Other Aggregate**, \% & 100 & 0 & 11 & 0 & 0 \\
\hline
\end{tabular}

* HM-1 produced with pyritic limestone instead of Dolomite A was used in Task 12

** Steel slag and natural sand.

Table 3.2. Plant produced mix compositions - Phase Two

\begin{tabular}{|c|c|c|c|c|c|c|}
\hline & HMA-A & HMA-B & HMA-C & HMA-D & HMA-E & HMA-F \\
\hline NMAS, mm & 9.5 & 19 & 9.5 & 9.5 & 9.5 & 9.5 \\
\hline Binder Grade & PG 64-22 & PG 58-28 & PG 76-22 & PG 70-22 & PG 64-22 & PG 76-22 \\
\hline $\begin{array}{c}\text { Design Binder } \\
\text { Content, \% }\end{array}$ & 5.3 & 3.7 & 5.4 & 5.8 & 5.6 & 6.1 \\
\hline RAP, \% & 25 & 25 & 0 & 0 & 0 & 0 \\
\hline Dolomite A, \% & 14 & 48 & 70 & 42 & 94 & 40 \\
\hline Dolomite B, \% & 48 & 27 & 0 & 58 & 0 & 0 \\
\hline Limestone, \% & 0 & 0 & 19 & 0 & 0 & 21 \\
\hline Other Aggregate* & $13 \% \mathrm{~ns}$ & 0 & $11 \% \mathrm{~ns}$ & 0 & $6 \% \mathrm{~ns}$ & $39 \% \mathrm{ss}$ \\
\hline
\end{tabular}

*Natural sand (ns) or steel slag (ss)

\subsubsection{Phase One Materials}

For Tasks 1 and 8, an HMA (called HM-0) with a non-problematic aggregate was used to essentially establish a base-line and to explore whether a two-step burn could effectively remove all the binder and soot. HM-0 was a plant-produced surface mix with 
a nominal maximum aggregate size (NMAS) of $9.5 \mathrm{~mm}$. It was composed of $90 \%$ steel slag and 10\% natural sand and contained 5.7\% polymer modified PG76-22 binder.

The problematic aggregate used during Tasks 2-12 of Phase One was a dolomite (designated as Dolomite A) from a quarry located in west-central Indiana. The selection of this material was based on information provided by both INDOT and the Indiana hot mix industry indicating that the binder contents of HMA mixtures with this aggregate were often in error when determined using the ignition oven (40). Four sizes of this aggregate were obtained for use in Phase One of the study; coarse aggregates \#5, \#8 and \#12 (as per INDOT's Standard Specifications (41)) and fine aggregate \#24 manufactured sand. An unmodified PG 64-22 binder was used to prepare the HMA mixtures. Due to the Indiana climate, this type of binder is commonly used in the state. The specific gravity of this binder, tested according to AASHTO T $228(2004)$ at $25^{\circ} \mathrm{C}\left(77^{\circ} \mathrm{F}\right)$, was equal to 1.028.

The specific gravity of the coarse dolomite aggregate was determined in accordance with AASHTO T 85 (1991). The average values of two replicate samples for each aggregate size are shown in Table 3.3.

Table 3.3. Average specific gravities of Dolomite A.

\begin{tabular}{|c|c|c|c|}
\hline Property & $\# 5$ & $\# 8$ & $\# 12$ \\
\hline Oven - Dried SG & 2.710 & 2.708 & 2.730 \\
\hline Saturated Surface Dried SG & 2.733 & 2.732 & 2.758 \\
\hline Apparent SG & 2.773 & 2.774 & 2.808 \\
\hline \% Absorption & 0.8 & 0.9 & 1.0 \\
\hline
\end{tabular}


The mix designs, including the aggregate gradation and binder content, were adaptations of typical interstate highways mixtures used locally in Indiana. Three types of laboratory prepared HMA were tested during the project: HM-1, a 25 mm NMAS base course; HM-2, a 9.5 mm NMAS surface course; and HM-3, a 19 mm NMAS intermediate course. The binder contents for HM-1, HM-2 and HM-3 were 4.6\%, 5.4\% and $4.5 \%$, respectively, as shown in Table 3.1. Gradation curves for each of the mix types are shown in Figure 3.1.

In addition, a separate blend of dolomitic aggregate alone, having the same gradation as HM-1, was also prepared. This blend was called DB-1.

The aggregate used during Task 12 was a pyritic limestone from the Laurel formation. This aggregate was obtained from the southern part of Indiana. This aggregate is commonly found and used in this region of Indiana and was reported to cause problems during the ignition test similar to those observed with some dolomites. A mix with the same binder content and aggregate gradation as for HM-1 was prepared using pyritic dolomite for evaluation in Task 12. 


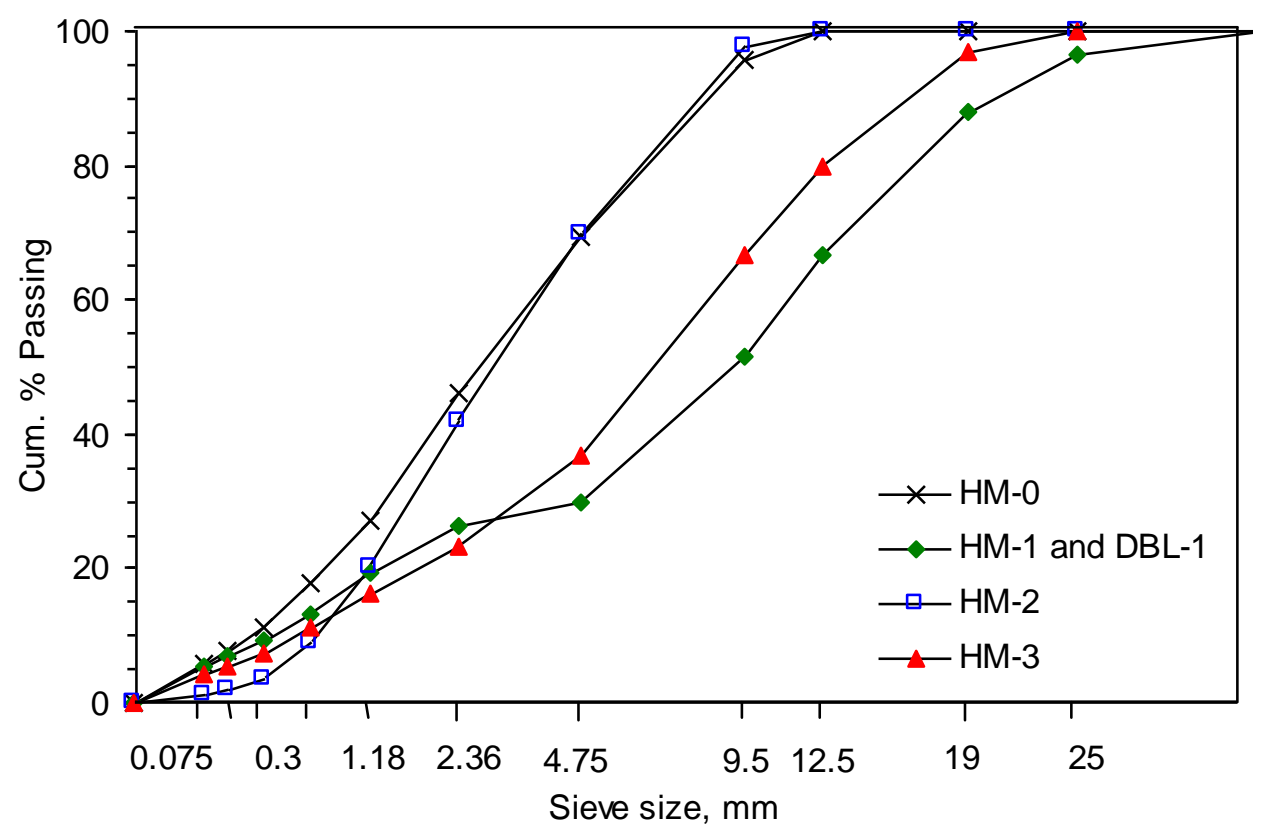

Figure 3.1. Gradation curves (Phase One)

In Task 11, a sample of pure dolomite (PD) was tested for comparison to the behavior of the dolomitic aggregate used in this study. This sample of pure dolomite (Dolomite Research Mineral, 49 E 5871) was obtained from Butte, Montana.

\subsubsection{Phase Two Materials}

Plant-produced mixes tested in Phase Two contained two sources of dolomite: Dolomite A, which was reported to be problematic and was previously used in Phase One, and Dolomite B, which was considered less or non-problematic. The compositions of these mixes are summarized in Table 3.2. In two mixes (HMA-A and HMA-B), RAP was substituted for $25 \%$ of the aggregate. 
All the mixes were $9.5 \mathrm{~mm}$ surface mixes except HMA-B, which was a $19 \mathrm{~mm}$ base course mix. Gradation curves for each of the plant-produced mixes are shown in Figure 3.2.

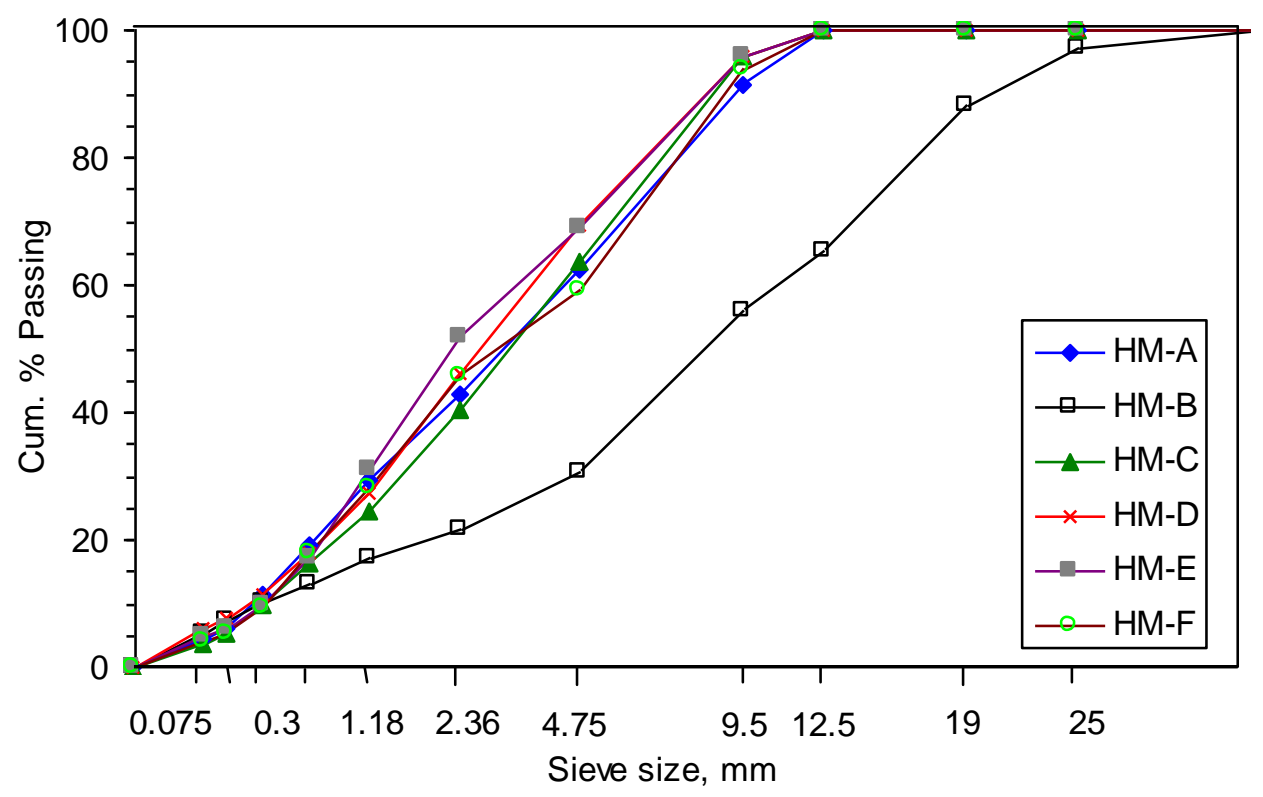

Figure 3.2. Plant-Produced HMA Gradation Curves (Phase Two)

\subsection{Equipment}

The most common ignition oven used in Indiana is the Thermolyne Ignition Oven. Most of the tests in this study were conducted using this type of oven at the INDOT Office of Research and Development, except where noted. In addition, a few tests were repeated using the same model of oven in a different lab (INDOT Crawfordsville Area Lab). The results obtained with both ovens were similar.

As reported in the previous chapter, some researchers have conducted binder ignition tests using the Tempyrox Pyro-Clean ${ }^{\circledR}$ glassware cleaning oven and have found 
the results to be more promising than those obtained with the standard ignition oven. In this study, a limited number of tests using this kind of oven was also conducted.

\subsubsection{Thermolyne Ignition Oven}

The Thermolyne Ignition Oven (Type F85930) used in this study is a conventional type of ignition oven in which a radiant heat source consisting of an electric heating element is used to heat the chamber. Figure 3.3 shows the Thermolyne ignition oven. The heating elements are located in both the left and right walls of the chamber. The heating elements heat the air in the main furnace chamber, which in turn heats the sample. The temperature set point range used in this study was between $427^{\circ} \mathrm{C}$ and $538^{\circ} \mathrm{C}\left(800^{\circ} \mathrm{F}\right.$ and $\left.1000^{\circ} \mathrm{F}\right)$, however, this type of oven is capable of maintaining a set point temperature between $100^{\circ} \mathrm{C}$ and $650^{\circ} \mathrm{C}\left(212^{\circ} \mathrm{F}\right.$ and $\left.1202^{\circ} \mathrm{F}\right)$. The furnace has a fan to pull air through the furnace to expedite the test and to reduce the escape of smoke into the laboratory. In order to maintain ignition, a blower pulls ambient air through four ceramic tube support openings located on the chamber floor in the sample chamber. This air promotes ignition and ashing. The exhaust gases pass out of the main chamber into a secondary chamber, which is set to a higher temperature, equal to $750^{\circ} \mathrm{C}\left(1382^{\circ} \mathrm{F}\right)$, where additional oxidation occurs. "This helps to reduce volatiles in the exhaust stream." (42) To measure the mass loss during the ignition process, this ignition oven uses an internal balance. Both ignition ovens used in this study met the requirements for AASHTO T308 Method B (2005).

In the standard version of the Thermolyne ignition oven, the mass, time and temperature at each minute are printed out continuously during the test. During this 
study, data was also collected using a PC connected to the ignition oven using an RS232 cable.

In the standard test arrangement, the temperature of the oven is monitored by a built-in thermistor. For the purposes of this study, two type K thermocouples (TC 1 and TC 2) were placed in the top and bottom sample baskets, respectively, to measure the sample temperature during tests in Task 4.

Each thermocouple was attached with a metal wire hook to the bottom of the basket (the TC was located $12 \mathrm{~mm}(0.5 \mathrm{inch})$ above the bottom of each basket). The vertical distance between TC 1 and TC 2 was equal to the distance between the bottom of baskets in which they were located, which was $90 \mathrm{~mm}$ (3.5 inches). The oven thermistor was located about half way between TC 1 and TC 2 . Both TC 1 and TC 2 thermocouples were located in the middle of the basket (in the horizontal plane), while the oven thermistor is located at the rear wall of the oven chamber. The details of the locations of thermocouples are shown in Figure 3.4 and Figure 3.5. The data acquisition system used to record the thermocouple data is shown in Figure 3.6. 


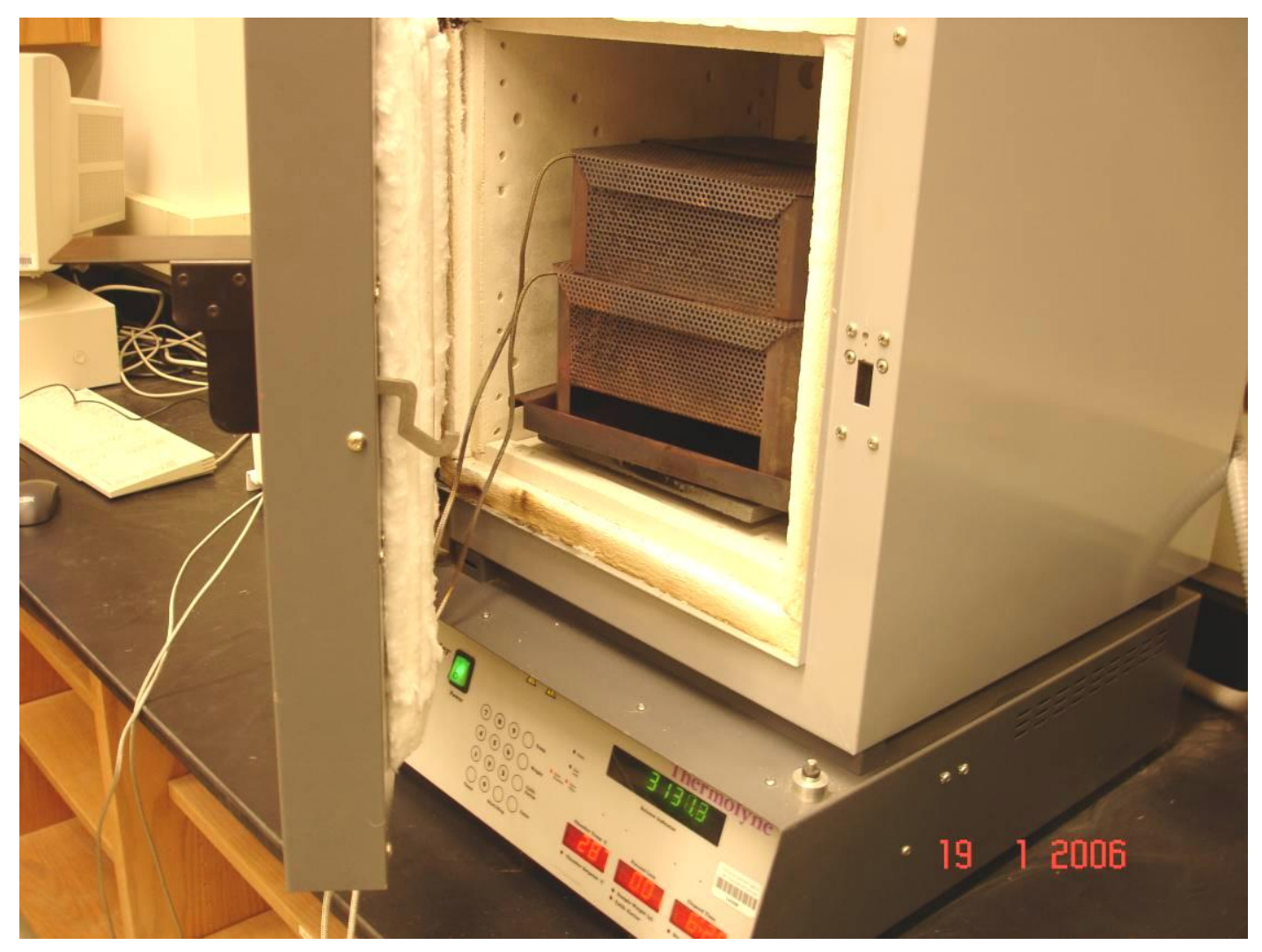

Figure 3.3. Thermolyne ignition oven.

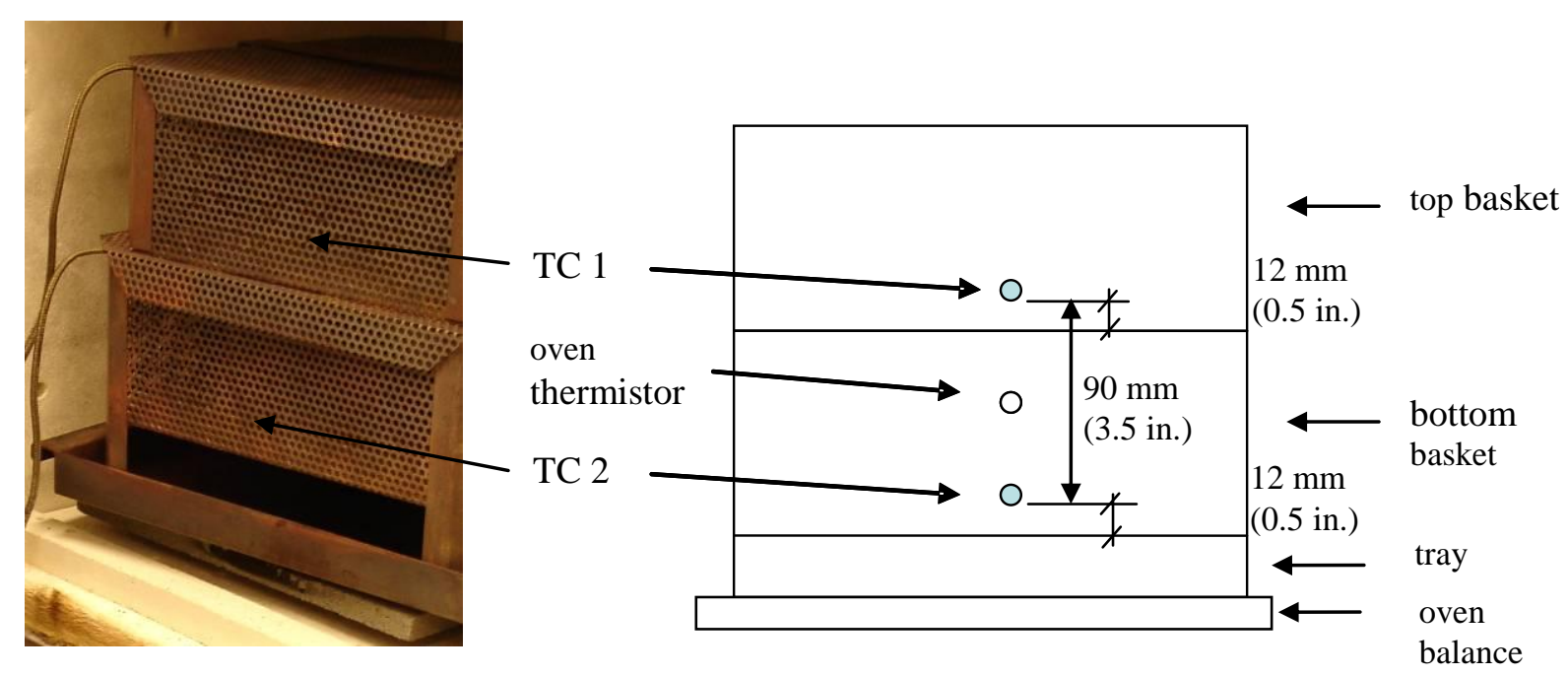

Figure 3.4. Setup of the thermistor and thermocouples - front view. 


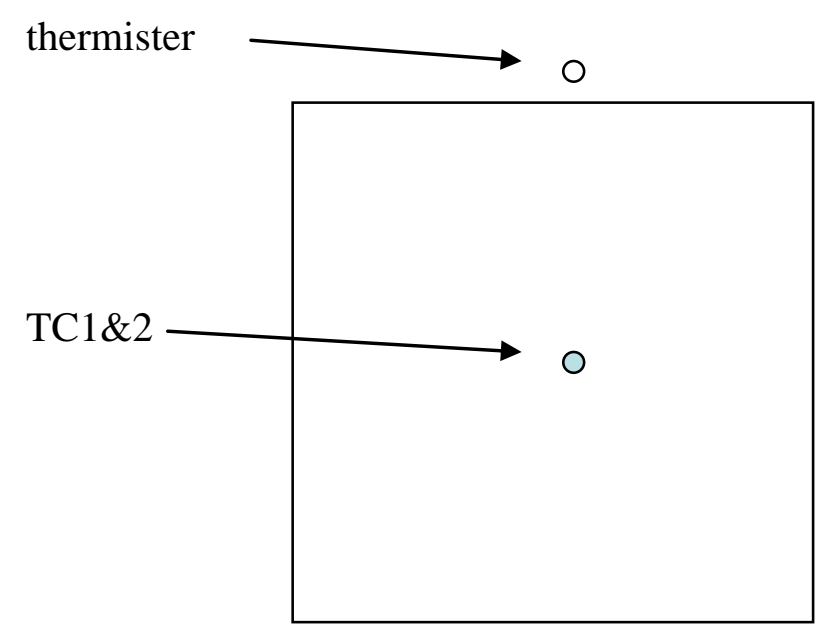

Figure 3.5. Setup of the thermistor and thermocouples - top view.

A thermocouple positioned in a basket is shown in Figure 3.7, where the junction is not covered by the HMA for illustrative purposes. Figure 3.8 show the junction covered by the HMA as it was during testing. During tests with the added thermocouples, data collected from the ignition oven balance was not used in the analysis, since the thermocouples could have interfered with the free movement of the balance. 


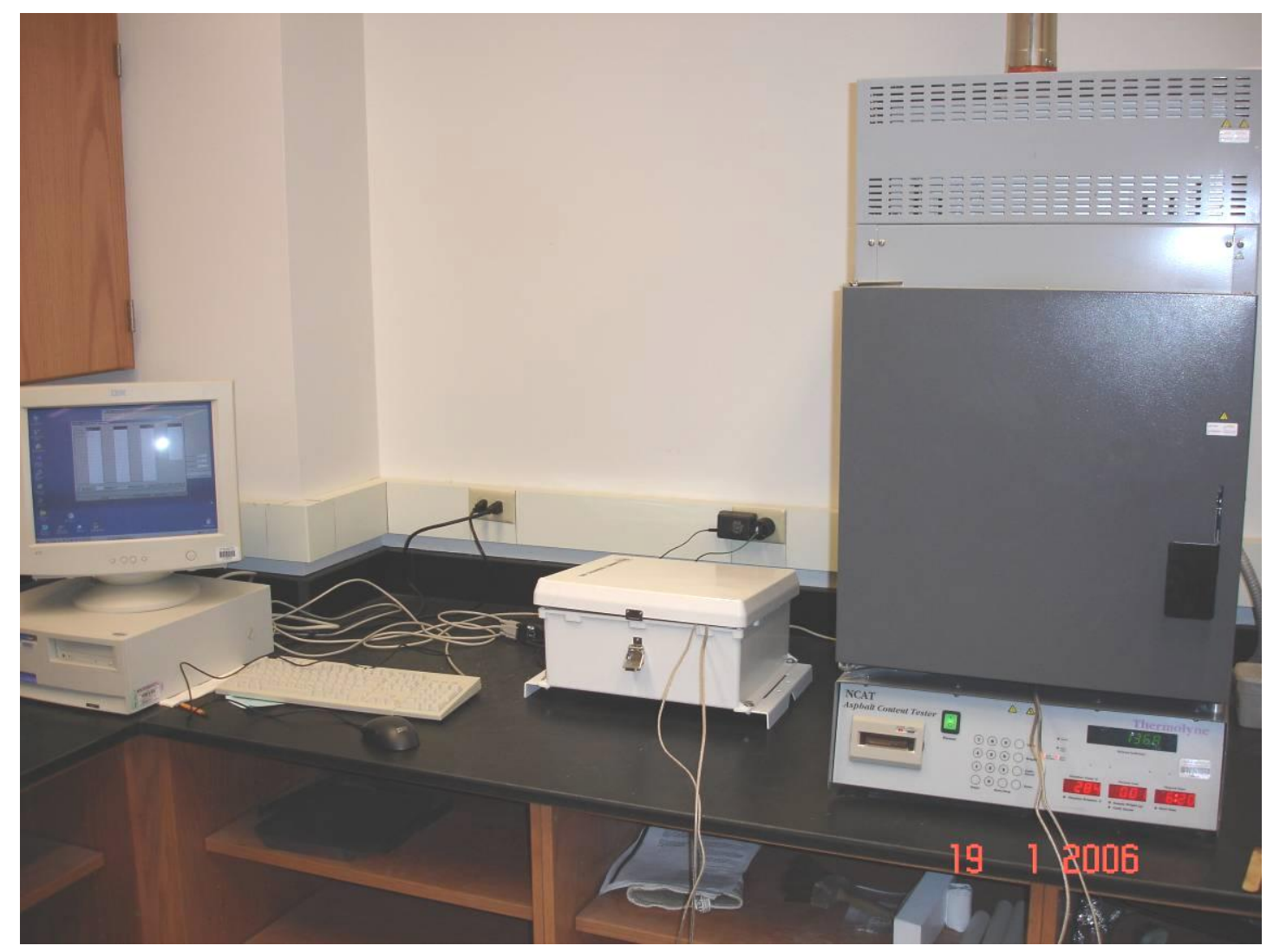

Figure 3.6. Data acquisition system.

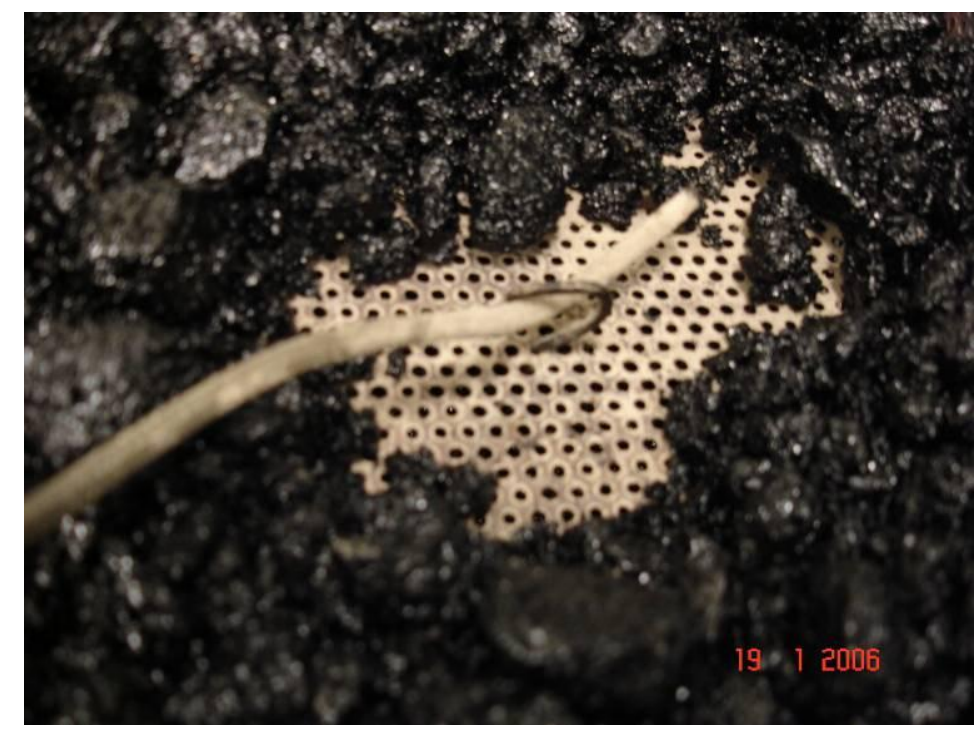

Figure 3.7. Thermocouple attached to a basket (junction not covered by the HMA). 


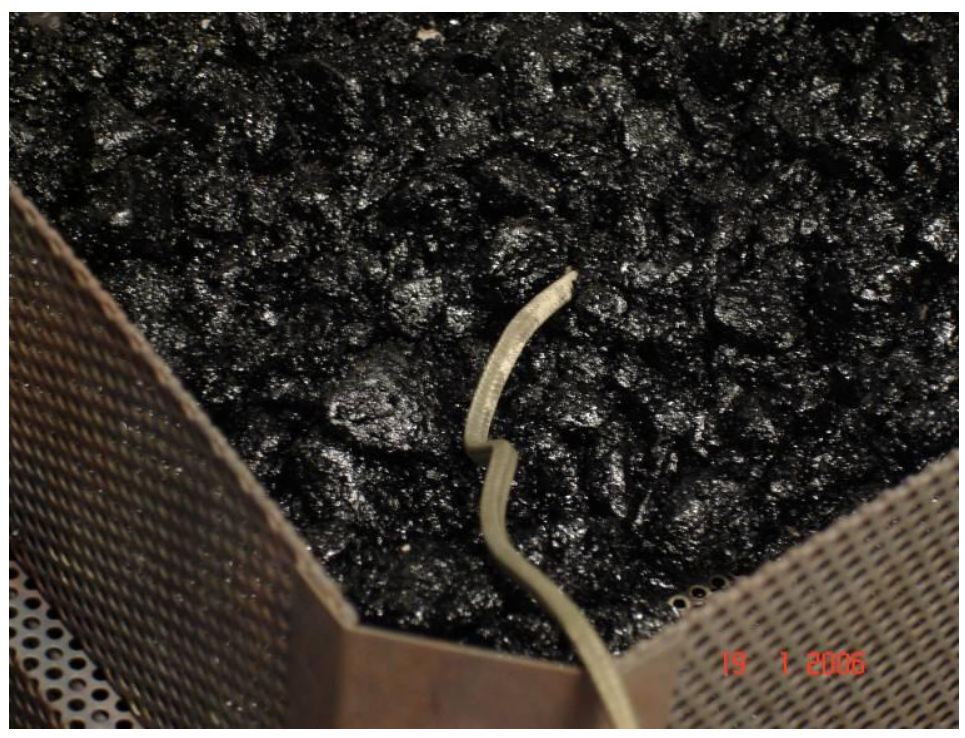

Figure 3.8. Thermocouple junction embedded in the HMA.

In addition, special tests were conducted for calibration of the Thermolyne

Ignition Oven. Repeatability of the weight and temperature readings was investigated in tests with no mix in the chamber as well as in tests with brass of known mass instead of HMA in the oven chamber. A sample of brass with a mass of around $3000 \mathrm{~g}$ (mass equal to tested HM-1 sample) was used. Brass was selected as a material which demonstrates stable mass at the range of temperatures experienced in an ignition oven. There were no significant differences in the weight and temperature readings, nor the mass of the brass during these tests, indicating that the oven and internal balance were working properly.

\subsubsection{Tempyrox Pyro-Clean® Glassware Cleaning Oven}

For a limited number of tests, the Tempyrox Pyro-Clean ${ }^{\circledR}$ Glassware cleaning oven, model 3AB, was used in this study. This oven, shown in Figure 3.9, is commonly 
used to clean precision laboratory glassware, e.g., Rolling Thin Film Oven (RTFO) bottles and viscometers.

As mentioned earlier in Chapter 2, the aggregate temperature may drastically exceed the target test temperature during the binder combustion process in a conventional ignition oven. In a glass cleaning oven, a special gasket system is built in to prevent outside air from leaking into the chamber during the cleaning cycle.

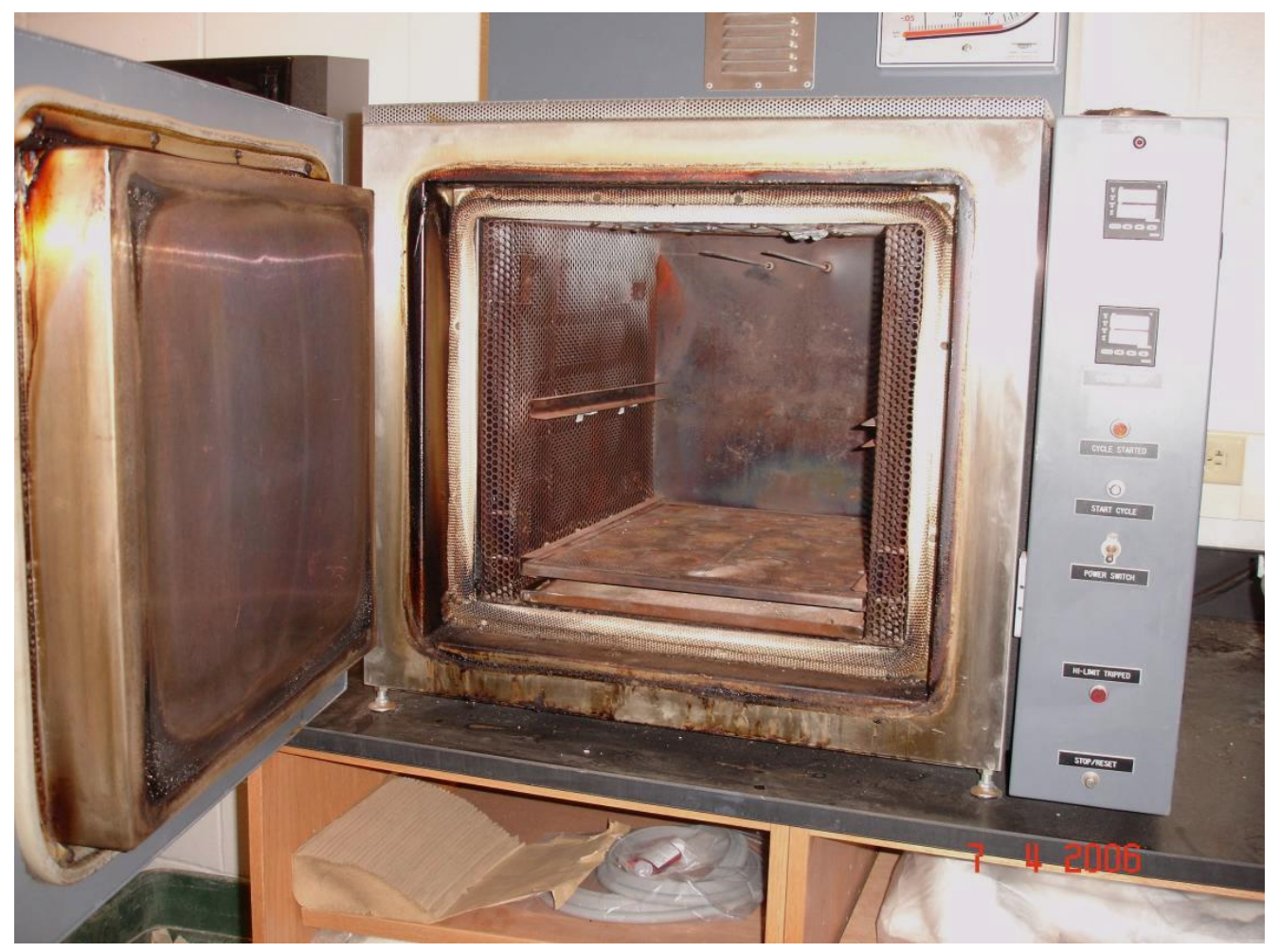

Figure 3.9. Tempyrox Pyro-Clean ${ }^{\circledR}$ Glassware Cleaning Oven

In the glass cleaning oven, the furnace temperature is well-controlled, which prevents the aggregate from exceeding the target temperature. This type of oven functions on the basis of pyrolysis oxidation, a two stage cleaning process in which organic material in an inert atmosphere is vaporized (pyrolysis stage) and heat combines 
with oxygen to remove carbon dioxide (oxidation stage). (43) This process allows for the volatile organics to be removed from the material in an oxygen-deprived atmosphere to the point at which there is nothing remaining except carbon ash.

As explained in the report by Prowell and Hurley (44),

"A bottom tray inside the chamber contains a catalyst. When the temperature inside the chamber reaches a level that begins to drive off volatile organics in the form of smoke or hydrocarbons, the catalyst will begin to react with the smoke and hydrocarbons and reduce the oxygen level inside the chamber to around 15 percent or less. This prevents ignition from occurring. In the absence of ignition, it is possible to control the temperature of the cleaning process to near exact values. Smoke being generated during the pyrolysis stage enters the oxidation chamber where it is subjected to a temperature of $1200^{\circ} \mathrm{F}\left(732^{\circ} \mathrm{C}\right)$ and another catalyst for near 100 percent destruction. When the oxidation chamber detects the absence of smoke coming from the cleaning chamber, an air pump located inside the control panel pumps room air into the cleaning chamber. The introduction of air into the cleaning chamber releases the carbon ash remaining on the test sample and it passes through the oxidation chamber where the high temperatures reduce it to carbon dioxide $\left(\mathrm{CO}_{2}\right)$ and water."

The chamber contains two stainless steel shelves for holding glassware. The upper steel shelf was removed so that a complete basket setup from the Thermolyne Ignition Oven could be used. Once the cleaning process is started, the heating elements inside the oxidation chamber turn on to achieve the set temperature of $732^{\circ} \mathrm{C}\left(1200^{\circ} \mathrm{F}\right)$. In this study, the temperature of the cleaning chamber was set at $482^{\circ} \mathrm{C}\left(900^{\circ} \mathrm{F}\right)$ for testing purposes, to allow comparison with tests at the same temperature in the conventional ignition oven. During the test air passes through the oxidation chamber due to the draft inducer blower. 


\subsubsection{Compositional Analysis}

An X-ray diffractometer manufactured by the Siemens Company was used in this study. This diffractometer operates at $50 \mathrm{kV}$ and $30 \mathrm{~mA}$ using $\mathrm{CuK} \alpha$ radiation $(\lambda=1.540598 \AA)$.

A Thermo Gravimetric Analyzer manufactured by TA Instruments Company (type 2050) and Universal Analysis software were used to examine the thermal decomposition of the dolomite aggregate. The purge gas used was $\mathrm{CO}_{2}$. 


\section{CHAPTER 4: TEST PROCEDURES}

The effects of various parameters on the ignition process were investigated in this research. The factors explored included: temperature, time, aggregate size, binder content and sample placement. In addition, the distribution of temperatures in the oven chamber during the ignition test was studied.

\subsection{Sample Preparation}

During the preparation of the laboratory mixes, all aggregates were oven dried at $105^{\circ} \mathrm{C}\left(220^{\circ} \mathrm{F}\right)$ and cooled to room temperature prior to being sieved and sorted into separate fractions. The aggregates were then combined into batches according to the mix designs. The batched aggregate blends and binder were heated up to the mixing temperature of $144^{\circ} \mathrm{C}\left(290^{\circ} \mathrm{F}\right)$ prior to mixing. The aggregate and binder were mixed in a 5-gallon bucket mixer. The laboratory mixer was first conditioned with a "butter" mixture in order to avoid binder loss during the preparation of test mixtures. After mixing, the HMA samples were placed in an oven set at the compaction temperature of $135^{\circ} \mathrm{C}\left(275^{\circ} \mathrm{F}\right)$ for two hours of conditioning, according to AASHTO R30.

Plant-produced mixes were obtained from a truck before it left the HMA plant. The collected HMA samples were immediately transported to the laboratory and split into smaller batches based on the NMAS and type of test to be performed. 
For the ignition oven test, the mass was in accordance with AASHTO T308, and for the solvent extraction test the mass according to AASHTO T319 was used. The prescribed amount of HMA depends on the NMAS of the mix. In ignition tests with HM-1 samples (25.0 mm NMAS), a total of $3000 \mathrm{~g}$ of HMA was used. For tests with HM-2 samples (9.5 mm NMAS), $1200 \mathrm{~g}$ of HMA was used, and for tests with HM-3 samples (19.0 mm NMAS), $2000 \mathrm{~g}$ of HMA was used.

All tests were replicated (conducted twice), and the results presented here are the average of both results.

Before the ignition test, the HMA sample was warmed up and softened at $125^{\circ} \mathrm{C}$ $\left(257^{\circ} \mathrm{F}\right)$ in order to facilitate the removal of the mix from the pan and placement in the ignition oven basket. The time needed for softening was found to be 20 minutes. Once the sample was equally distributed in the bottom and top baskets (taking care to keep the material away from the edges of the basket), the sample was left for an hour to cool to room temperature.

In the modified test method introduced in Phase Two, half of the prescribed AASHTO T308 sample mass was tested. All the mix was placed in the lower basket, while the top basket was left empty.

\subsection{Tests in the Thermolyne Ignition Oven}

The Thermolyne ignition oven was used for testing of both problematic and nonproblematic mixes. In this study most of the tests were conducted using HM-1. (A schematic of the tests conducted on the base course mix (HM-1) containing dolomite is 
shown in Figure 4.1.) Both asphalt mix (HM-1) and blended dolomite (DB-1), of the same gradation but without binder, were tested. Tests were conducted using the Thermolyne Ignition Oven and Pyro-Clean ${ }^{\circledR}$ oven. Similar, but limited, suites of tests were conducted on the intermediate (HM-2) and surface (HM-3) mixes as well. In addition limited testing was conducted on mixes following the HM-1 mix design but in which the dolomite was replaced with pyritic limestone.

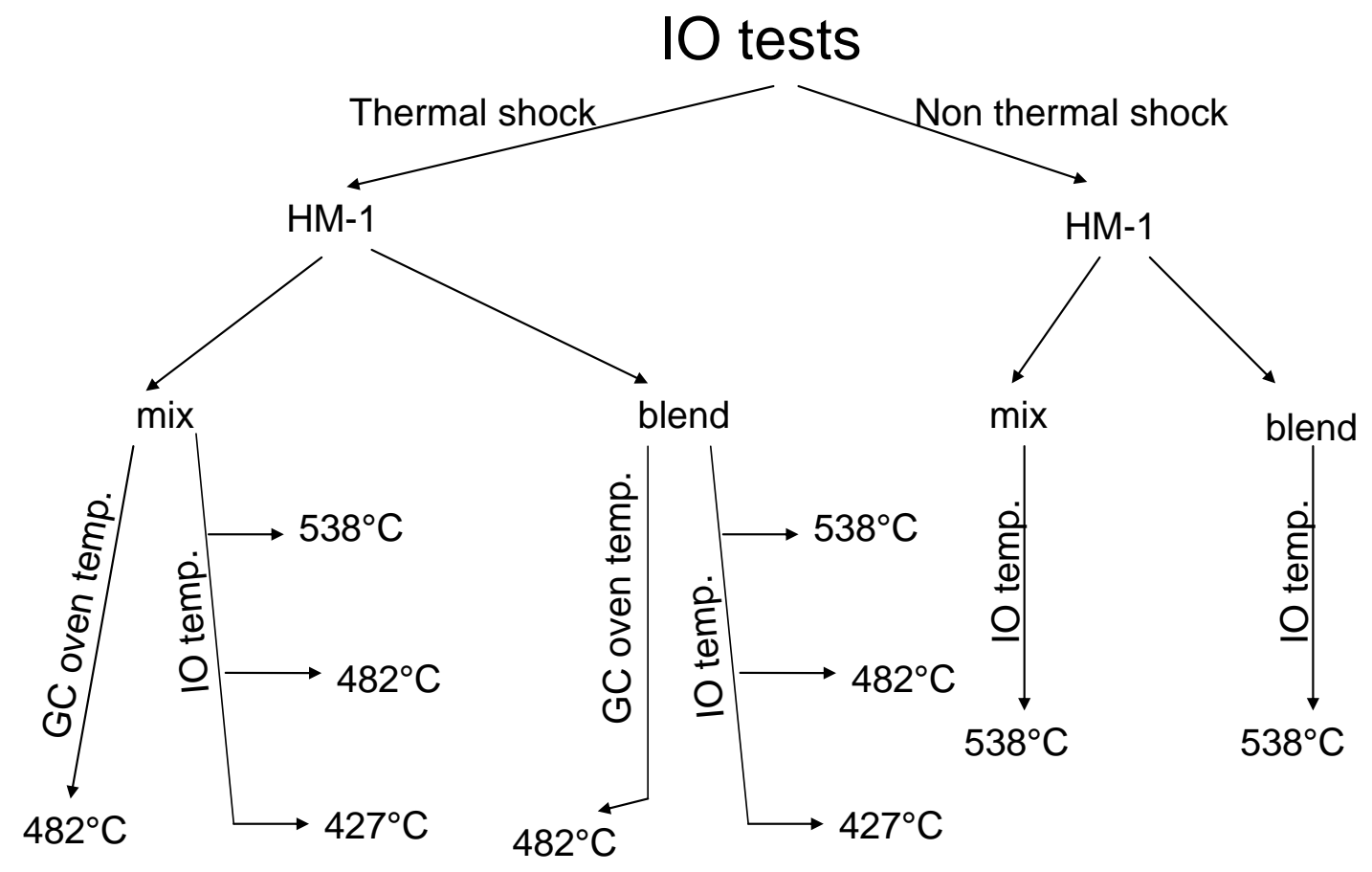

Figure 4.1. HMA and dolomite blend - sketch of the tests in Thermolyne Ignition Oven (IO) and Tempyrox Pyro-Clean ${ }^{\circledR}$ Glassware Cleaning Oven (GC).

Two types of tests were conducted in the Thermolyne Ignition Oven: standard thermal shock and modified non thermal shock. (These tests are described in more detail in the followings sections.) This was done to explore whether the rapid increase in 
temperature caused by placing room temperature mix into a very hot oven contributes to the mass loss problems observed with dolomite. The thermal shock ignition tests were conducted at temperatures of $427^{\circ} \mathrm{C}\left(800^{\circ} \mathrm{F}\right), 482^{\circ} \mathrm{C}\left(900^{\circ} \mathrm{F}\right)$ and $538^{\circ} \mathrm{C}\left(1000^{\circ} \mathrm{F}\right)$; these temperatures were selected in accordance with ITM No. 586-06T. The non thermal shock tests were conducted at a temperature of $538^{\circ} \mathrm{C}\left(1000^{\circ} \mathrm{F}\right)$.

In addition, a two-step test was conducted in Task 8 to verify if all the binder was burnt off during the thermal shock test at the lowest temperature $\left(427^{\circ} \mathrm{C}\right.$ or $\left.800^{\circ} \mathrm{F}\right)$. During the second step of this test, the temperature was increased to $538^{\circ} \mathrm{C}\left(1000^{\circ} \mathrm{F}\right)$ for a short period of time to see if any of the remaining soot or ash could be burned off.

\subsubsection{Thermal Shock Method}

In the thermal shock (TS) type of test - which is the procedure specified in AASHTO T308, ASTM D 6307 and ITM No. 586-02T - the mix was spread into a thin layer in the basket and placed in the preheated oven. (The term thermal shock is used here to refer to tests where extreme temperature changes result when room temperature mix is placed in the preheated oven.) Tests were conducted at three temperatures: $427^{\circ} \mathrm{C}$ $\left(800^{\circ} \mathrm{F}\right), 482^{\circ} \mathrm{C}\left(900^{\circ} \mathrm{F}\right)$ and $538^{\circ} \mathrm{C}\left(1000^{\circ} \mathrm{F}\right)$; however, most tests were conducted at $538^{\circ} \mathrm{C}\left(1000^{\circ} \mathrm{F}\right)$. This temperature is believed to be more problematic than the lower temperatures when testing dolomitic aggregate mixes.

In a typical test conducted according to the AASHTO standard, the oven is set to terminate the burn when the mass loss stabilizes below a certain value (difference between the three continuous readings taken at one minute intervals). In practice, such a cut-off level is usually set at $0.01 \%$. With a cut-off level equal to $0.01 \%$, the typical test 
time is around one hour. In some tests in this study, no cut-off level was used. Instead, the sample was placed in the oven for a predetermined amount of time, ranging from 1.5 $\mathrm{h}$ to $5.0 \mathrm{~h}$.

The mass of the empty basket and the mass of the basket with the sample were measured before each test. During the test, the mass and temperature changes were recorded each minute, based on the ignition oven internal balance and oven thermistor readings. In addition, during some of the tests two thermocouples were placed in the mix (or in the dolomite blend) attached to the basket (as described in 3.3.1), and the temperature was recorded over the duration of the test. Immediately after removing the basket with sample from the oven, the mass was determined. This process typically took two to three minutes. In order to observe the sample mass changes after the end of test, the mass of entire setup was also determined after approximately 20 minutes, 60 minutes, 120 minutes, 24 hours and 3 days. When the sample was removed from the basket, the basket mass was checked and compared with the initial mass of basket. No significant changes in the basket mass were noticed, as expected.

\subsubsection{Non Thermal Shock Method}

The non thermal shock (nTS) test method is similar to the standard thermal shock test except that instead of placing the sample in a preheated oven, the sample was placed in a room temperature oven. This type of test was conducted in order to better control the maximum temperature that occurred during the ignition process. After the sample was placed in the baskets and into the oven, the oven was started and both the chamber and sample were gradually heated until the chamber reached the designated test temperature. 
In practice, the time required to reach the test temperature was observed to be around $2 \mathrm{~h}$ (for a target test temperature equal to $\left.538^{\circ} \mathrm{C}\left(1000^{\circ} \mathrm{F}\right)\right)$. As in the thermal shock method, for some of the tests two thermocouples were attached to the sample (as described in 3.3.1) and the temperature was recorded. Mass changes were recorded in a manner similar to that described in the thermal shock method.

For this type of test the HM-1 mix was used. A limited number of tests was conducted with the dolomite blend (DB-1) instead of the corresponding mix (HM-1).

\subsubsection{Two-Step Tests}

As reported by contractors, the main concern in dealing with ignition oven test conducted at the lower temperature $\left(800^{\circ} \mathrm{F}\right.$ or $\left.427^{\circ} \mathrm{C}\right)$ was whether or not the binder would completely burn off during the test. To ensure that all the binder was burned during tests conducted at the lowest temperature of $427^{\circ} \mathrm{C}\left(800^{\circ} \mathrm{F}\right)$, a special "two-step" test was conducted. This special test type was conducted for both non-problematic and problematic mixes.

The test procedure for the two-step testing of the non-problematic mix tested in Task 1 was as follows: first, the typical ignition oven test at the lowest temperature $\left(427^{\circ} \mathrm{C}\right.$ or $800^{\circ} \mathrm{F}$ ) was conducted. When this test was completed (using a cut-off level equal to $0.01 \%$ ), the sample was removed from the oven and left for one hour to cool while the oven temperature was raised for the second step of the procedure. After this period, the mass of entire set (basket and sample) was determined. Next, the same sample was placed in a preheated $538^{\circ} \mathrm{C}\left(1000^{\circ} \mathrm{F}\right)$ ignition oven for one hour. This one hour period was selected in order to ensure the sample was at the designated temperature 
for at least 30 minutes. (The oven cools down when the door is opened to insert the sample, and it regains temperature in less than 30 minutes.) After removing the sample and allowing it to cool for one hour, the mass of sample was determined.

For the problematic mix, a different procedure was conducted. A known mass of HM-1 sample with $4.6 \%$ asphalt was placed in the baskets in the preheated oven at $427^{\circ} \mathrm{C}$ $\left(800^{\circ} \mathrm{F}\right)$ and left for 4.0 hours $(240$ minutes $)$. The four hour period was used to provide a consistent heating time and manual termination of the test, which would likely not terminate automatically. During the burning process, temperature and mass changes were recorded as described earlier. After 4.0 hours, the basket was removed and the mass was determined. This operation took approximately four minutes. After that, the basket with the sample was placed back in the ignition oven. The target oven temperature was bumped up to $538^{\circ} \mathrm{C}\left(1000^{\circ} \mathrm{F}\right)$. It was observed that the time needed to reach $538^{\circ} \mathrm{C}$ $\left(1000^{\circ} \mathrm{F}\right)$ was around 40 minutes. Raising the oven temperature with the sample inside was a modification of the nTS type of test and was used here in an attempt to limit decomposition of the sample. Then the test was continued at $538^{\circ} \mathrm{C}\left(1000^{\circ} \mathrm{F}\right)$ for 1 hour after reaching temperature. The total time for this step was 100 minutes. After this period, the basket was removed and the mass was determined. This operation also took approximately four minutes. Then the basket with the sample was placed in ignition oven again for 1.5 hours $\left(90\right.$ minutes) at $538^{\circ} \mathrm{C}\left(1000^{\circ} \mathrm{F}\right)$. The final mass was determined two minutes after removing the sample from the oven. The mass of the entire setup was determined after 20 minutes, 60 minutes, 120 minutes, 24 hours and 3 days. 


\subsection{Tests in Tempyrox Pyro-Clean ${ }^{\circledR}$ Glassware Cleaning Oven}

In addition to the tests conducted using the standard NCAT ignition oven, tests were performed using the Pyro-Clean ${ }^{\circledR}$ Glassware cleaning oven in Task 10. The HM-1 and DB-1 samples were tested for 4 hours at $483^{\circ} \mathrm{C}$ using the thermal shock (TS) method. The final masses from both types of oven were compared. In addition, the ovens' temperatures were recorded from the oven thermistor readings. Samples were prepared in the same way as described for tests using the NCAT ignition oven. During the tests, samples were placed in the same baskets as used in the NCAT ignition oven.

\subsection{Solvent Extraction Test}

The plant-produced HMAs used in second phase of the project were tested for binder content by solvent extraction. This test was conducted following AASHTO T319 using a toluene plus ethanol blend as a solvent.

\subsection{Compositional Analysis}

The main objective of Task 11 of the study was to determine the influence of the ignition oven test procedure and sample preparation on the chemical changes in dolomite aggregates. Such changes in the chemical composition, if properly characterized, could suggest modification to the ignition oven procedure to reduce variable mass loss problems. To characterize the mineral properties, thermogravimetric (TG) and x-ray diffraction (XRD) techniques were used. Properties of the dolomitic aggregates used in this study were also compared with the properties of the pure dolomite (PD) mineral. 
The TG is a thermal analysis technique used to measure changes in the mass of a sample as a function of temperature and/or time. During the test, changes in the mass of a specimen are recorded as the specimen is heated in a controlled atmosphere. Different chemical compounds will react and change at specific temperatures. Characteristic thermogravimetric curves (temperature versus mass loss) are created for each chemical compound or material tested due to unique sequences of physico-chemical reactions occurring over specific temperature ranges. Observations of the mass changes that occur at specific temperatures thus indicate the presence of those chemical compounds.

$\mathrm{X}$-ray diffraction (XRD) is a non-destructive technique for the qualitative analysis of crystalline materials in powder or solid form. Each crystalline material has a unique characteristic set of interplanar spacings which may be used as a "fingerprint" for its identification using the XRD technique. XRD patterns for solid materials contain peaks in characteristic places that allow determination of the chemical constituents in the sample. Using Bragg's Law:

$$
n \lambda=2 d \sin \theta
$$

where: $n$ - integer $(\mathrm{n}=1)$,

$\lambda=$ wavelength $(\lambda=1.540598 \AA$, in this case $)$,

$d=\mathrm{d}$-spacing (interatomic spacing) and

$\theta=$ diffraction angle,

the d-spacing was calculated for each observed XRD peak and compared with the characteristic d-spacing taken from the reference Powder Diffraction File. (45) Based on this analysis, the main peaks were identified. The peak identification process is explained further in Chapter 5.11. 


\subsubsection{Sample Preparation}

Three groups of samples were collected from the ignition oven experiments for the XRD and TG testing. In all cases, the target oven temperature used was $538^{\circ} \mathrm{C}$. The length of time the samples remained in the oven was determined based on the preliminary HM-1 sample trials with different binder contents. The tests indicated that the rate of mass loss of the sample significantly decreased and reached an asymptotic point around 6.3-10.0 hours. The groups of samples were:

\section{- Aggregate recovered from HMA after the ignition test (HM-1):}

$\mathrm{XRD}$ and TG tests were performed on samples of the dolomitic aggregate from HM-1 samples after ignition. For this test, the HMA samples were prepared with three binder contents: $3.6 \%, 4.6 \%$ and 5.6\%. The HM-1 samples were subjected to nTS heating for 10.0 hours. Selected samples were heated for a reduced time of 6.3 hours. In addition, HM-1 samples with $4.6 \%$ binder were examined after the TS test. In this case, samples were placed in the oven for 1.5 and 5.0 hours.

\section{- Unbound aggregate (DB-1):}

Further analyses were performed on samples taken from the dolomitic aggregate blend before and after an ignition oven test (both TS and nTS methods). Samples were heated in the ignition oven for 10.0 hours (nTS) and for 8.0 hours (TS) prior to the TG and XRD analyses. Selected nTS samples were heated for reduced times of 6.4 and 9.1 hours.

\section{- Pure dolomite (PD):}

The pure mineral sample was split into individual $2.5 \mathrm{~g}$ samples. Again, samples before and after heating were prepared for further analysis. Both TS and nTS 
methods of the ignition test were conducted on the pure dolomite in a muffle furnace instead of the ignition oven. A muffle furnace was used instead of the ignition oven because of the small mass and gradation of the sample. The samples were heated in the furnace for 8.0 hours (TS) and for 8.4 hours (nTS). The heating time for the nTS test type was reduced from 10.0 hours due to the differences in heating rate characteristics between the muffle furnace and ignition oven. The muffle furnace needs only 0.4 hours to preheat to the target test temperature of $538^{\circ} \mathrm{C}$; the ignition oven needed more time for preheating (around two hours).

\subsubsection{Test Procedure}

Samples for XRD and TG testing were quartered, crushed and ground in order to obtain a sample that passed the $0.075 \mathrm{~mm}(\# 200)$ sieve size.

Platinum pans were used to hold the powdered sample (50-70 mg) under study. The samples were heated from room temperature up to the target TG temperature of $1000^{\circ} \mathrm{C}$. A heating rate of $10^{\circ} \mathrm{C} / \mathrm{min}$ was used in all of the tests. The purge gas used in the thermal analysis experiments was carbon dioxide $\left(\mathrm{CO}_{2}\right)$. Compressed gas was supplied at gas flow rate of $108 \mathrm{ml} / \mathrm{min}$. For each sample type, three test repetitions were conducted.

Another sieved sample was placed and compacted in the aluminum sample holder of the X-ray diffractometer. While preparing the specimen, particular attention was paid to ensure random orientation of the individual grains. The XRD test was carried out over

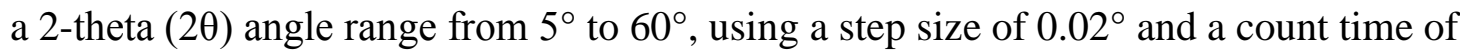


$1.0 \mathrm{~s}$ per step. Using Bragg's Law for each observed XRD peak, the d-spacings were calculated and compared with the characteristic d-spacing taken from the Powder Diffraction File (46). Based on this analysis, the main peaks were identified. For each sample type, two test repetitions were conducted. 


\section{CHAPTER 5: TEST RESULTS AND DISCUSSION - PHASE ONE}

The influence of various parameters on asphalt mass loss and changes of the aggregate properties was investigated in this study. Because dolomite decomposition

depends on the temperature, research interest in Phase One was focused on observation of the variation and distribution of ignition temperature within the oven chamber.

First, some general terms used in this report are defined as follows:

- \% mass loss

$\%$ mass loss $=\left(m_{T 2}-m_{T 1}\right) * 100 / m$,

where:

$m_{T 1}$ - sample mass at time $\mathrm{T}_{1}$

$m_{T 2}$ - sample mass at time $\mathrm{T}_{2} ; \mathrm{T}_{2}=\mathrm{T}_{1}+1$ '

$m$ - total sample mass before the test

- Rate of \% mass loss

Rate of $\%$ mass loss $=\% m_{T 2}-\% m_{T 1 \text {, }}$

where:

$\% m_{T l}$ - percent of sample mass loss at time $\mathrm{T}_{2}$

$\% m_{T 2}-$ percent of sample mass loss at time $\mathrm{T}_{2} ; \mathrm{T}_{2}=\mathrm{T}_{1}+1$

\subsection{Task 1 - Standard Ignition Oven Results for Non-Problematic Aggregate}

During Task 1, temperature and mass changes during the conventional ignition oven test with "non problematic" HM-0 were investigated, as illustrated in Figure 5.1. It 
was observed that the maximum temperature during the test was reached about 9 minutes after placing the sample into the preheated oven. The oven temperature then decreased to the target temperature and increased again reaching another peak after about 30 minutes. Analysis of the temperature plots leads to the conclusion that the typical ignition oven test contains three stages:

- Stage 1 - Pre-heating. Once preheated, the ignition oven maintained the preset test temperature with maximum differences of $\pm 1^{\circ} \mathrm{C}$. At the end of this stage, the oven temperature dropped rapidly due to opening of the oven door and sample placement (door remained open for around 30 seconds).

- Stage 2 - Burning. Once the test started, the temperature continued to decrease -- a process which commenced at the end of Stage 1. The temperature decreased to $440^{\circ} \mathrm{C}\left(824^{\circ} \mathrm{F}\right)$. Because of the oven heat capacity and the burning of the binder, however, the oven reached the desired test temperature again after approximately 8 minutes. The highest rate of increase of the temperature was found to be around $100^{\circ} \mathrm{C}$ in 2 minutes $\left(50^{\circ} \mathrm{C} / \mathrm{min}\right)$. The temperature exceeded the desired test temperature $\left(538^{\circ} \mathrm{C}\right.$ or $\left.1000^{\circ} \mathrm{F}\right)$, then decreased and increased again. A likely explanation for this is the time of the oven reaction and inertia of the controller. The oven overshoots the target, then cools as it tries to stabilize at the target temperature. Ignition of the binder during this phase causes the oven temperature to increase above the target temperature. At the end of this phase (45 minutes), the temperature decreased again to the target test temperature, presumably when all of the binder has ignited. 
- Stage 3-Stabilization. The temperature in the ignition oven chamber stabilized at the target test temperature $\left(538^{\circ} \mathrm{C}\right.$ or $\left.1000^{\circ} \mathrm{F}\right)$ at the beginning of this stage. About 6 minutes after the temperature stabilized, the rate of mass loss reached the cut-off level set for $0.01 \%$ and the test stopped.

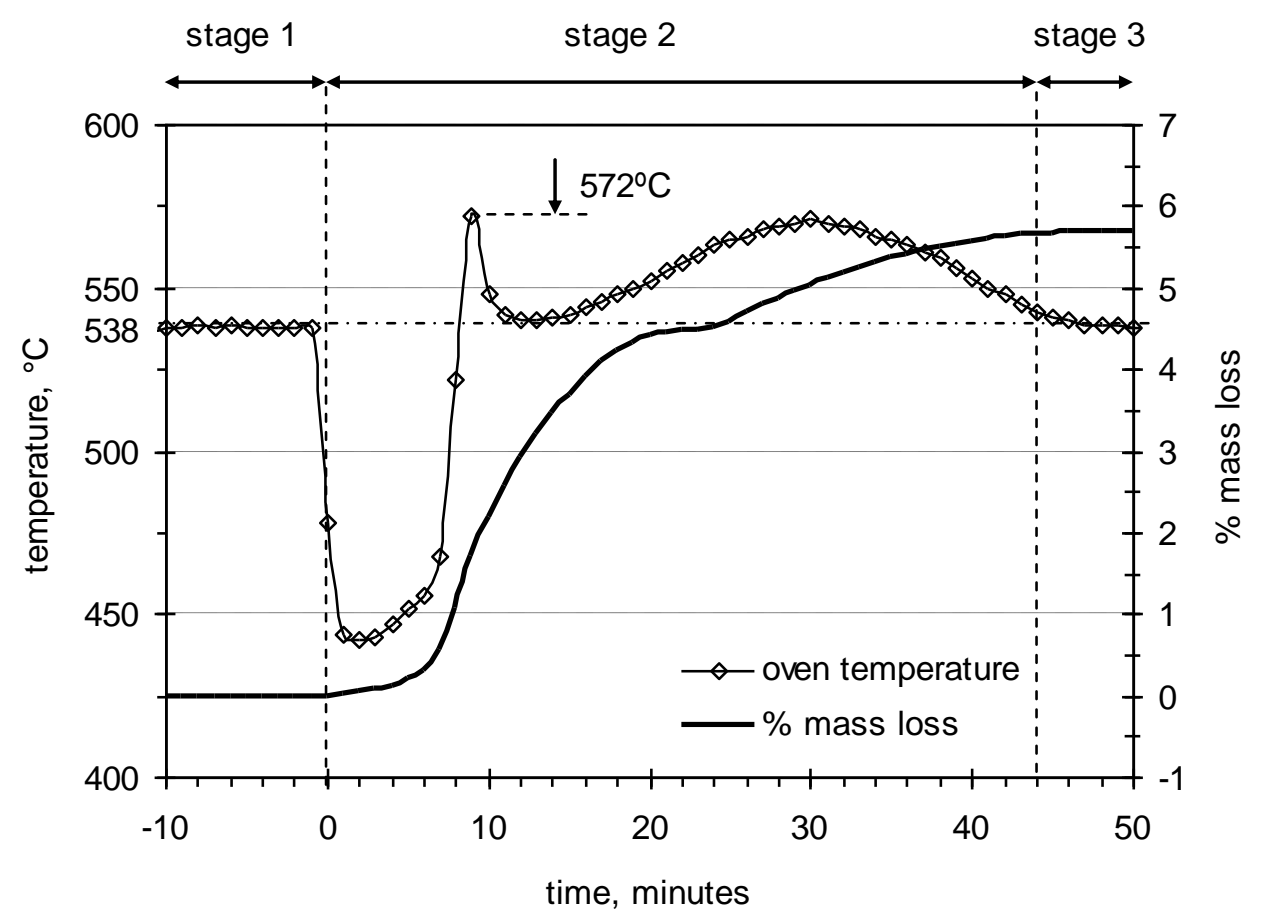

Figure 5.1. Ignition oven temperature and mass loss versus time for non problematic $\mathrm{HM}-0$ at $538^{\circ} \mathrm{C}\left(1000^{\circ} \mathrm{F}\right)$.

Although the rate of mass loss was low during the first six minutes of Stage 2, it quickly increased, with the highest rate occurring less than 10 minutes after initiation of the test. The slowest rate of mass loss was observed in Stage 3. The visible plateau in the mass loss plot (mass loss less than $0.01 \%$ ) terminates the ignition oven test. 
This task, then, established the baseline for comparison to other tests on problematic materials. It clearly defined the behavior expected from non-problematic materials when tested in the ignition oven.

\subsection{Task 2 - Influence of Test Method on HMA with Problematic Aggregate}

The standard ignition oven test method, which is referred to here as the "thermal shock method, TS" and the modified test method, called the "non thermal shock method, nTS", were investigated in this task, as described in Chapter 4. (Recall that the TS method involves placing the sample and basket in a preheated oven while the nTS method involves heating the sample and the oven from room temperature together.) The problematic HM-1 mixture with $4.6 \%$ binder was used for these tests.

A comparison of the temperature and mass loss changes during these ignition oven tests is shown in Figure 5.2. At the beginning of the standard (TS) ignition test, the oven temperature drops rapidly from $538^{\circ} \mathrm{C}$ to $452^{\circ} \mathrm{C}$ when the door is opened to place the sample in the oven (door remains open for approximately 30 seconds). After around 8 minutes, the oven reaches the desired test temperature. The greatest rate of temperature increase was found to be around $100^{\circ} \mathrm{C}$ in 2 minutes. The temperature is observed to exceed the desired test temperature $\left(538^{\circ} \mathrm{C}\right)$, after which it decreases and increases again. A likely explanation for this phenomenon again is the oven reaction time. Initially, the oven overshoots the target slightly and then it cools down as it tries to stabilize at the target temperature. The temperature stabilized at the pre-set temperature level $\left(538^{\circ}\right)$ after around 55 minutes. Analysis of the mass loss plot leads to the conclusion that once the oven temperature stabilizes, the mass loss plot starts to exhibit a linear character. 


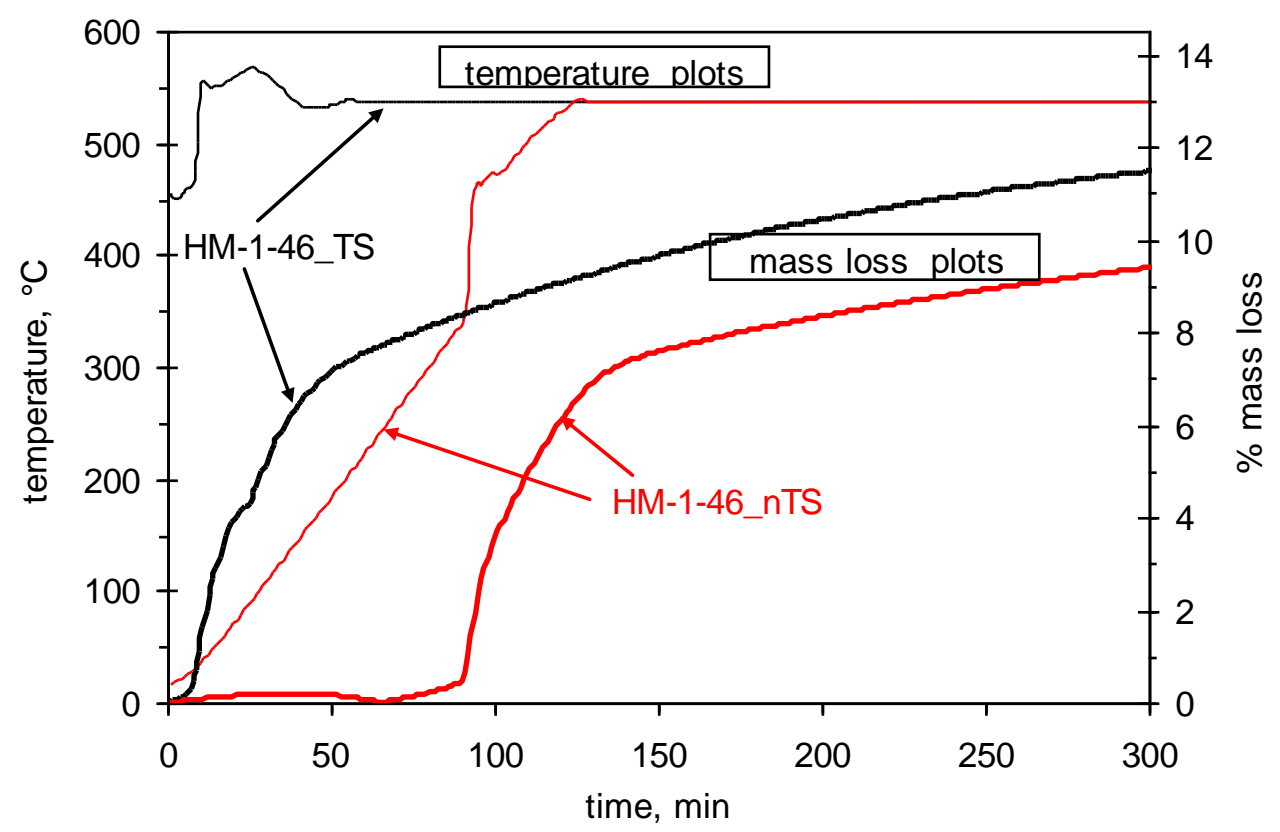

Figure 5.2. Typical TS and nTS ignition test results for $\mathrm{HM}-1$ with $4.6 \%$ binder at $538^{\circ} \mathrm{C}$.

In the nTS test, the temperature increased linearly up to $350^{\circ} \mathrm{C}$. No significant mass changes were observed during that time. At a temperature of about $350^{\circ} \mathrm{C}$, rapid temperature and mass changes, similar to those occurring in TS, were observed. During the TS tests, a temperature of $450^{\circ} \mathrm{C}$ was reached in first minute of the test while for nTS tests it was reached after 90 minutes. During the nTS test, the target oven temperature was reached after around 115 minutes. In addition, the maximum test temperature did not exceed the target test temperature significantly, in contrast to the thermal shock method. Since the rate of heating was slower in the nTS method, the oven could react to control the temperature more closely.

The mass loss in the nTS test is lower than in the TS at a given point in time, perhaps because the temperature was better controlled but also perhaps because the mix 
had not been at high temperature for as long. In the nTS test, the dolomite was not exposed to temperatures higher than the target temperature.

As shown in Figure 5.3, after the ignition test the amount of fine particles in the sample appears to be slightly lower than it was before the test. Furthermore the amount of intermediate particles is slightly higher. These differences are so small, however, that they are within the precision of the test method. Finally, no significant differences were observed in aggregate gradation measured before and after the thermal and non thermal shock ignition tests.

One method to quantify and compare aggregate gradations is the use of the fineness modulus. The fineness modulus is frequently used in the design of cement concrete mixtures to describe a weighted average for the aggregate being analyzed. The fineness modulus is obtained by adding the sum of the cumulative percentages by mass of a sample aggregate retained on each of a specified series of sieves and dividing the sum by 100 . The specified sieves are: $150 \mu \mathrm{m}$ (No. 100), $300 \mu \mathrm{m}$ (No. 50), $600 \mu \mathrm{m}$ (No. 30), $1.18 \mathrm{~mm}$ (No. 16), $2.36 \mathrm{~mm}$ (No. 8), and $4.75 \mathrm{~mm}$ (No.4), and $9.5 \mathrm{~mm}$ (3/8 in.), 19.0mm (3/4-in.), $37.5 \mathrm{~mm}$ (1-1/2 in.), and larger, increasing in the ratio of 2 to 1 . The calculated fineness modulus (for the gradations shown in Figure 5.3) was not significantly affected by the ignition test: it was 5.55 for the gradation before the test, 5.56 for the gradation measured after the non thermal shock ignition test and 5.53 for the gradation measured after the thermal shock ignition test. This is consistent with the small changes observed in the gradations themselves. This finding suggests that thermal shock does not cause increased changes in the gradation of the problematic dolomite, which is consistent with anecdotal reports from local users of the method. 


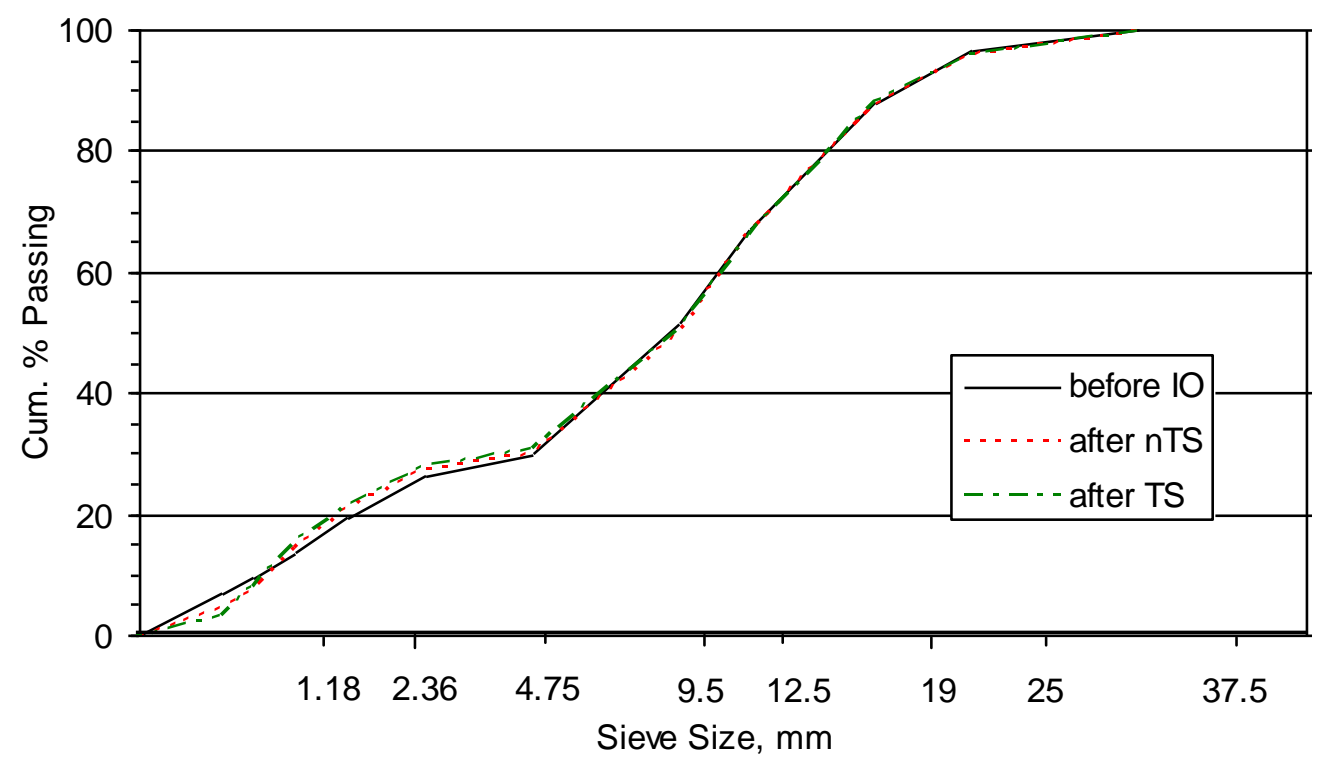

Figure 5.3. Comparison of aggregate gradation before IO, after nTS and TS tests; HM-1 mix with $4.6 \%$ binder at $538^{\circ} \mathrm{C}$; test time: $3.8-4.2 \mathrm{~h}$.

As shown in Table 5.1, the ignition oven test influenced the sample specific gravity and absorption significantly. However, the differences between specific gravity and absorption measured for the samples tested in the TS and nTS methods were not significantly different.

Table 5.1. Changes in dolomite absorption and specific gravity before and after TS and nTS tests.

\begin{tabular}{|l|c|c|c|}
\hline $\begin{array}{l}\text { Sample/Test } \\
\text { DB- } 1 \text { at } 538^{\circ} \mathrm{C}\end{array}$ & Before IO & After IO (TS) & After IO (nTS) \\
\hline Sp. grav. oven - dried & 2.710 & 2.423 & 2.447 \\
\hline Sp. grav. apparent & 2.773 & 2.642 & 2.658 \\
\hline \% absorption & 0.8 & 3.4 & 3.3 \\
\hline
\end{tabular}

The results of this task show that use of the ignition oven does affect the properties (specific gravity and absorption) of the problematic Dolomite A used in this 
study. They also show, however, that thermal shock, which the aggregate experiences during a conventional IO test, does not cause increased aggregate degradation (gradation changes) nor changes in properties (specific gravity and absorption) compared to more gentle heating. The nTS test, however, does allow better control of the oven temperature and results in lower mass loss at a given point in time. The nTS test procedure is time consuming, however, so is not a viable option for production control testing.

\subsection{Task 3 - Influence of Mix Type on Ignition Test Results}

The influence of mix type on the ignition oven test results was investigated using the lab-produced mixes HM-1, HM-2 and HM-3. The tests were conducted at $538^{\circ} \mathrm{C}$ using the standard TS type test.

As shown in Figure 5.4, the temperature plots for each sample type are different. Initially, the temperature increased rapidly for the fine-graded $9.5 \mathrm{~mm}$ mix (HM-2 with $5.4 \%$ binder); followed by the $19 \mathrm{~mm}$ mix (HM-3 with $4.5 \%$ binder) and finally the 25 mm mix (HM-1 with $4.6 \%$ binder). For each of the mixes, two temperature peaks were observed. The time lag between those two peaks was 4 minutes for HM-2, 8 minutes for HM-3 and 18 minutes for HM-1. The highest peak of $600^{\circ} \mathrm{C}$ was observed for HM-3 while it was $585^{\circ} \mathrm{C}$ for $\mathrm{HM}-2$ and $580^{\circ} \mathrm{C}$ for $\mathrm{HM}-1$.

For HM-2 and HM-3, the mass loss plots correspond with the temperature plots in the same way as for HM-1 mix in Task 2 (as described in 5.2). In all cases, the mass loss increased rapidly as the temperature increased. The plot flattened out (low constant slope) and became linear after 35 minutes for HM-2 while for HM-1 and HM-3 this occurred 
after approximately 40-50 minutes. The mass loss plots for HM-1 and HM-3, which have very similar binder contents, are quite similar after about 50 minutes.

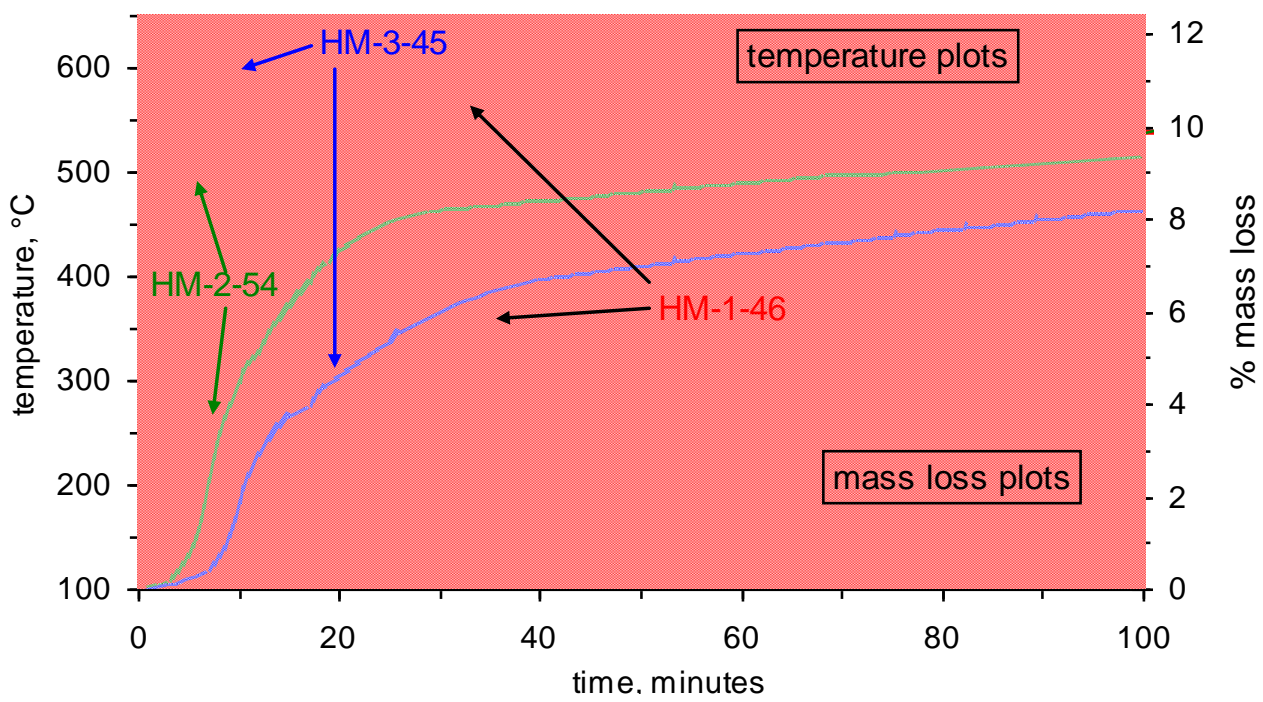

Figure 5.4. Comparison of temperature and mass loss during IO tests at $538^{\circ} \mathrm{C}$ for $\mathrm{HM}-1$ (4.6\% AC), HM-2 (5.4\% AC) and HM-3 (4.5\% AC).

These results show that the mix with the smallest NMAS and highest binder content was markedly different from the other two mixes, which have similar, lower binder contents. This is logical since a binder content test should certainly be sensitive to changes in the binder content. Finer mixes have higher surface areas to coat, so tend to have higher binder contents. The results also show that these mixes demonstrated two peaks in the temperature plot, similar to what was observed with non-problematic mix in Task 1. The time lag between the peaks differed between the mixes and may be related to the binder content and/or NMAS. In these tests, binder content and aggregate NMAS are confounded, but the results of later tests (Task 4) will help to differentiate the effects. 


\subsection{Task 4 - Influence of Binder Content on the Ignition Process}

The influence of the binder content (including $0 \%$ binder content) on the ignition process was investigated in Task 4. In addition to tests with Dolomite A in a mix (HM-1) and aggregate blend with $0 \%$ binder (DB-1), limited tests with pure dolomite (PD) were conducted.

\subsubsection{Dolomite Blend Ignition}

Results of tests similar to those described above, but conducted for DB-1 instead of HM-1, are shown in Figure 5.4. For both the thermal and the non thermal shock test methods, no rapid temperature changes were observed. The temperature plots in both cases are linear. The target test temperature was not significantly exceeded in any cases. During the nTS test, a temperature of $450^{\circ} \mathrm{C}$ was reached after around 120 minutes, and the target temperature was reached in about 160 minutes. During the TS test, the temperature reached $450^{\circ} \mathrm{C}$ in the first minute of the test and the target in less than 50 minutes.

Except for some noise in the first stage of the test, the mass loss plots for both cases are linear when the test temperature is higher than $450^{\circ} \mathrm{C}$. As shown in Figure 5.5, both mass loss plots are parallel. 


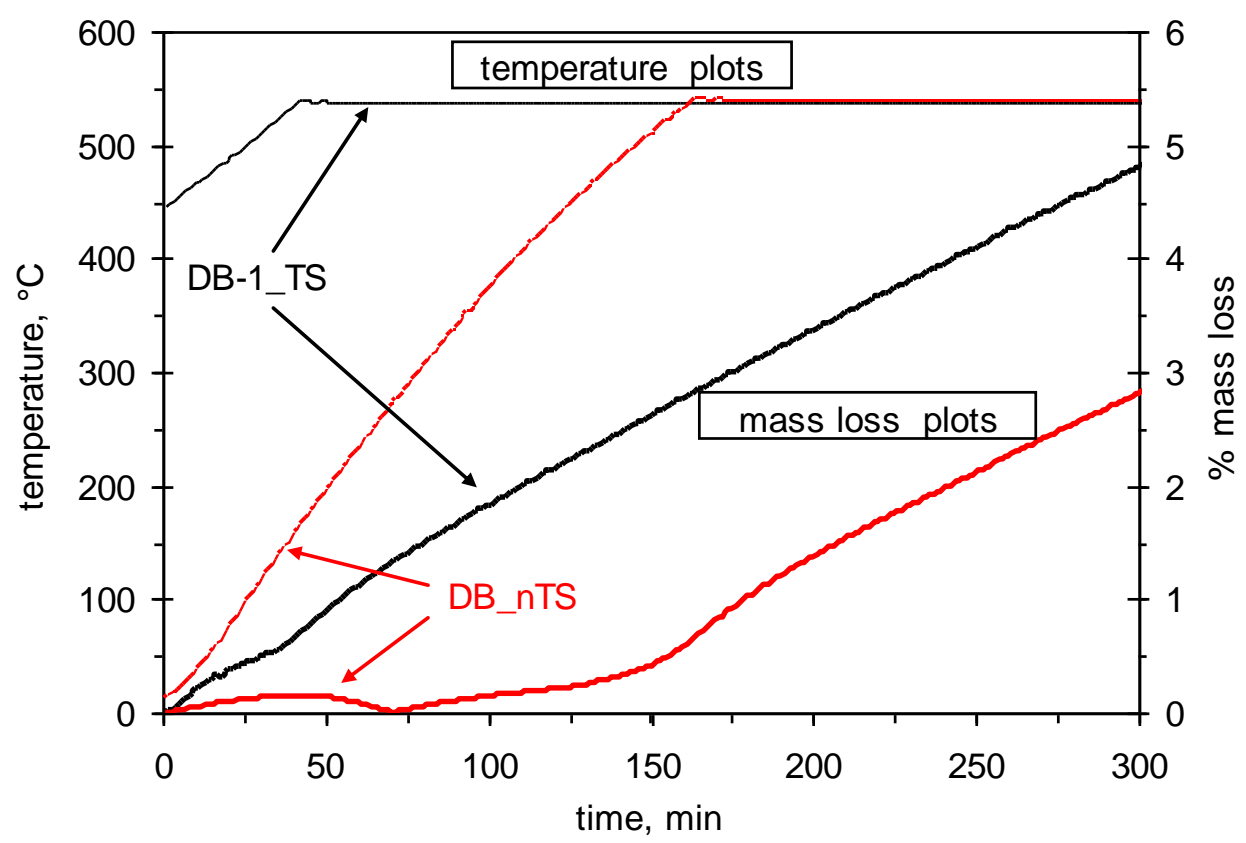

Figure 5.5. Typical TS and nTS ignition test results for DB-1 at $538^{\circ} \mathrm{C}$.

Aggregate gradation, specific gravity and absorption of the various sizes of

Dolomite A measured before and after the ignition oven test were compared, as shown in Figure 5.6 and Table 5.2. The greatest changes in aggregate gradation were observed for the coarse aggregate (difference in sieve analysis measured before and after the test was up to $10 \%$ ). For the fine aggregate, no significant difference was observed. The ignition oven test also influenced the sample specific gravity and absorption. Again, the highest changes in absorption occurred for the coarsest aggregate, \#5, and the smallest for the finest, \#12. 


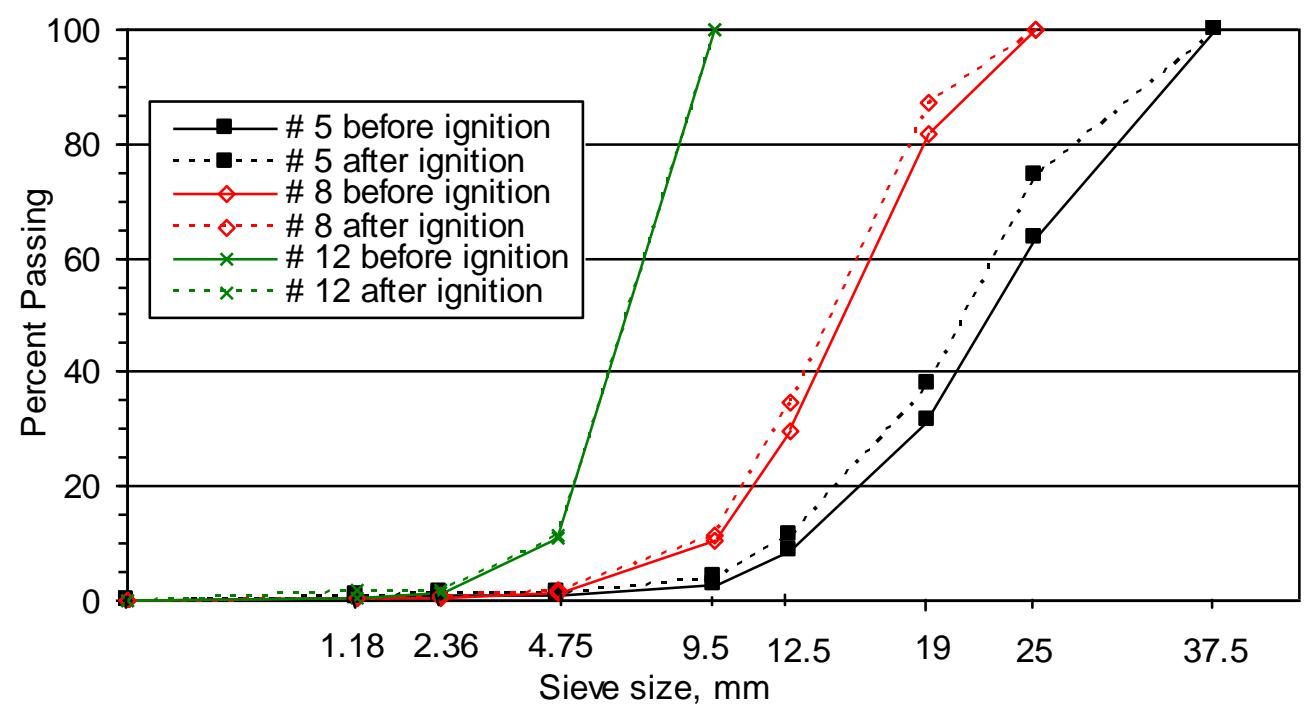

Figure 5.6. Influence of ignition process on gradation; sample without binder at $538^{\circ} \mathrm{C}$.

Table 5.2. Changes in dolomite absorption and specific gravity before and after IO test.

\begin{tabular}{|l|c|c|c|c|c|c|}
\hline \multirow{2}{*}{$\begin{array}{l}\text { Sample / Test } \\
\text { DB-1 at } 538^{\circ} \mathrm{C}\end{array}$} & \multicolumn{2}{|c|}{$\# 5$} & \multicolumn{2}{c|}{$\# 8$} & \multicolumn{2}{c|}{$\# 12$} \\
\cline { 2 - 7 } & before IO & after IO & before IO & after IO & before IO & after IO \\
\hline Sp. grav. oven - dried & 2.710 & 2.423 & 2.708 & 2.439 & 2.730 & 2.580 \\
\hline Sp. grav. apparent & 2.773 & 2.642 & 2.774 & 2.643 & 2.808 & 2.740 \\
\hline \% absorption & 0.8 & 3.4 & 0.9 & 3.2 & 1.0 & 2.3 \\
\hline
\end{tabular}

The strong relationships between specific gravity and absorption measured before and after the test are shown in Figure 5.7 and Figure 5.8. The ignition test decreased the specific gravity and increased the absorption of the tested aggregates. 


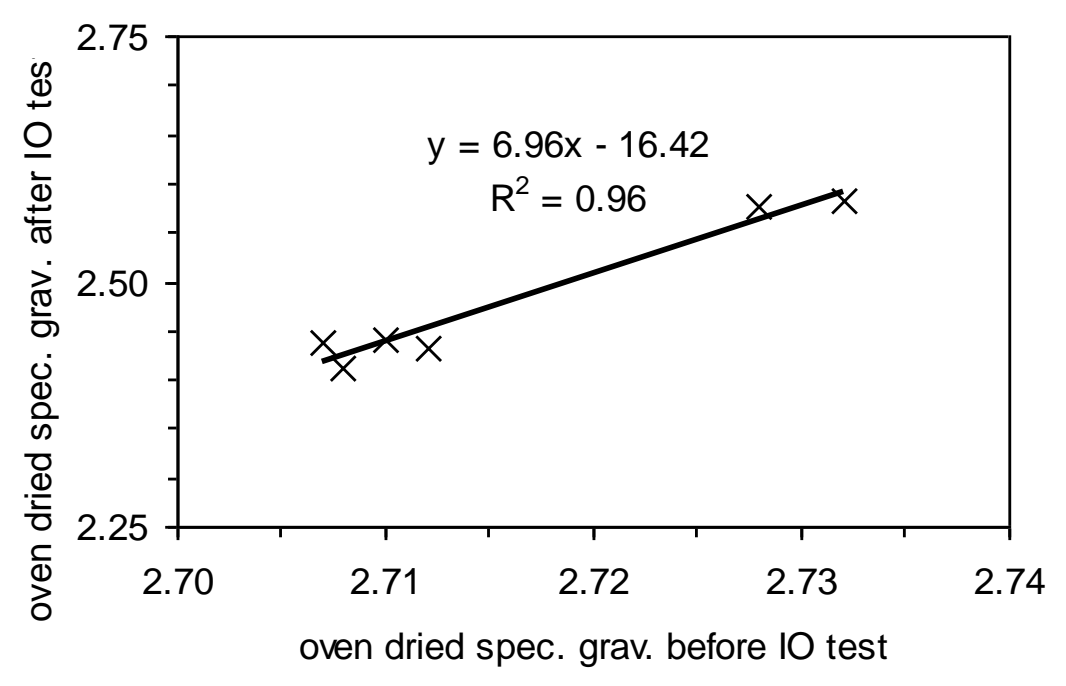

Figure 5.7. Relationship between dolomite oven dried specific gravity measured before and after IO; sample without binder at $538^{\circ} \mathrm{C}$.

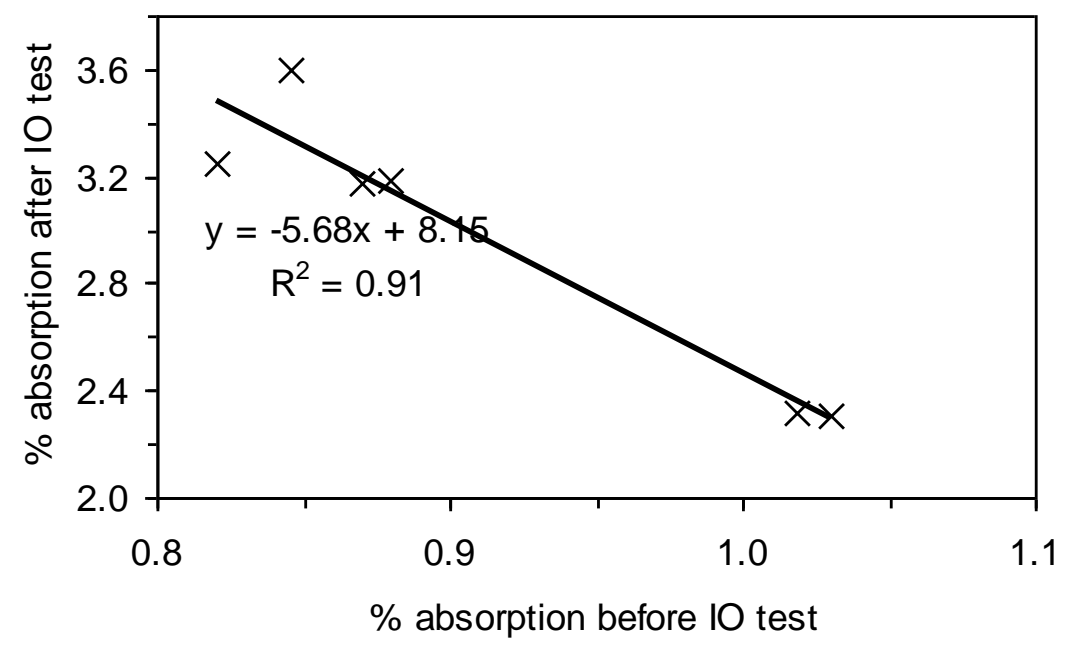

Figure 5.8. Relationship between dolomite absorption measured before and after IO; sample without binder; at $538^{\circ} \mathrm{C}$.

\subsubsection{Pure Dolomite Mass Loss}

In addition to the tests with DB-1, limited ignition tests with PD samples were conducted. DB-1 and PD samples were heated using a TS type test for a predetermined 
length of time ( 8 hours). In addition, DB-1 was tested using the nTS type test in which it was heated for 600 minutes, (which is 120 minutes longer than the TS). The time extension was based on the observation that when DB-1 was tested in the nTS method; it took 120 minutes for the oven to reach $450^{\circ} \mathrm{C}$, which was attained in only 1 minute in the TS method. For the PD sample, the time was reduced from 600 to 505 minutes for the nTS method, due to the differences in the heating rate between the muffle furnace and ignition oven.

Comparisons between the mass losses of the DB-1 and PD samples are shown in Figure 5.9. For the PD sample, the differences between both test methods were small, however, for DB-1 they were significant. The pure dolomite exhibited much higher mass losses than the dolomitic aggregate blend; this is logical since the pure dolomite contains a higher percentage of dolomite that can undergo changes.

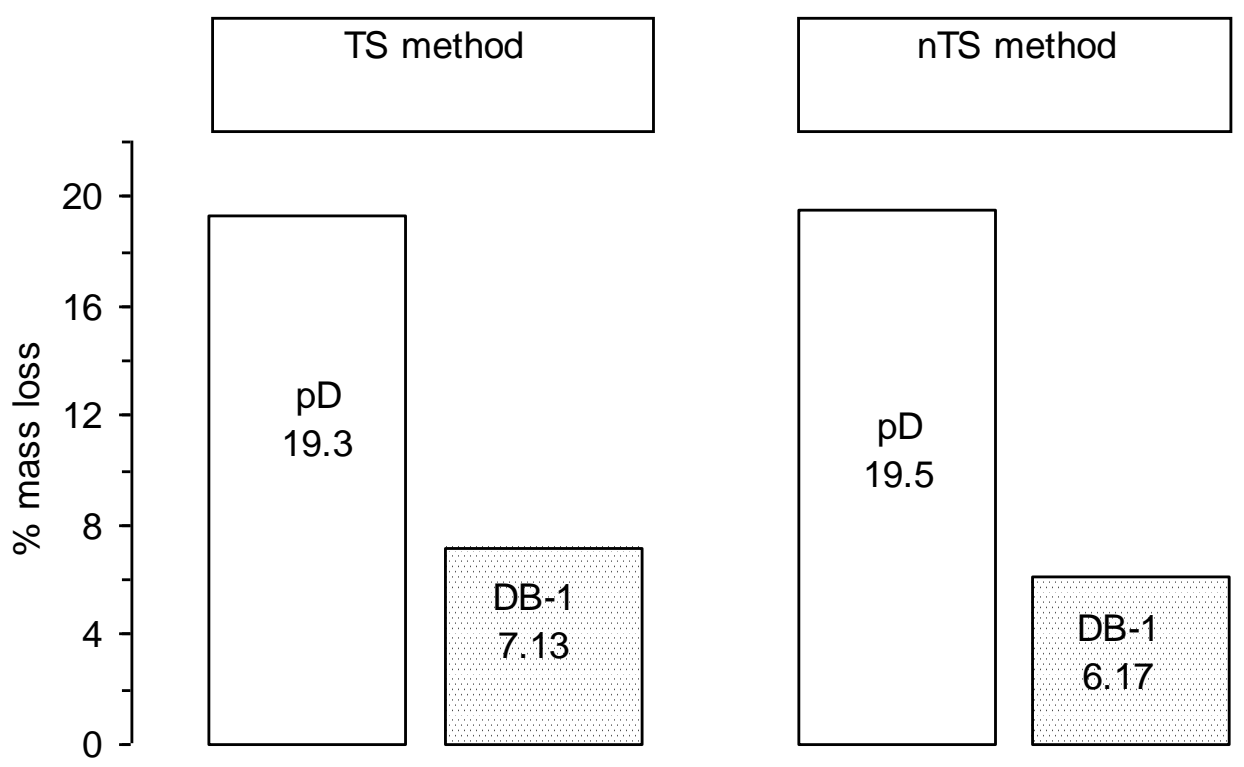

Figure 5.9. Comparison of DB-1 and PD samples mass loss in TS and nTS tests at $538^{\circ} \mathrm{C}$. 


\subsubsection{HMA Ignition}

In order to investigate the influence of binder content on the ignition oven process, HM-1 mixes with optimum (4.6\%), higher $(+1 \%)$ and lower $(-1 \%)$ binder contents were prepared and tested using the nTS test type. (The nTS method was used here to try to limit the dolomite decomposition so that the effect of binder content could be observed more clearly.) The comparison of temperature and mass loss dependence versus time is shown in

Figure 5.10. During the first stage of the test (at temperatures below $250^{\circ} \mathrm{C}$ or the first 60 minutes of test), all the temperature and mass loss plots follow the same path. At higher temperatures, differences in the mass and oven temperatures between the samples were observed. Once the temperature in the ignition oven chamber exceeded about $350^{\circ} \mathrm{C}$, the mass loss increased drastically.

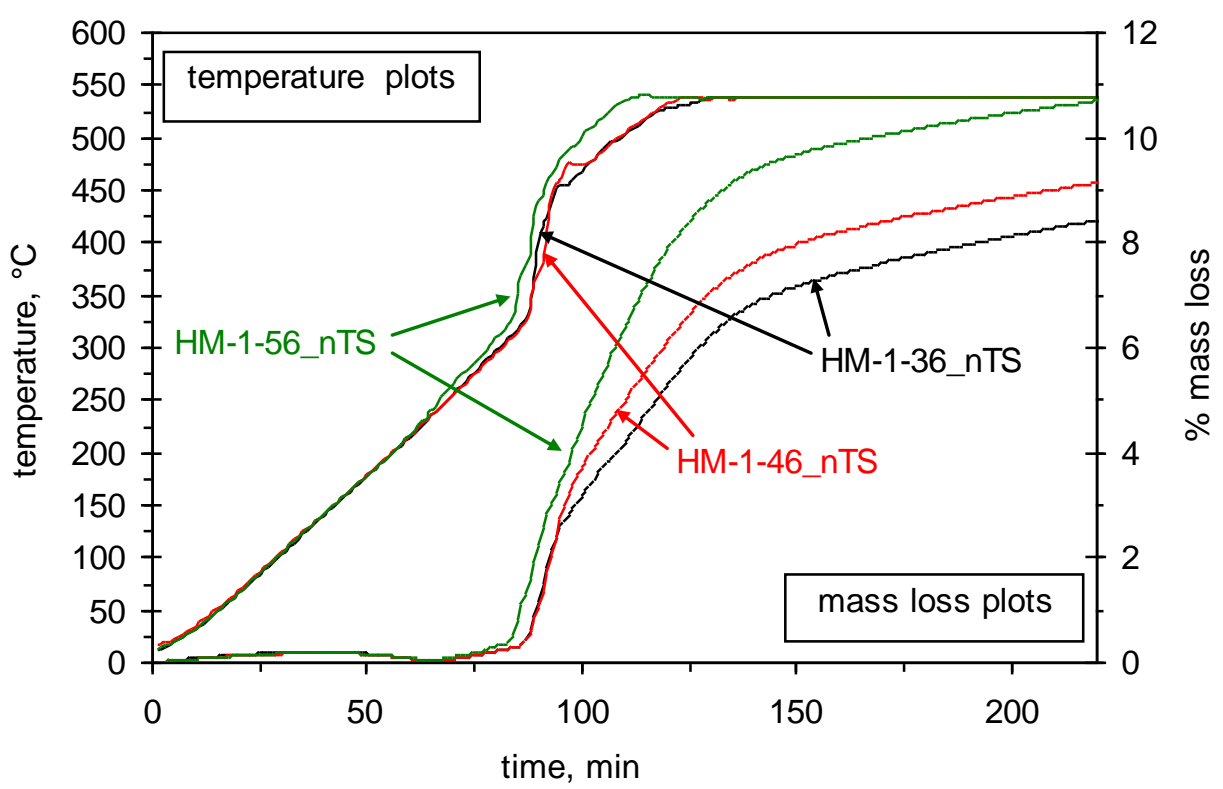

Figure 5.10. Influence of binder content on the nTS results for HM-1 with 3 binder contents at $538^{\circ} \mathrm{C}$. 
Closer analysis of the temperature/time relationship shows that the temperature increased first for the sample with the highest binder content (5.6\%). For the samples with $4.6 \%$ and $3.6 \%$ of binder, no significant differences in the temperature plots were observed. Similarly, for the mass loss/time relationship, the sample with the highest binder content (5.6\%) exhibited the highest mass loss, as expected. For samples with $4.6 \%$ and $3.6 \%$ of binder, significantly lower mass losses were observed. Again, once the oven temperature stabilized (reached $538^{\circ} \mathrm{C}$ ), the mass loss plots exhibited a linear trend.

Mass losses measured for HM-1 with binder contents of 3.6\% - 5.6\% and for DB1 (0\% binder) are shown in Figure 5.11. The mass loss obtained after 6.5 hours of heating in the ignition oven (using the nTS type test) shows similar trends to the discussion above; the higher the binder content, the higher the mass loss. Differences in mass losses between DB-1 and HM-1 samples with 3.6\% of asphalt were 4\%. Differences in mass losses between samples with 3.6\% of asphalt and those with 5.6\% of asphalt were measured to be $2.5 \%$. 


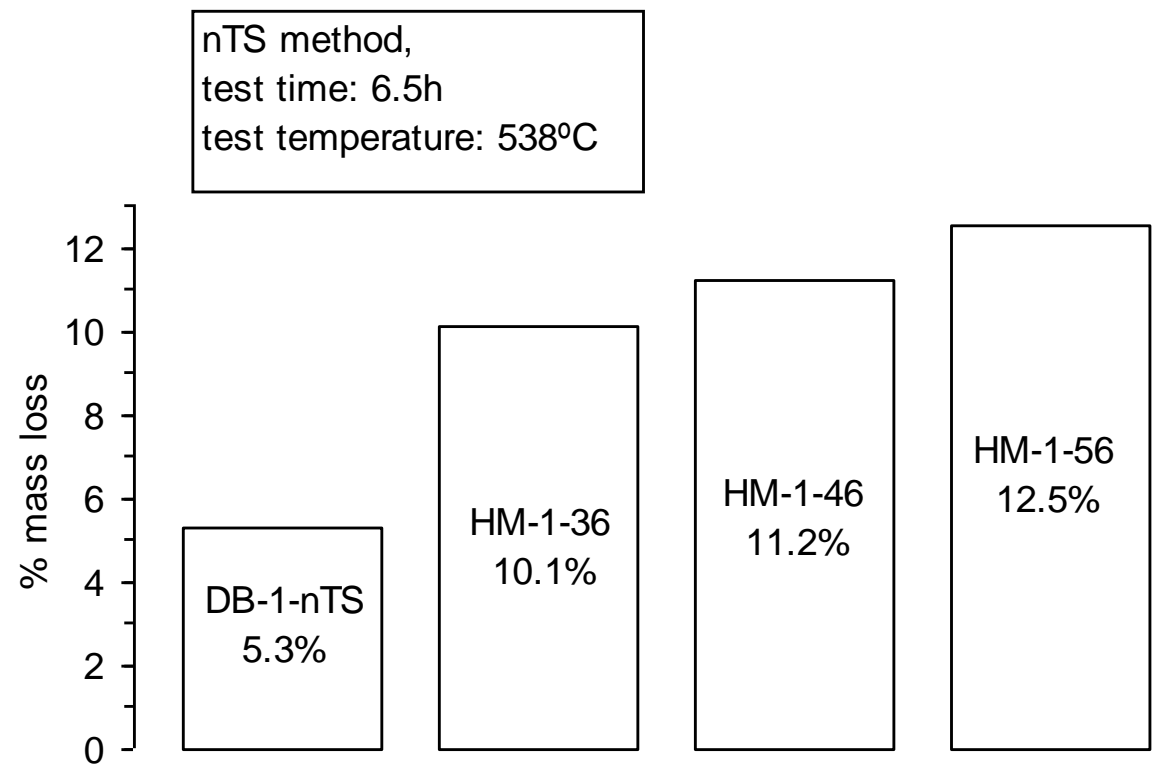

Figure 5.11. Effect of binder content on mass loss in nTS ignition test for DB-1 and HM1 at $538^{\circ} \mathrm{C}$.

These results show that the observed differences in mass losses for the HM-1 samples with different binder contents correspond roughly to the difference in binder content; that is, as the binder content increases by $1 \%$, the mass loss also increases by about $1 \%$. The difference in the mass loss between mixes increases as the binder content increases, however, suggesting that the increased binder content may cause higher temperature and somewhat more decomposition. Specifically, the difference in mass loss is $1.1 \%$ when the binder content increases from 3.6 to $4.6 \%$, but it is $1.3 \%$ when the binder content increases from 4.6 to $5.6 \%$. The aggregate blend with no binder also shows a mass loss. If the mass loss were solely a function of binder content, the difference in mass loss between DB-1 and the mix samples would be expected to correlate to the binder content of the mix. That is not the case here; for example, the difference in binder content between DB-1 and HM-1-36 is $3.6 \%$, but the difference in 
mass loss is $4.8 \%$. This suggests that another factor is affecting the results, which may be the increase in temperature in the oven caused by ignition of the binder. The increased temperature may cause increased mass loss. Testing of the pure dolomite sample shows very high mass losses, indicating that as the dolomite content increases, the mass loss also increases. This may explain, in part, why different dolomitic aggregates exhibit different susceptibilities to decomposition and unstable mass loss.

\subsection{Task 5 - Influence of Test Time on the Mass Loss}

In order to observe the influence of test time on the sample mass loss, ignition oven procedures lasting 90 minutes to 240 minutes (1.2 hours to 4 hours) were conducted. The dolomite aggregate blend (no binder) was tested for up to 8.2 hours. The mass loss was verified at the end of the procedure by comparing the ignition oven balance mass loss reading to that determined on an external scale two minutes after removing the sample from the oven.

The linear relationship of mass loss versus test time, shown in Figure 5.12 indicates that for HMA each 10 minutes of test time produced a sample mass loss of $0.2 \%$. The high $\mathrm{R}^{2}$ value shows the strength of the relationship. In Figure 5.13 the relationship between time and mass loss for the dolomite blend is shown. In this case, each 10 minutes of test time cause sample losses of $0.1 \%$ of initial mass. The slope of mass loss plot for hot mix is twice that of the dolomite blend. 


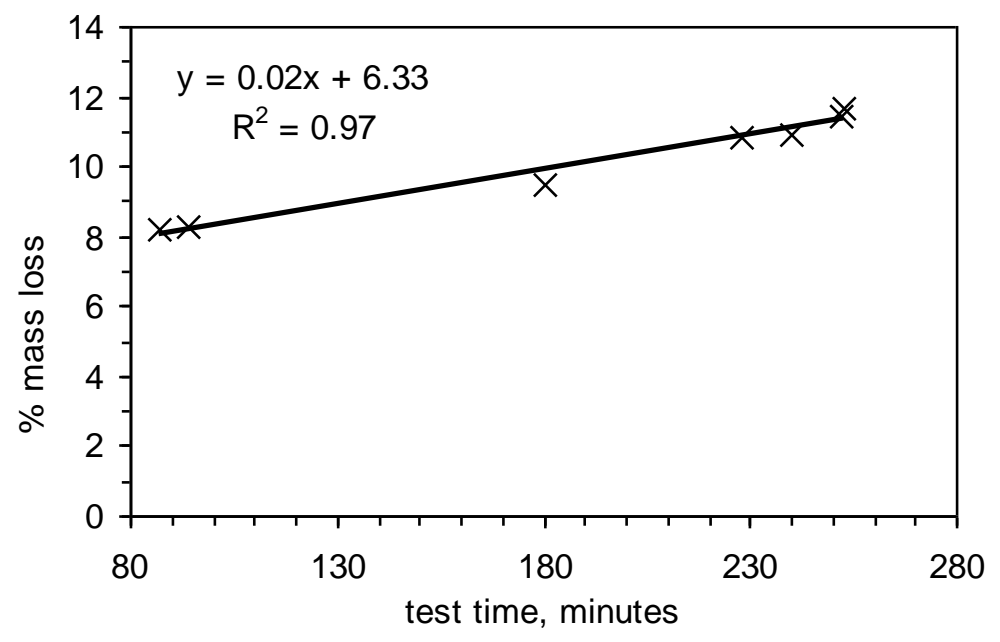

Figure 5.12. Relationship between mass loss and IO test time; HM-1, 4.6\% binder at $538^{\circ} \mathrm{C}$.

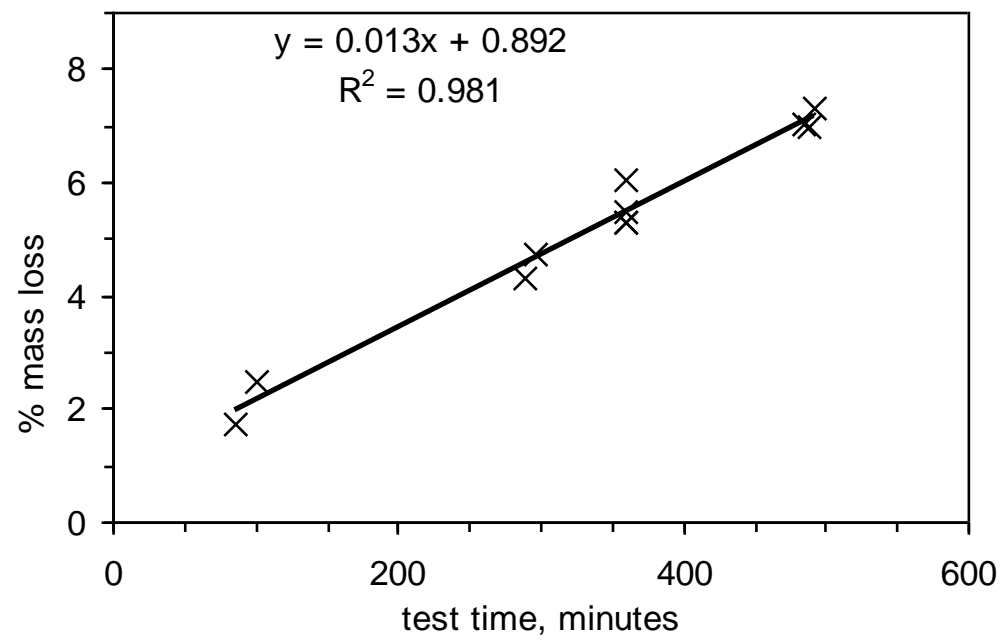

Note: Scale differs from that in Figure 5.12.

Figure 5.13. Relationship between dolomite blend mass loss and IO test time at $538^{\circ} \mathrm{C}$.

In conclusion, the length of time at high temperature does impact the mass loss. In addition, these results provide further evidence that the presence of binder to ignite does increase the rate of mass loss, as the mass loss rate is about double for the HMA sample as for the aggregate blend. 


\subsection{Task 6 - Influence of Test Temperature on Mass Loss}

In this study, the influence of the target test temperatures on the ignition process was investigated during 4-hour long tests conducted using the TS type of test. Tests were conducted at $538^{\circ} \mathrm{C}, 482^{\circ} \mathrm{C}$ and $427^{\circ} \mathrm{C}$ in Task 3 .

Temperature and mass loss relationships for HM-1 samples tested at different target temperatures are shown in Figure 5.14. All of the temperature plots exhibit the three test stages discussed in 5.1, however the time of occurrence of these stages seems to vary depending on the target test temperature. The rapid increase in temperature marking Stage 2 was observed to occur later for the lowest test temperature (at 8 minutes for tests at $538^{\circ} \mathrm{C}, 13$ minutes at $483^{\circ} \mathrm{C}$ and 18 minutes at $427^{\circ} \mathrm{C}$ ). The temperature peak located in the second stage of the process (ignition) is higher than the target test temperature in all cases; for tests at $538^{\circ} \mathrm{C}$, the peak is greater by around $34^{\circ} \mathrm{C}$; for tests at $483^{\circ} \mathrm{C}$, the peak is greater by around $53^{\circ} \mathrm{C}$; and for tests at $427^{\circ} \mathrm{C}$ the peak is greater by around $73^{\circ} \mathrm{C}$. The temperature stabilized after around 60 minutes for tests conducted at $538^{\circ} \mathrm{C}$ and at $483^{\circ} \mathrm{C}$. For tests conducted at $427^{\circ} \mathrm{C}$, temperature stabilization occurred after approximately 70 minutes.

The observed mass losses were clearly a function of test temperature, with higher temperatures resulting in higher losses. Specifically, while the total mass loss for the test temperature of $538^{\circ} \mathrm{C}$ was about $8.5 \%$, it was reduced to about $6.5 \%$ for the test temperature of $483^{\circ} \mathrm{C}$. The smallest mass loss (about 5.8\%) was observed for the lowest test temperature $\left(427^{\circ} \mathrm{C}\right)$. Since the asphalt content for mixture HM-1 was $4.6 \%$, any increase $(\Delta)$ in total mass loss above this number must represent the mass loss due to thermal decomposition of dolomite. These increases $(\Delta)$ were, respectively, $3.9 \%$ for test 
temperature of $538^{\circ} \mathrm{C}, 1.5 \%$ for test temperature of $483^{\circ} \mathrm{C}$ and $1.2 \%$ for test temperature of $427^{\circ} \mathrm{C}$. The higher losses associated with higher test temperatures are visibly linked to the rate of temperature increases at the end of Stage 2, as represented by the slopes of the mass-temperature curves from about 50 minutes onward. Figure 5.14 shows that these slopes (indicated by dotted lines labeled $\operatorname{tg} \alpha$ ) were, respectively, 0.022 for $538^{\circ} \mathrm{C}, 0.005$ for $483^{\circ} \mathrm{C}$ and 0.002 for $427^{\circ} \mathrm{C}$.

As was explained in 5.4, the DB-1 samples exhibited the lowest slope (not shown in Figure 5.14) during all the tests conducted at $538^{\circ} \mathrm{C}$. Similar observations can be made for tests run at $483^{\circ} \mathrm{C}$ and $427^{\circ} \mathrm{C}$.

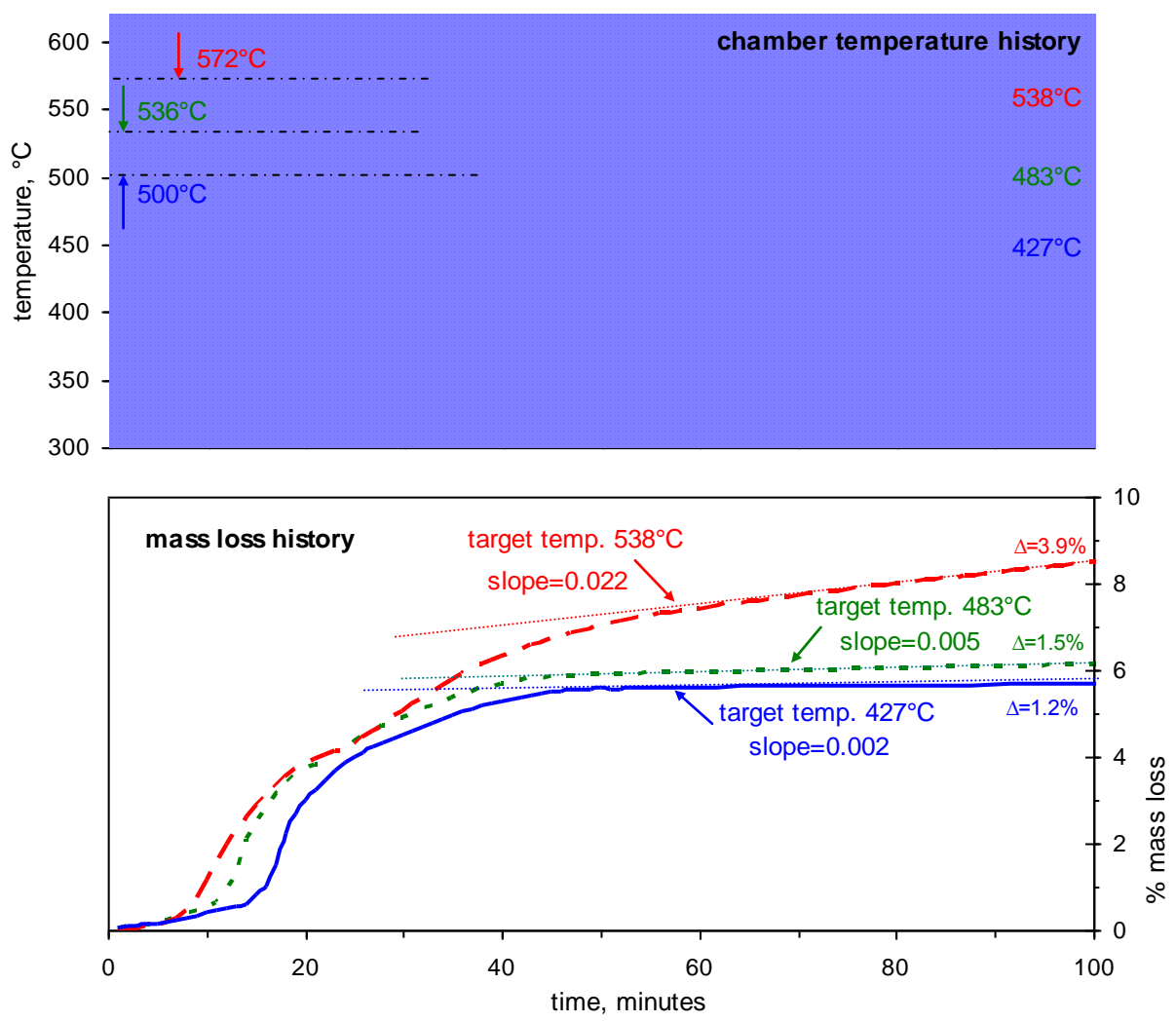

Figure 5.14. Influence of target test temperature on mass loss and oven temperature during IO; HM-1 with $4.6 \%$ binder at $538^{\circ} \mathrm{C}, 483^{\circ} \mathrm{C}, 427^{\circ} \mathrm{C}$. 
A comparison of the mass loss slopes calculated for DB-1 and for HM-1 tested at different temperatures is shown in Figure 5.15. It can be seen that decreasing the test temperature decreased the slope significantly for both DB-1 and HM-1.

For both HM-1 and DB-1, there is a relationship between the test temperature and sample mass loss. A strong logarithmic relationship with an $\mathrm{R}^{2}$ value greater than 0.94 was found for HM-1, as shown in Figure 5.16. Similarly, a strong logarithmic relationship with an $\mathrm{R}^{2}$ value greater than 0.99 was found for DB-1, as shown in Figure 5.17.

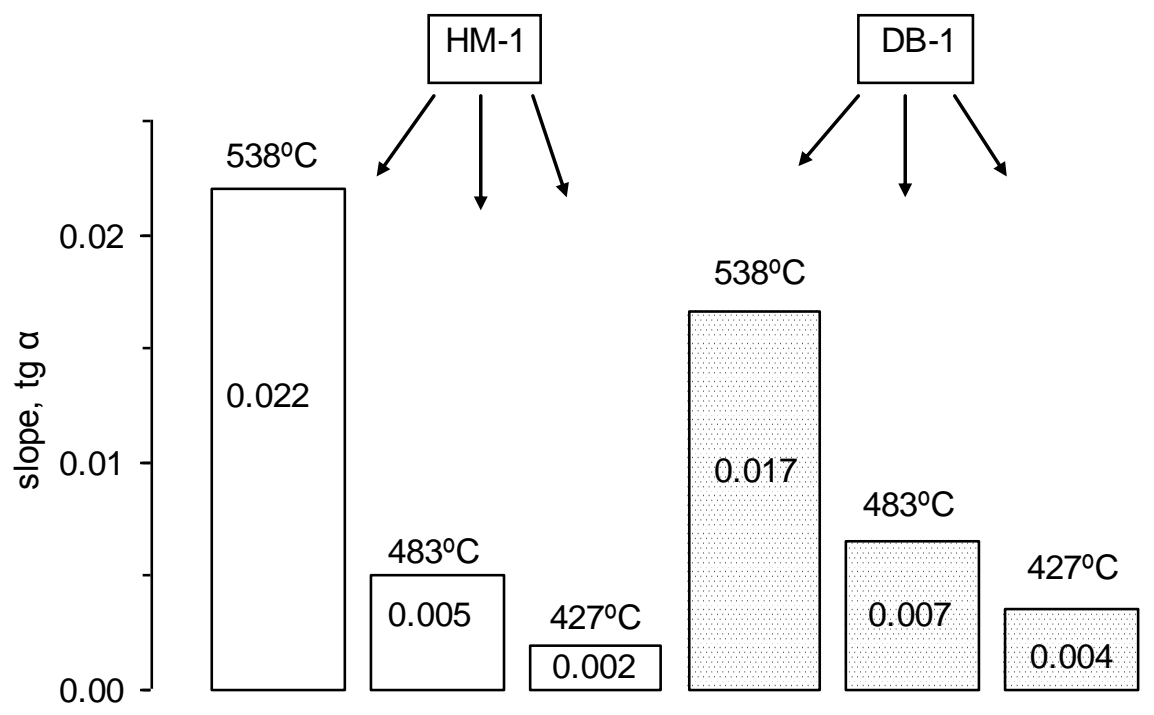

Figure 5.15. Slope comparison; test time: 240 minutes, TS test method; HM-1 with $4.6 \%$ binder and DB-1; at $538^{\circ} \mathrm{C}, 483^{\circ} \mathrm{C}, 427^{\circ} \mathrm{C}$. 


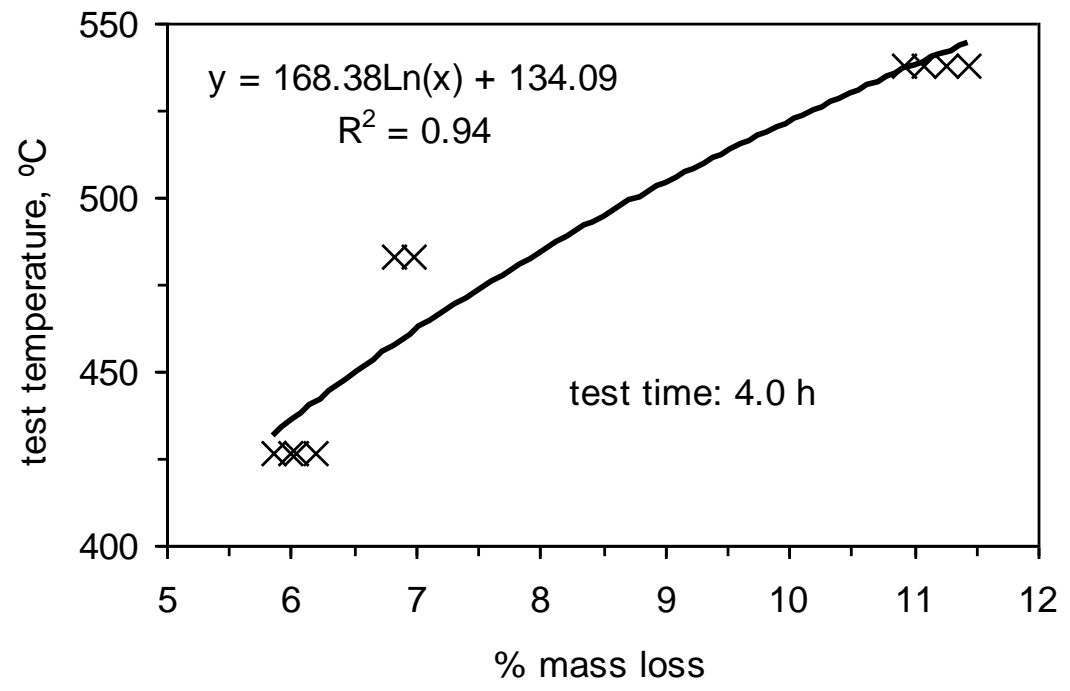

Figure 5.16. Relationship between test temperature and mass loss; HM-1 with $4.6 \%$ binder at $538^{\circ} \mathrm{C}, 483^{\circ} \mathrm{C}, 427^{\circ} \mathrm{C}$.

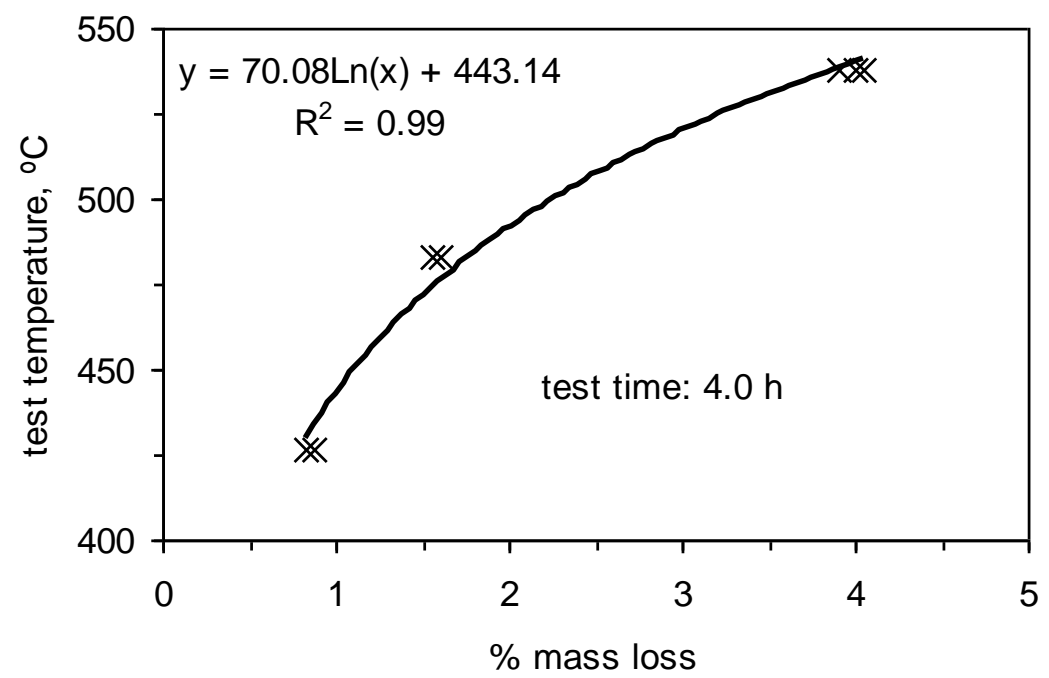

Figure 5.17. Relationship between test temperature and mass loss; DB-1 sample at $538^{\circ} \mathrm{C}$, $483^{\circ} \mathrm{C}, 427^{\circ} \mathrm{C}$.

The results of this task show that higher test temperatures do indeed lead to higher mass losses with these problematic aggregates. The oven temperature overshot the target temperature in all cases during the ignition stage of the test. The higher the test 
temperature, the sooner the oven temperature exceeded the target and the sooner the oven temperature peaked; that is, the greater the temperature differential between the preheated oven and the mix, the faster the oven tried to heat. Decreasing the test temperature decreased the slope of the mass loss plot during the stabilization stage of the test, especially when the temperature was dropped from 538 to $483^{\circ} \mathrm{C}$. Decreasing the oven temperature, then, can have a significant effect on the mass loss and rate of mass loss.

\subsection{Task 7 - Ignition Oven Temperature Distribution}

During this portion of the study (Task 7), the mix temperature was monitored with two additional thermocouples, TC 1 and TC 2, during testing. The oven thermistor reading was compared with the readings from TC 1 and TC 2. Temperature distributions measured during tests with DB-1 (no binder) and HM-1 samples are shown in Figure 5.18 .

In this task, samples were tested at three temperatures. To avoid repetition, only the results for tests at $483^{\circ} \mathrm{C}\left(900^{\circ} \mathrm{F}\right)$ are presented here. The results for tests at $427{ }^{\circ} \mathrm{C}$ $\left(800^{\circ} \mathrm{F}\right)$ and for tests at $538^{\circ} \mathrm{C}\left(1000^{\circ} \mathrm{F}\right)$ demonstrated similar trends to those observed at $483^{\circ} \mathrm{C}$; those results are presented in Appendix A, Figures A-1, A-2, A-3. 

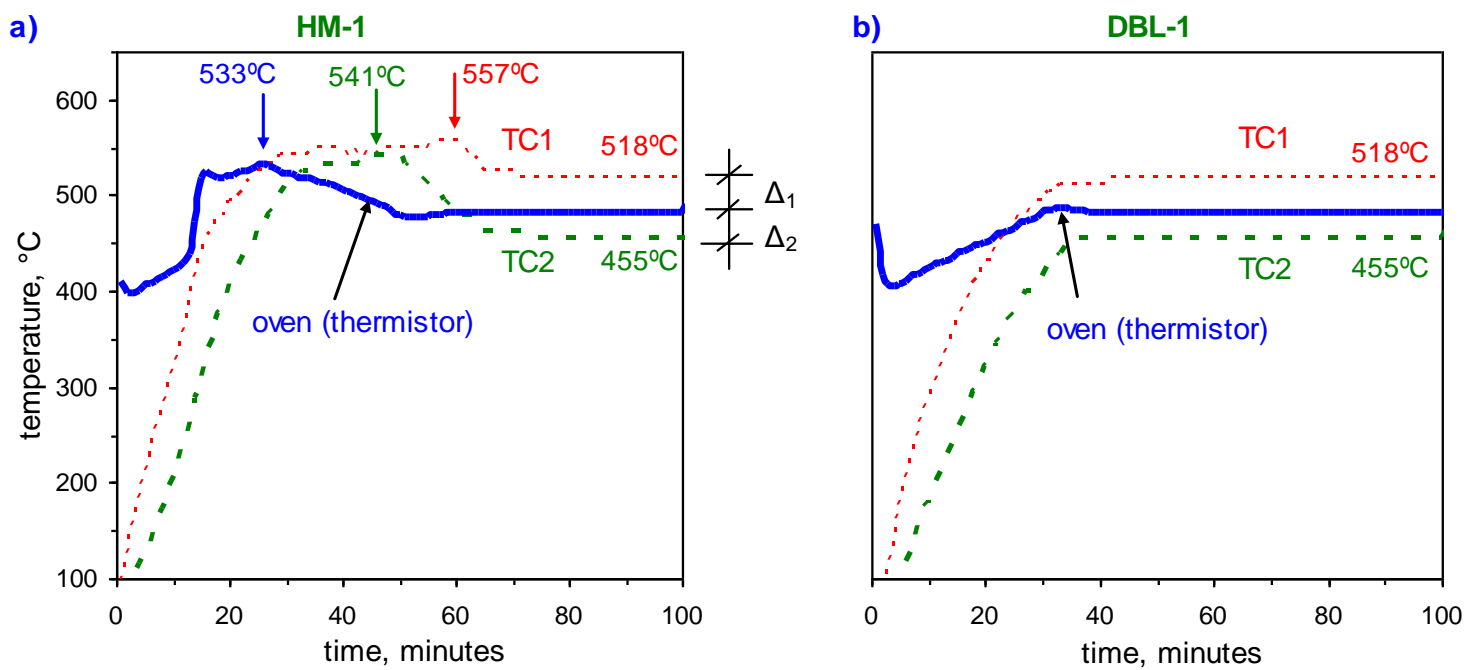

Figure 5.18. Typical temperature distribution plot: a) HM-1, b) DB-1 at $483^{\circ} \mathrm{C}$.

Initially, the oven thermistor registered a higher temperature (since the ignition oven chamber was preheated) than the thermocouples, which were embedded in the cold (room temperature) sample. For HM-1, the temperature peak measured by the oven thermistor was reached 10-20 minutes before the temperature peak measured by the thermocouples; it took longer for the mix temperature to peak than for the oven temperature to peak. The plot of temperature data obtained from both thermocouples (both top and bottom) appears to be flatter and smoother than that observed for the oven thermistor, most likely due to the "smoothing" effect of the mixture surrounding the thermocouples. Temperatures measured using both thermocouples leveled off after about 50 minutes of test, with the bottom basket thermocouple (TC 2) readings being lower than the thermistor data and the upper thermocouple (TC 1) readings being above the thermistor data. This observed distribution of temperatures corresponds well with the relative location of temperature sensors. 
During tests with DB-1, the thermocouples exhibited a lower rate of temperature increase than when HM-1 was tested. In the tests of DB-1 no significant temperature peak was observed. Instead, when the maximum temperature was reached, both TC 1 and TC 2, as well as the oven thermistor, kept constant temperature. This behavior was to be expected since there was no binder to ignite during this test. Similar to what was observed for HM-1, the top thermocouple showed a higher temperature and the lower thermocouple showed a lower temperature than the oven thermistor. This may be the result of air circulation in the chamber (from the air inlet located at the bottom to the air outlet located at the top of the chamber).

Once the temperature reached a constant value, the temperature difference between the top and bottom baskets (TC1 and TC 2) was constant and equal to $58^{\circ} \mathrm{C}$. The difference between the top thermocouple and the oven thermistor $\left(\Delta_{1}\right)$ was $35^{\circ} \mathrm{C}$, and the difference between the bottom thermocouple and the oven thermistor $\left(\Delta_{2}\right)$ was $24^{\circ} \mathrm{C}$. Similar temperature differences during tests run at different target temperatures were observed. (It should be noted that the thermocouples were randomly placed in the top or bottom basket so that a given TC was not placed in the same basket every time. In addition, the two thermocouples were compared to each other by placing side by side during dummy tests, and they were compared to the oven thermistor by placing them near the thermistor location. The readings were comparable in all cases. These efforts confirmed that the thermocouples were reading correctly and there was no bias between the readings from individual thermocouples.)

Figure 5.19 summarizes the temperature differences between the oven thermistor and the thermocouples at all three tested temperatures. Similar differences were noticed 
at each temperature. Once the temperature stabilized, the difference between the top and bottom basket was constant and equal to $58^{\circ} \mathrm{C}$. The difference between the top thermocouple and the oven thermistor was $35^{\circ} \mathrm{C}$ and between the bottom thermocouple and the oven thermistor was $24^{\circ} \mathrm{C}$.

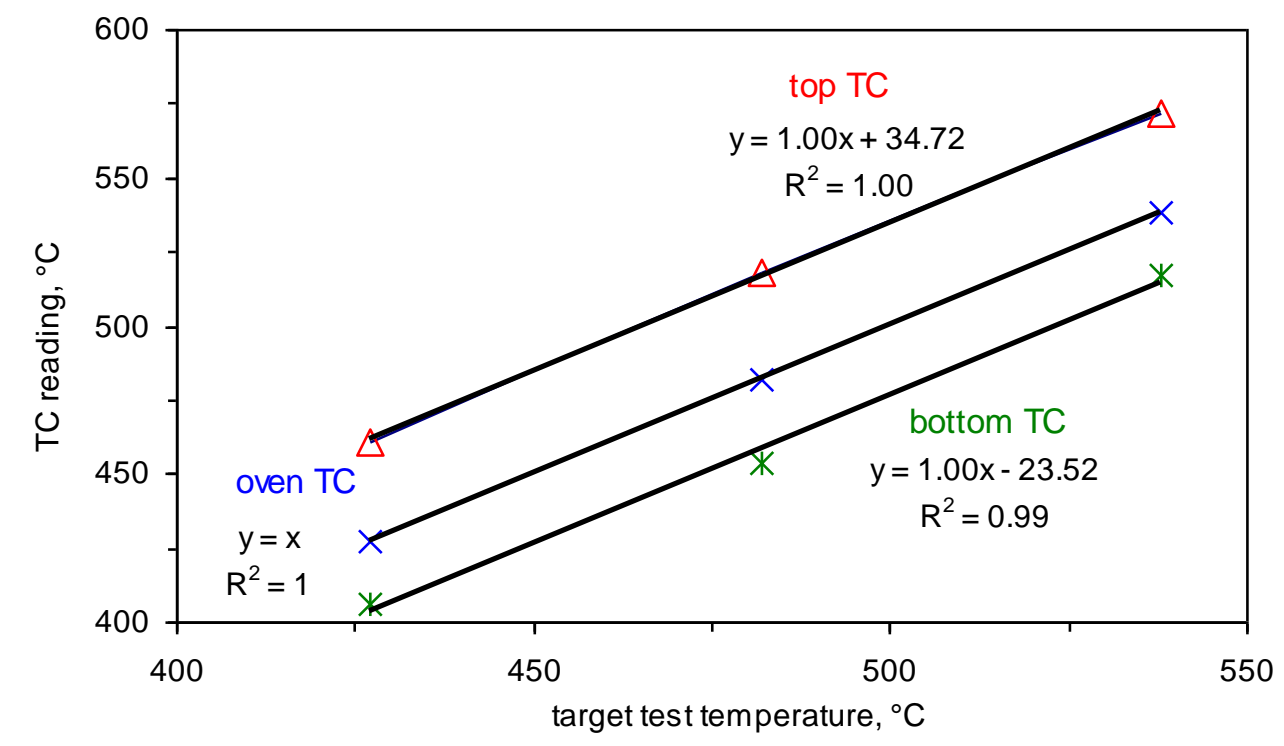

Figure 5.19. Relationship between IO thermistor, TC 1 and TC 2 readings when temperature stabilized at constant value.

Temperature variations (measured by oven thermistor) during replicate IO tests with HM-1 with $4.6 \%$ binder are shown in Figure 5.20. Each group of plots (same target test temperatures) looks similar. However, it can be seen that each plot has a unique path. Furthermore, during the tests the maximum temperature occurred at slightly different times. Thermocouple readings (TC1 and TC2) during these same tests are shown in the appendix (Figure A-4, A-5). 


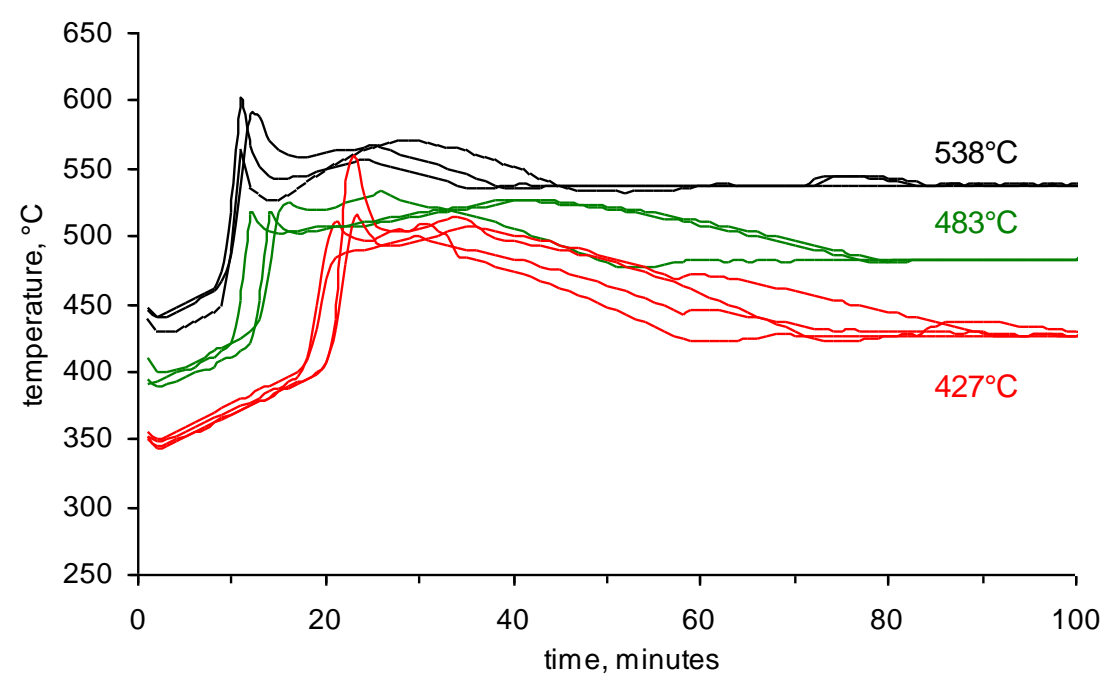

Figure 5.20. Oven thermistor temperature variation during tests with HM-1, 4.6\% binder.

In order to compare the plots to each other, the area under the temperature plot was calculated (area under the temperature curve versus time up to 240 minutes). The relationship between the calculated areas is shown in Figure 5.21. For both tested samples, HM-1 and DB-1, strong relationships could be observed.

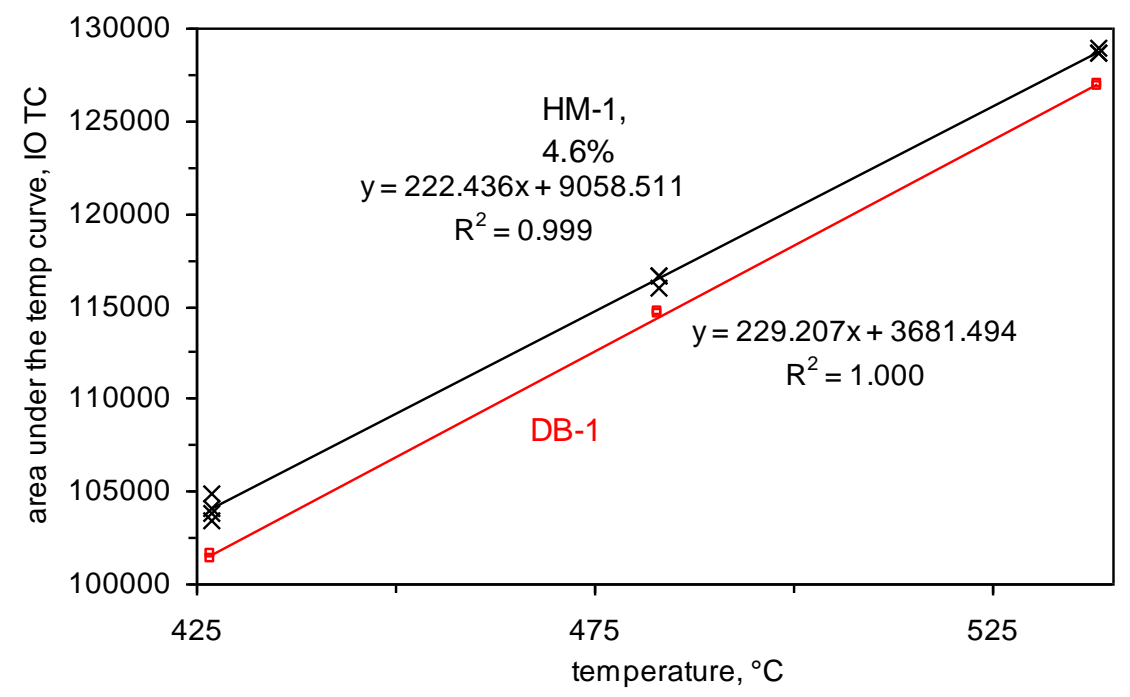

Figure 5.21. Calculated area under the IO thermistor temperature curve for HM-1 with $4.6 \%$ binder and DB-1 (no binder). 
The results of this task clearly show that the temperature is not constant throughout the oven chamber. Heat rises in the chamber so the temperature in the upper basket is higher than that in the lower basket. The oven thermistor, being located approximately midway between the baskets reads a temperature between those experienced in the baskets. The differences between the locations are greater when binder is present and ignites, producing more heat.

\subsection{Task 8 - Two-Step Burn-Off of HMA}

Task 8 consisted of evaluating two-step tests, as described in 4.2.3. The two-step tests conducted on non problematic mix, HM- 0 with steel slag, verified that all the binder was burned-off (removed) by ignition at the lower set temperature of $427^{\circ} \mathrm{C}$. Differences between cooled sample masses after the first (at $427^{\circ} \mathrm{C}$ ) and the second (at $538^{\circ} \mathrm{C}$ ) burnings were less than $1.0 \mathrm{~g}$.

Two-step IO tests were also conducted on samples of HM-1 to determine if all the binder is removed during tests conducted at the lowest temperature $\left(427^{\circ} \mathrm{C}\right.$ or $\left.800^{\circ} \mathrm{F}\right)$. As shown in Figure 5.22, step 1 exhibits all three phases which are typical for the ignition test for hot mix asphalt (as described in 5.1). During step 1 both thermocouples reached similarly high temperatures, which were higher than that of the oven thermistor. The peak thermistor temperatures were observed 20 minutes after the oven thermistor temperature peak. After the first step (at $427^{\circ} \mathrm{C}$ ), the sample was removed from the oven, its mass was determined and it was returned to the oven. At that time, the ignition oven target temperature was set to $538^{\circ} \mathrm{C}\left(1000^{\circ} \mathrm{F}\right)$. Step 2 was split into two parts; between 
those parts, the sample mass was determined. In step 2 once the temperature reached its highest value, the plots were flat. After weighing the sample in the middle of step 2, the temperatures returned to the same levels.

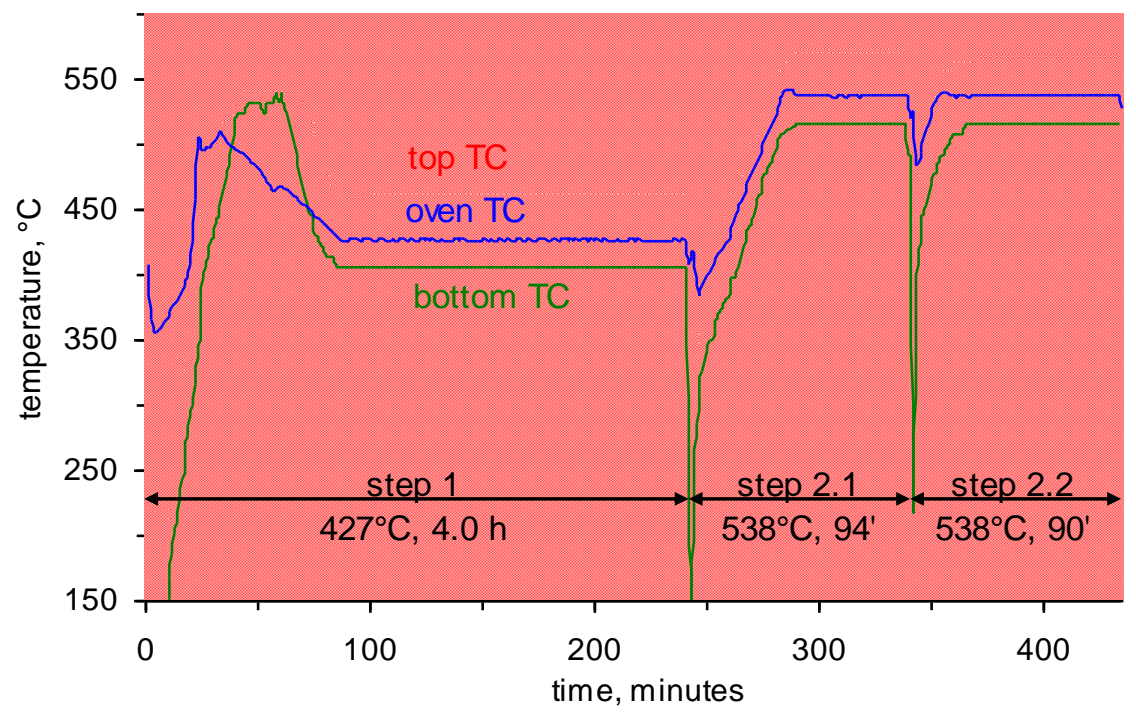

Figure 5.22. Temperature distribution during two step ignition test (HM-1 with 4.6\% binder).

Mass loss is shown in Figure 5.23. The mass loss during the first step was around $6.0 \%$ and in each part of step 2 the mass loss was about $2 \%$. When the mass loss plot began to demonstrate a linear character, a linear regression line was drawn and the function slope was calculated. This slope for step $1(\alpha 0)$ was 0.002 and for step 2 was observed to be 0.017 and 0.016 ( $\alpha 1$ and $\alpha 2$, respectively). A slope equal to 0.017 corresponds to the mass loss for DB- 1 tested at the $538^{\circ} \mathrm{C}\left(1000^{\circ} \mathrm{F}\right)$ (please compare with Figure 5.15). 


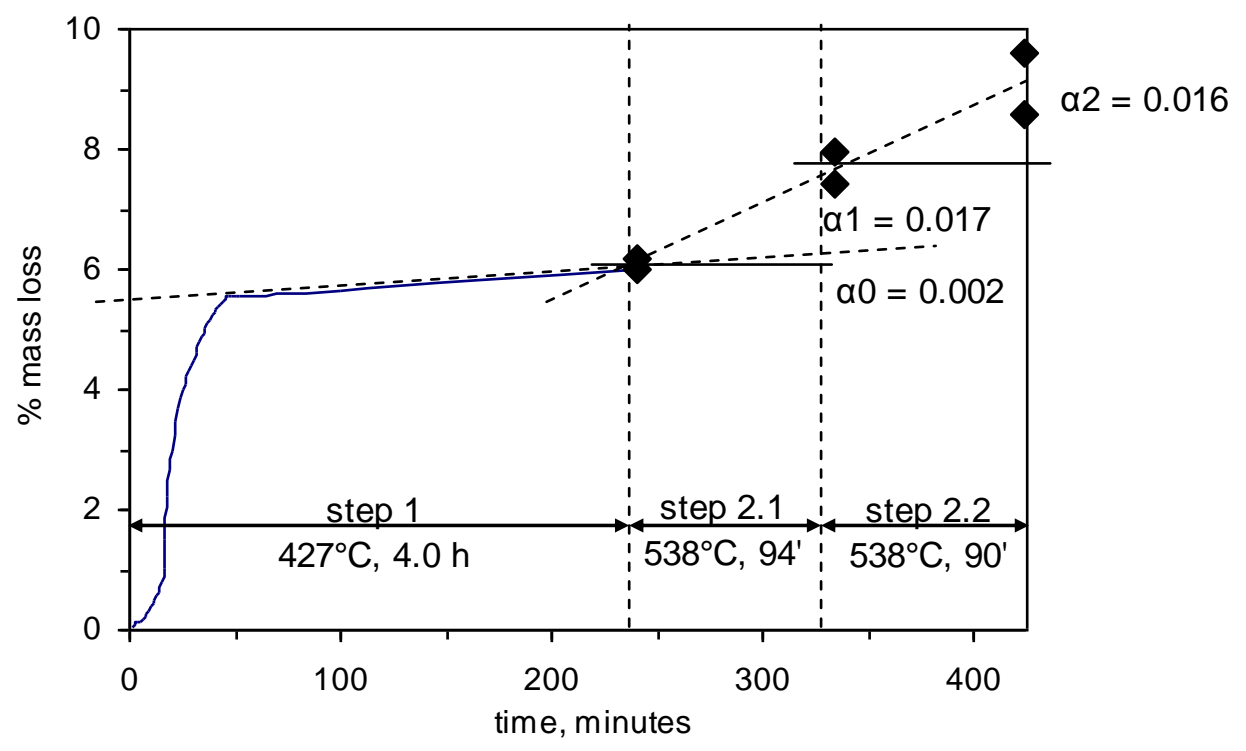

Figure 5.23. Mass loss during the typical two step ignition test (HM-1 with $4.6 \%$ binder).

During the conventional IO test on HM-1 with $4.6 \%$ binder, the mass loss at $427^{\circ} \mathrm{C}$ was about 6 to $6.5 \%$; at $483^{\circ} \mathrm{C}$, it was about $7 \%$ and at $538^{\circ} \mathrm{C}$, it was about 11 to $11.5 \%$ after 4 hours. In the two-step test, the mass loss was around 6\% after 4 hours in the first step. This is still greater than the binder content and, if accurate, would imply a calibration factor of approximately $1.5 \%$, which is still considered high. The time spent at $538^{\circ} \mathrm{C}$ to remove any soot or ash does cause additional mass loss.

In summary, the two-step process on the non-problematic mix did verify that essentially all of the binder was burned off at the lower temperature; minimal mass loss was observed during the second, high temperature burn. With the problematic mix, the mass loss continued during the second burn, but the rate was similar to that observed when testing dolomite only, indicating that the mass loss is due to decomposition of the 
dolomite not the removal of binder. This also suggests that the two-step procedure is not necessary.

\subsection{Task 9 - Changes in Sample Mass Observed after the Ignition Test}

The sample mass determined at various times after removing a sample from the oven was not constant. In Figure 5.24 and Figure 5.25, the mass losses at various times after completion of the ignition oven test are shown relative to the initial sample masses. When time is expressed on a logarithmic scale, the mass loss changes exhibit a linear character.

According to specifications and based on practice, the sample mass loss should be determined after the specimen has completely cooled. When the sample is warmer than the air surrounding the sample, the total mass reading is influenced by the buoyancy effect. It was observed here that the buoyancy effect changed the mass reading by $2.5 \mathrm{~g}$, which is equal to around $0.08 \%$ of mass loss; in other words, the mass reading obtained 2 minutes after removing the sample from the oven was $2.5 \mathrm{~g}$ lower than the mass when the sample was completely cooled. The influence of the buoyancy effect became insignificant at around 25 minutes after removing the sample from the oven; by that time the sample had cooled sufficiently.

After the sample cooled, however, the sample mass continued to increase (and consequently the mass loss decreased). A likely explanation of this phenomenon is that after the sample was removed from the ignition oven, humidity from the air was absorbed by the aggregate, increasing its mass. This implies that if external mass measurements 
are to be conducted, the sample should be allowed to cool but not allowed to sit for an extended period of time. The time to measure should be consistent.

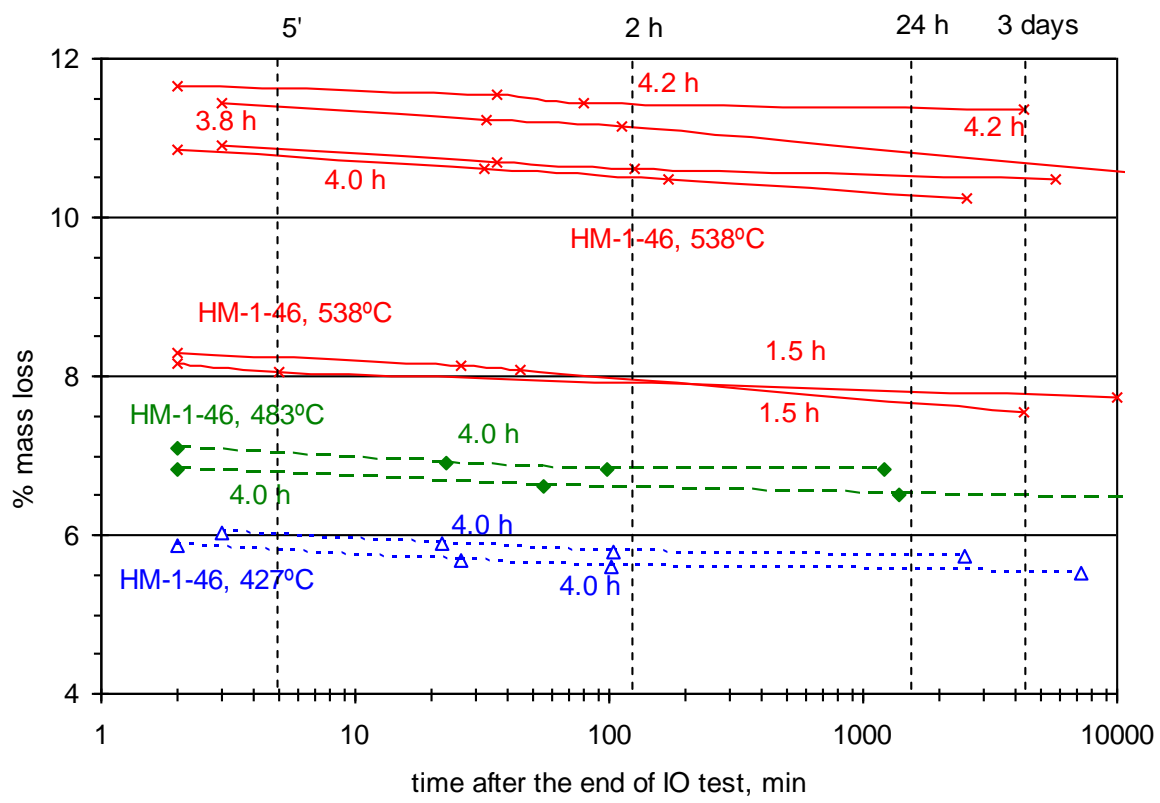

Figure 5.24. HM-1 mass loss measured at various times after the end of IO test; TS method.

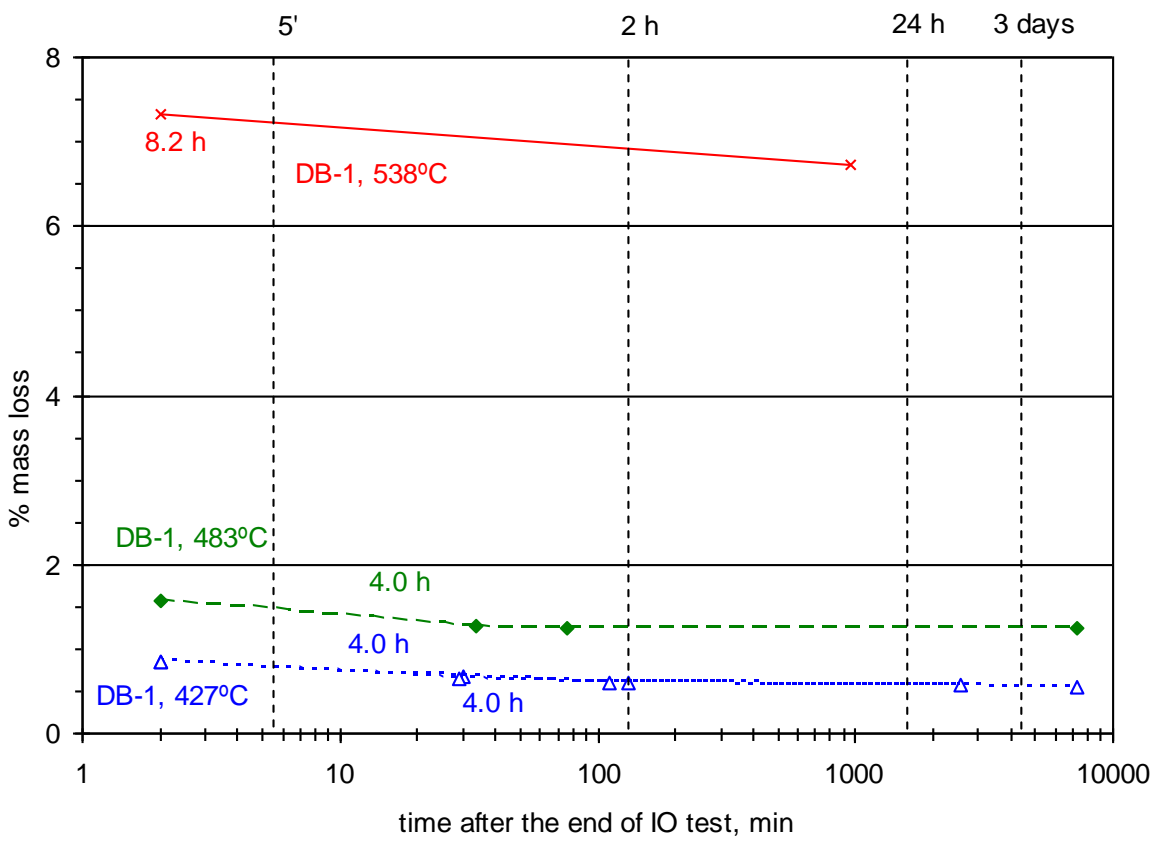

Figure 5.25. DB-1 mass loss measured at various times after the end of IO test; TS method. 
These results show the importance of allowing the sample to cool before determining its mass with an external balance. The cooling time should be consistent and limited, however, to avoid a mass increase.

\subsection{Task 10 - Comparison of Test Results from Ignition and Glass Cleaning Ovens}

In Task 10 of this study, samples of DB-1 and HM-1 (with $4.6 \%$ binder) were tested using both the Thermolyne Ignition Oven (IO) and the Pyro-Clean ${ }^{\circledR}$ glass cleaning oven (GCO). Tests in both kinds of ovens were conducted using the TS test type at $483^{\circ} \mathrm{C}$ for 4.0 hours. As presented earlier, the time required to reach the target test temperature in the Thermolyne Ignition Oven was 10-20 minutes and during second ignition phase the chamber temperature exceeded the target test temperature significantly. As shown in Figure 5.26, in tests with the Pyro-Clean ${ }^{\circledR-}$ Oven and HM-1, the temperature was well controlled and never exceeded the target test temperature by more than $4^{\circ} \mathrm{C}$ (according to the oven's thermistor reading).

Also shown in Figure 5.26, when the temperature in Thermolyne Ignition Oven increased significantly during the initial 15 minutes, the temperature in the Pyro-Clean ${ }^{\circledR}$ Oven showed a decrease over the same time period. The glass cleaning oven did not reach the target temperature until about 20 minutes after the ignition oven, but this may be an artifact of the way the pyrolysis oven works. It was also noted, though not shown here, that the time required for the Pyro-Clean ${ }^{\circledR}$ Oven to reach the target test temperature was observed to be similar for both samples types (HM-1 and DB-1). 


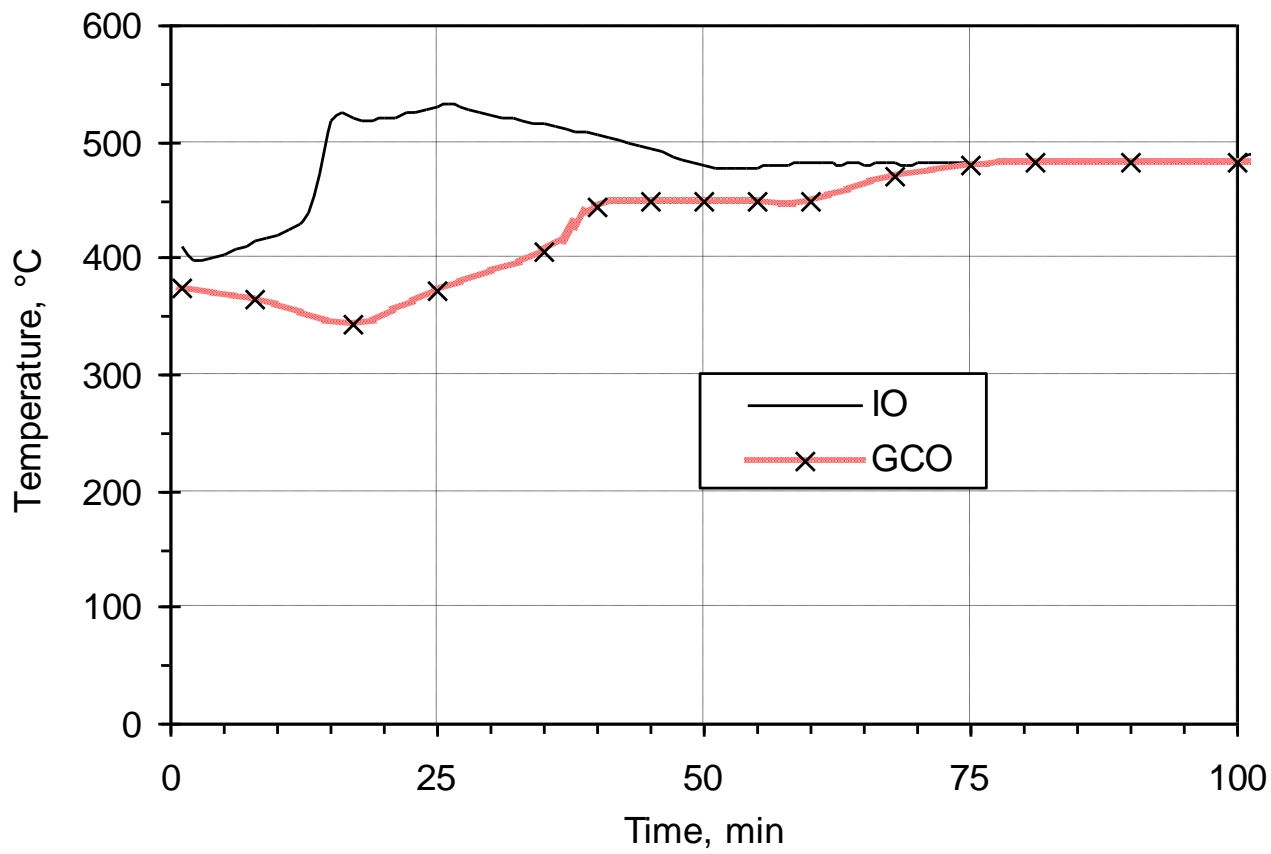

Figure 5.26. Comparison of the temperature measured during tests with HM-1 (4.6\% of binder) in $\mathrm{IO}$ and in $\mathrm{GCO}$; at $483^{\circ} \mathrm{C}$ target test temperature.

A comparison of the mass losses using the two ovens is shown in

Figure 5.27. For both sample types tested (HM-1 and DB-1), the mass losses were higher for tests conducted in the Thermolyne Ignition Oven. The mass loss of HM-1 was 2\% lower when tested in the Pyro-Clean ${ }^{\circledR}$ Oven and the mass loss of DB- 1 was $0.5 \%$ lower. 


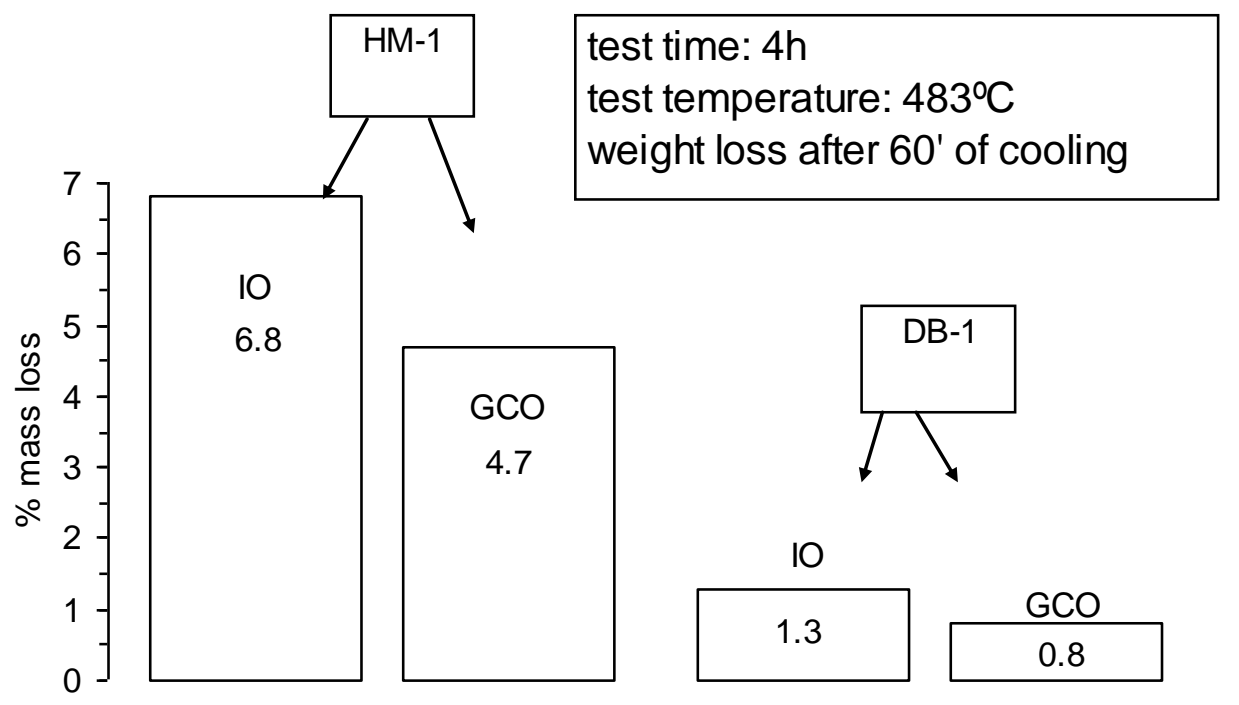

Figure 5.27. Comparison of sample mass losses after tests conducted in IO and GCO.

These results show that use of the GCO still led to mass loss in the dolomite itself, but the mass loss in the mix using the GCO was closer to the true binder content than when using the IO. The GCO exhibited better temperature control, and the target temperature was never exceeded, which may have limited the dolomite decomposition. Use of the GCO, then, may be feasible but it is not ideal for INDOT to implement. Not all labs have glass cleaning ovens though many have ignition ovens. In addition, the GCO does not have an internal balance, making the determination of test termination more complicated and more labor intensive, similar to Method A in AASHTO T308 for ignition ovens without the internal balance. If the GCO is used, the sample should be allowed to cool for a controlled and limited amount of time, as shown in Task 9. 


\subsection{Task 11 - Compositional Analysis}

The X-ray diffraction (XRD) and thermogravimetric (TG) methods were used to determine compositional changes in the dolomitic aggregate resulting from the ignition oven test. This section of the report presents the results of both of these tests for pure dolomite (PD) samples, for the dolomitic aggregate blend tested alone (DB-1) and for the dolomitic aggregate recovered from one of the mixes (HM-1). For each specimen, two XRD and three TG tests were conducted. The differences between results obtained from each of the individual tests were relatively small, indicating good reproducibility. (Additional data from this task is shown in Appendix B.)

\subsubsection{Dolomitic Aggregate Extracted from the HM-1 Mixture}

Figure 5.28 shows the TG and derivative thermogravimetric (DTG) plots for dolomitic aggregate from the HM-1 mixture after testing in the ignition oven (set test temperature $538^{\circ} \mathrm{C}$ ) under the non-thermal shock (nTS) conditions and the $\mathrm{CO}_{2}$ atmosphere. The TG curve (at the top and using the left axis) shows the change in mass versus temperature in the Thermogravimetric Analyzer (TGA). The derivative mass plot (near the bottom and using the right axis) shows the slope of the TG plot; in other words, it shows the rate of change of the mass. These plots reveal that the thermal decomposition process of this aggregate consists of four distinctive stages. Stage 1 (from about $590^{\circ} \mathrm{C}$ to about $745^{\circ} \mathrm{C}$ ) is characterized by a gradually increasing rate of mass loss (for a total mass loss of about $3.1 \%$ from $99.3 \%$ of the initial mass to $96.2 \%$ ). A large (about $13.1 \%$ from $96.2 \%$ to $83.1 \%$ ) and rapid mass loss is observed in Stage 2, which 
ends at about $813^{\circ} \mathrm{C}$. A small mass loss (only about $0.9 \%$ to $82.2 \%$ ) was observed during Stage 3 that ended at $926^{\circ} \mathrm{C}$. Finally, a very rapid rate of mass loss was observed during Stage 4 that ended at about $970^{\circ} \mathrm{C}$ (total mass loss about $25.5 \%$, from about $82 \%$ to $57 \%$ ).

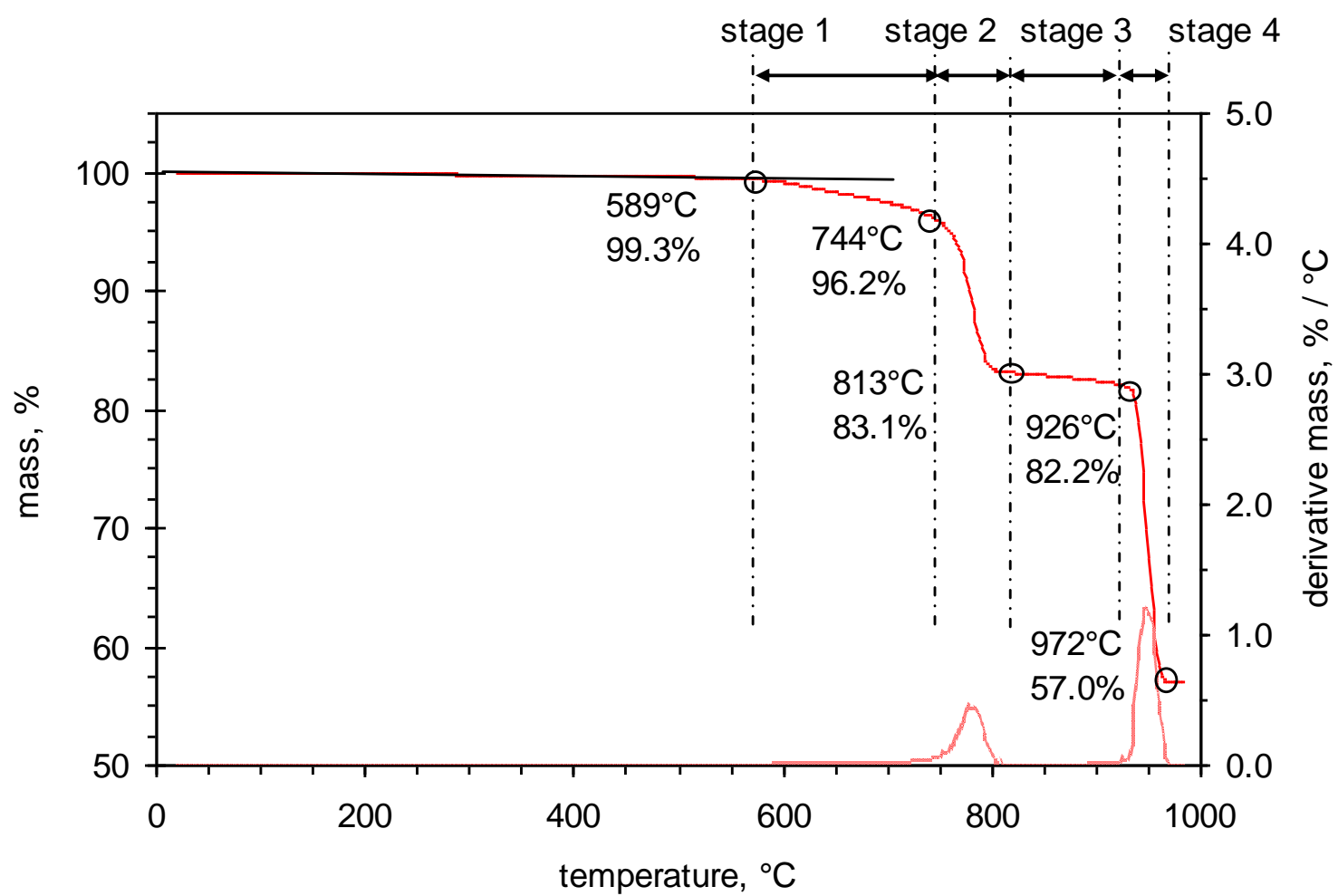

Figure 5.28. Typical TG and DTG plots for dolomitic aggregate from HM-1 mixture tested under non-thermal shock conditions (HM-1-46-nTS).

The X-ray data for the same dolomitic aggregate (extracted from HM-1 after the thermal shock method) are shown in Figure 5.29. It can be seen that in addition to the peaks for dolomite (D) and calcite (C), the XRD pattern also reveals the presence of a small amount of periclase $(\mathrm{MgO})$ as indicated by a broad peak (marked $\mathrm{M}$ ) located at about $42.9^{\circ} 2 \theta$. The presence of the calcite and periclase peaks indicates that partial decomposition of the dolomite must have taken place during the ignition oven test even 
though the set test temperature of $538^{\circ} \mathrm{C}$ was below that indicated in the TG plots as marking the beginning of Stage 1 (about $590^{\circ} \mathrm{C}$ ).

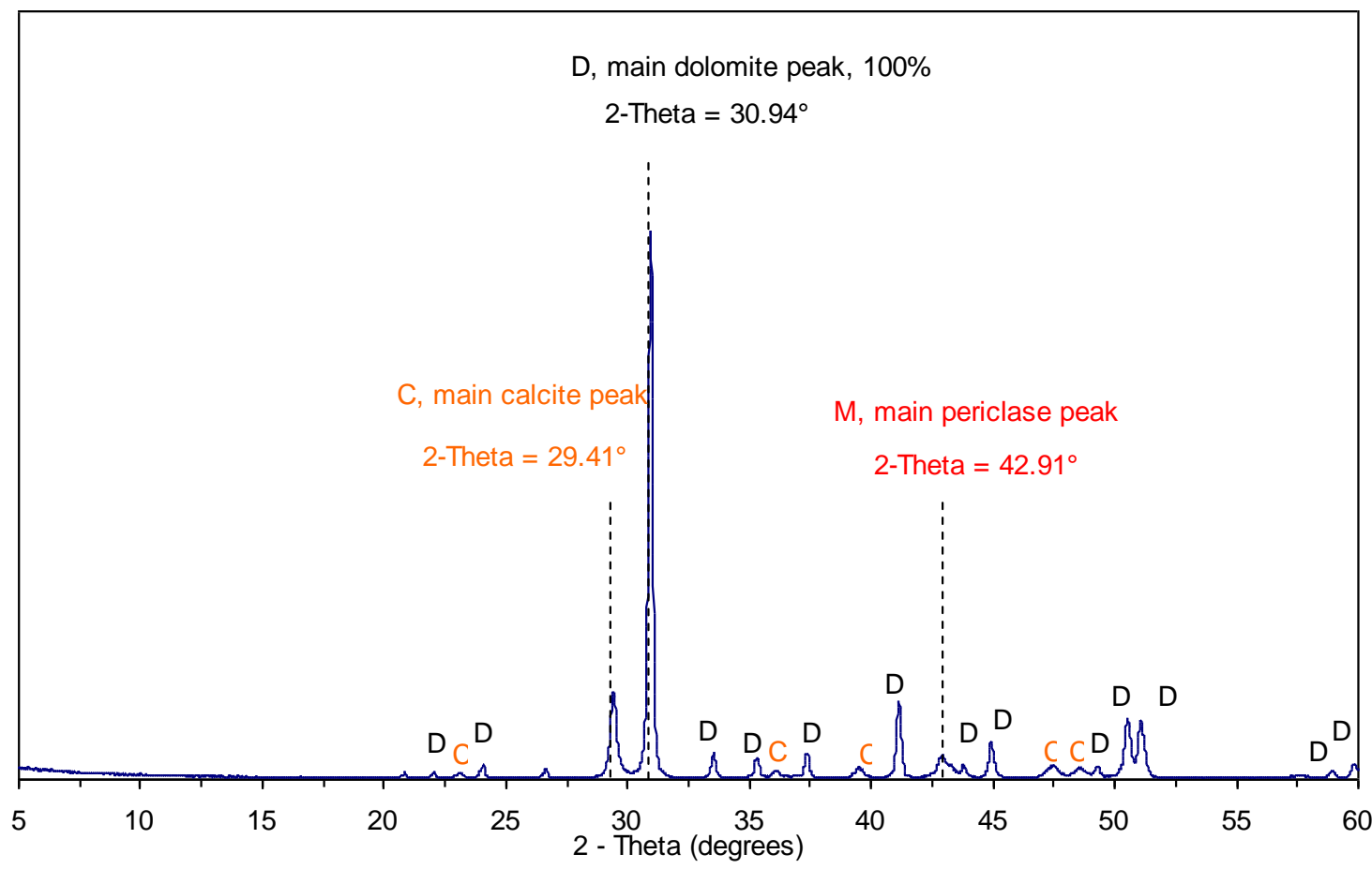

Figure 5.29. Typical XRD pattern for HM-1-46-TS dolomitic aggregate (length of ignition test 10 hours, set test temperature $538^{\circ} \mathrm{C}$ ).

\subsubsection{Dolomitic Aggregate Blend Tested Alone (No Prior Binder Contact)}

Figure 5.30 and Figure 5.31 show, respectively, the TG and the XRD patterns for the dolomitic aggregate blend (DB-1) that was tested alone (never exposed to the binder). The data obtained for this aggregate before the ignition oven exposure (DB-1_b) and after exposing it to the ignition oven test in both non-thermal shock (DB-1_nTS) and thermal shock (DB-1_TS) modes (for various lengths of time) are presented.

It can be seen from Figure 5.30 that the DB-1_b samples lost a higher amount (about $16 \%$ ) of their mass during the second stage of decomposition (from about $700^{\circ} \mathrm{C}$ 
to about $800^{\circ} \mathrm{C}$ ) than the samples previously exposed to the ignition oven test (about $14 \%$ ). The amount of mass lost for the previously exposed samples did not seem to depend on the method of exposure (shock vs. non-shock). That observation is consistent with the notion that partial decomposition of dolomite is taking place during prolonged exposure in the ignition oven, even if there is no binder in the sample and thus the test temperature remains relatively stable (at the pre-set value of $538^{\circ} \mathrm{C}$ ). The DB-1_b samples lost more mass in the TGA because they had not previously decomposed in the ignition oven.

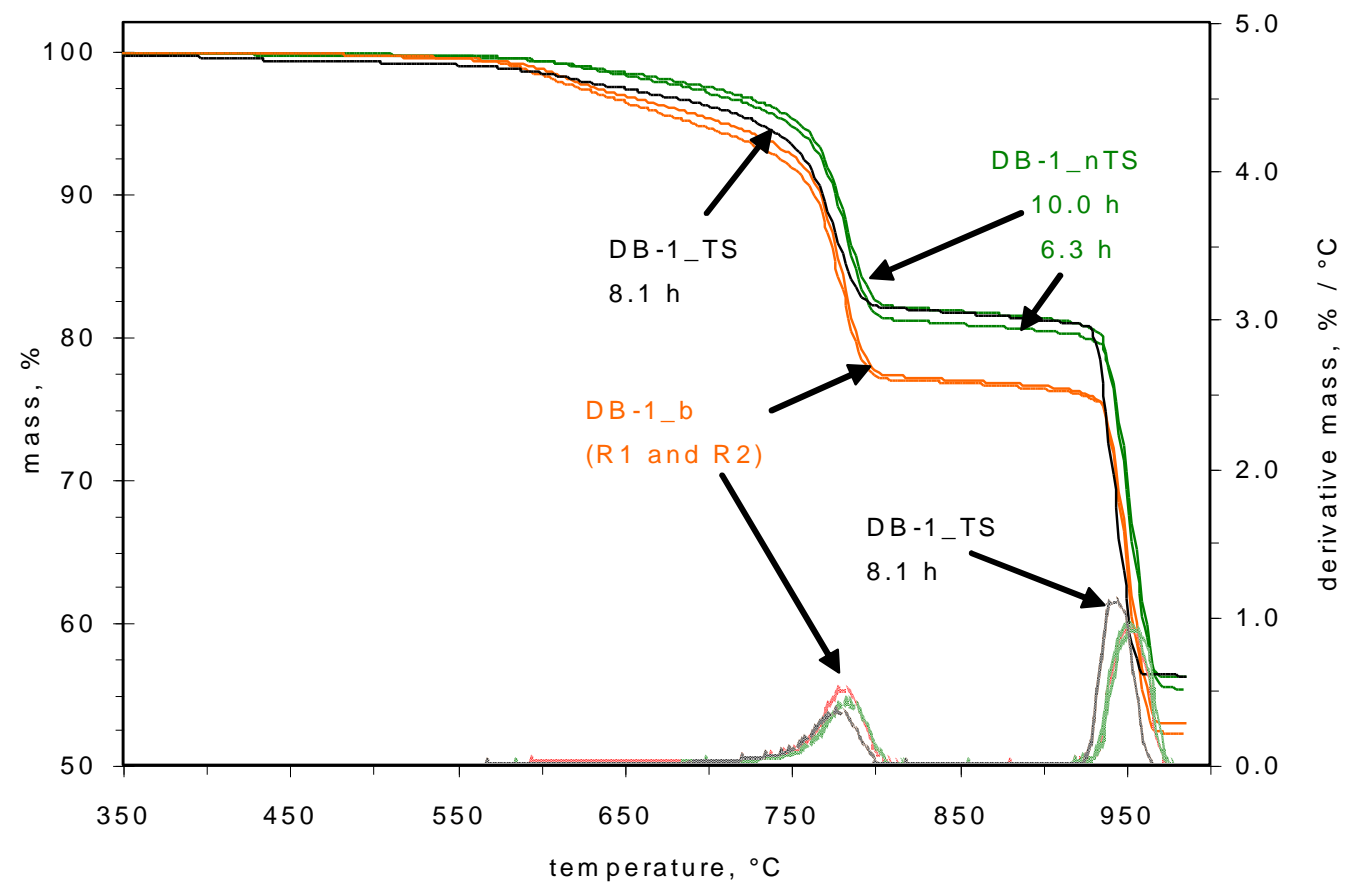

Figure 5.30. TG and DTG plots for DB-1 dolomitic aggregate blend tested before the ignition oven exposure (DB-1_b) and after nTS and TS ignition oven tests.

The analysis of X-ray patterns in Figure 5.31 confirms the previously discussed observations from the TG test that all the specimens exposed to the ignition oven test had undergone partial decomposition. For all of these specimens one can observe a small 
reduction of the dolomite (D) peak accompanied by the appearance of the calcite (C) and the periclase $(\mathrm{M})$ peaks. It should be noted that these two last peaks are totally absent from the XRD spectra for the specimens that were tested before exposure to the ignition oven (DB-1_b), also shown in Figure 5.32.

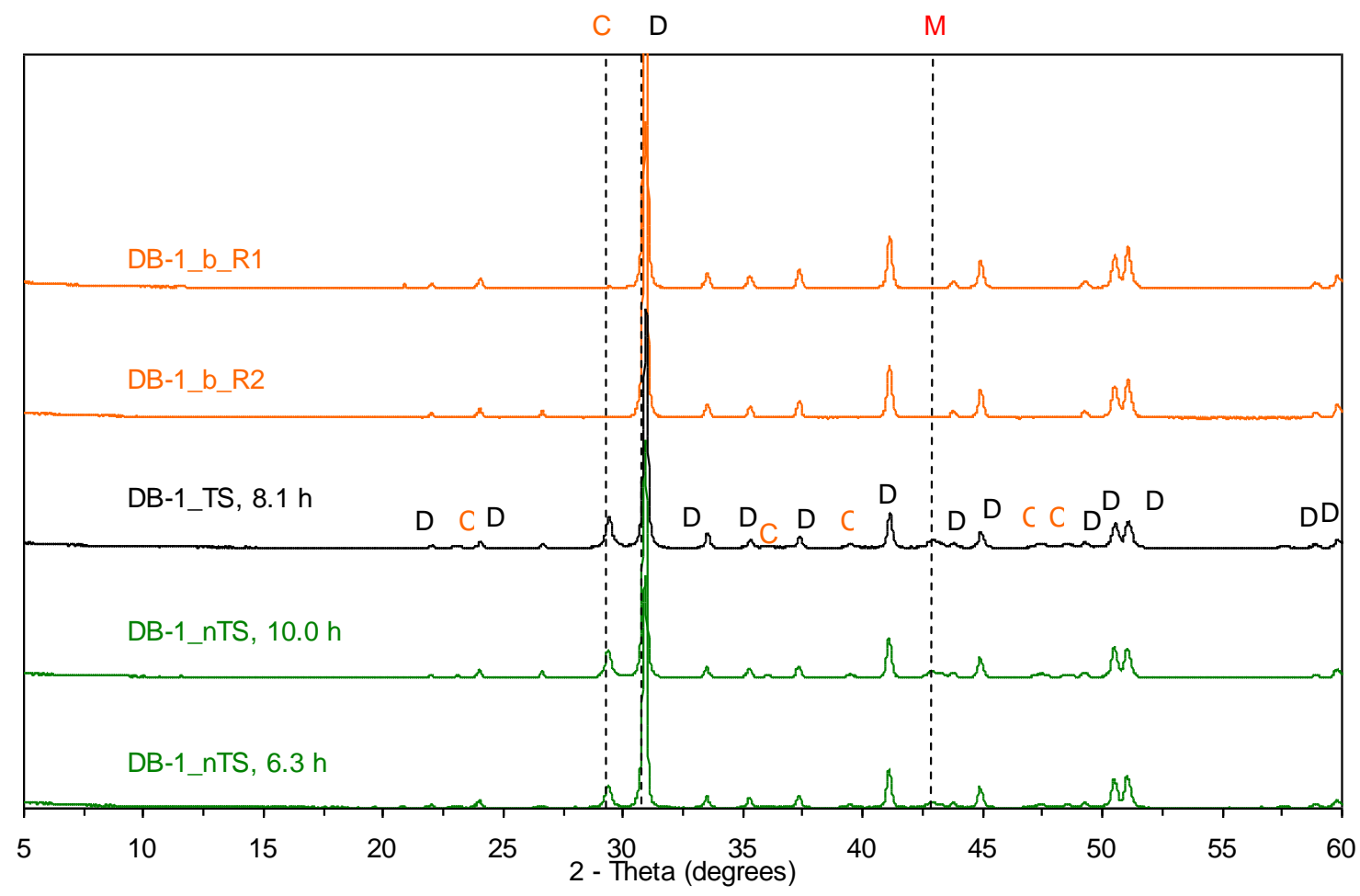

Figure 5.31. XRD pattern for DB-1 dolomitic aggregate blend tested before the ignition oven exposure (DB-1_b) and after nTS and TS ignition oven tests.

\subsubsection{Comparison of Dolomitic Aggregate Blend with Dolomite from Mix}

The comparison of the TG and XRD results for the dolomitic aggregate tested alone with those obtained for the same dolomitic aggregate extracted from the HM-1 mixture after the ignition oven procedure is given in Figure 5.32 and Figure 5.33, 
respectively. (The results for the dolomite blend before the ignition oven (DB-1_b) are also shown for comparison.)

It can be seen from Figure 5.32 that the dolomitic aggregate extracted from HM-1 (HM-1-46) has lower mass losses during the second step of the thermogravimetric cycle (from about $750^{\circ} \mathrm{C}$ to about $800^{\circ} \mathrm{C}$ ) than the aggregate that has been tested alone (no binder exposure, DB-1_nTS). The samples of HM-1 had previously decomposed in the ignition oven and therefore decomposed less in the TGA. That clearly indicates that the presence of the binder does increase the extent of dolomite decomposition in the ignition oven, presumably by increasing the temperature during the burning stage of the test. This observation is also confirmed by the X-ray data from Figure 5.33 which shows the presence of higher periclase $(\mathrm{M})$ and calcite $(\mathrm{C})$ peaks in the patterns obtained from the extracted aggregates. The periclase and calcite were formed when the dolomite in the HM-1 samples partially decomposed in the ignition oven. 


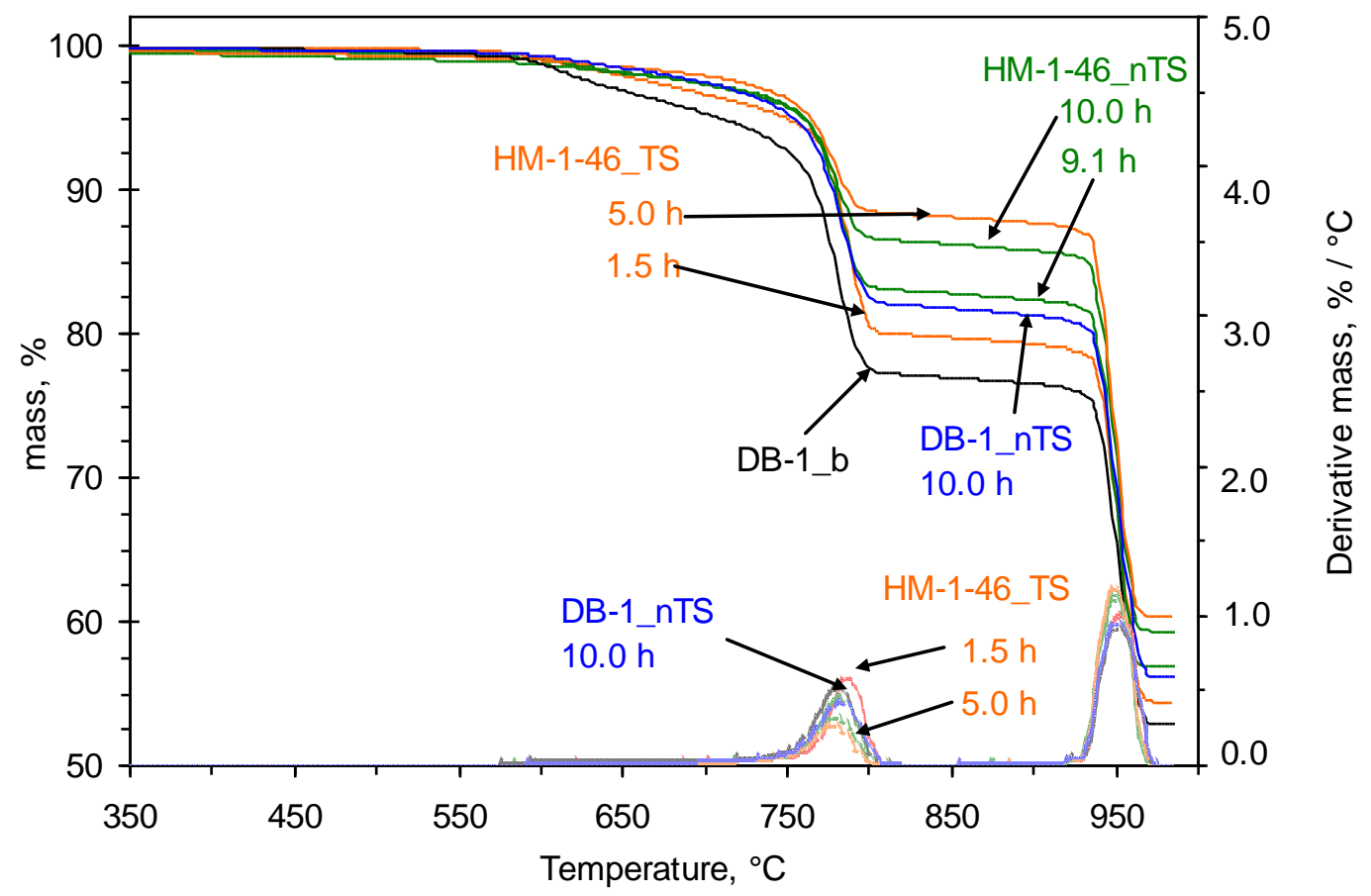

Figure 5.32. TG and DTG plots for DB-1 and HM-1 samples, TS and nTS ignition; ignition time: $1.5-10.0 \mathrm{~h}$.

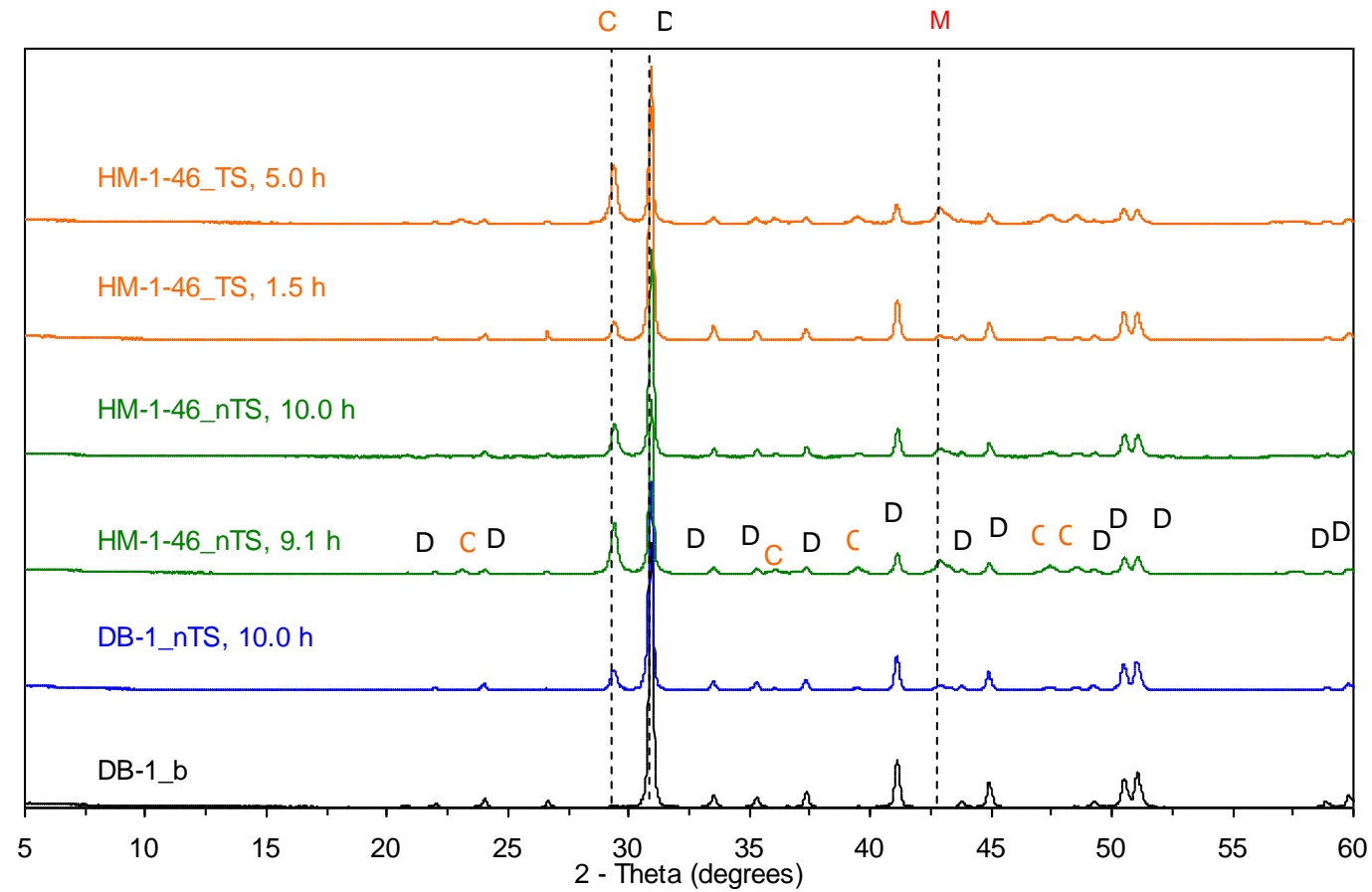

Figure 5.33. Comparison of XRD patterns for DB-1 and HM-1 samples, nTS and TS method; ignition time: 1.5-10.0 h. 


\subsubsection{Comparison of Pure Dolomite with DB-1 and HM-1 Dolomitic Blends}

Figure 5.34 shows the TG and DTG plots obtained from three types of materials: pure dolomite (PD), dolomitic aggregate blend not exposed to contact with the binder (DB-1) and dolomitic aggregate blend extracted from HM-1 mixture. It can be seen that the sample of pure dolomite experienced the highest mass loss during the second step of the thermogravimetric cycle (from about $780^{\circ} \mathrm{C}$ to $820^{\circ} \mathrm{C}$ ) while the mass loss recorded for the HM-1 sample was the smallest. The mass loss observed for the pure dolomite samples was not at all influenced by the ignition oven exposure, as the TG curves for dolomite samples not heated in the oven (PD_b) are very similar to the curves obtained for the thermal shock (PD_TS) and non-thermal shock (PD_nTS) samples. Since this sample consists solely of dolomite crystals, even after being subjected to high temperature and partial decomposition in the muffle furnace, there is still sufficient dolomite present to decompose more in the TGA. Therefore, there are no significant differences between the pure dolomite samples before and after thermal shock or nonthermal shock exposures. In addition, the pure dolomite samples show very little change in mass until the TGA temperature reaches about $750^{\circ} \mathrm{C}$; the samples were only exposed to a temperature of $538^{\circ} \mathrm{C}$ in the muffle furnace since there was no binder present to increase the temperature above the target. When the TGA reached $750^{\circ} \mathrm{C}$, the pure dolomite reached its decomposition temperature and rapid mass loss began, as indicated by the sharp peak in the DTG plot.

The mass loss observed for the DB-1 sample was in between those of the HM-1 and pure dolomite samples. As seen in section 5.11.2, the aggregate only blend had not 
decomposed as much in the ignition oven as the dolomite from the HM-1 mixture sample. This provides one more confirmation of the fact that the presence of the binder during the ignition oven test increases the susceptibility of this aggregate to decomposition.

Figure 5.35 shows the XRD patterns for the same group of aggregates previously shown in Figure 5.34. The progressive increase in the height of the calcite (C) peak and the corresponding reduction in the height of the main dolomite (D) peak associated with moving up from the (PD_b) pattern to the DB-1 and HM-1 patterns confirms greater susceptibility to decomposition of impure dolomitic aggregates and its dependence on temperature history.

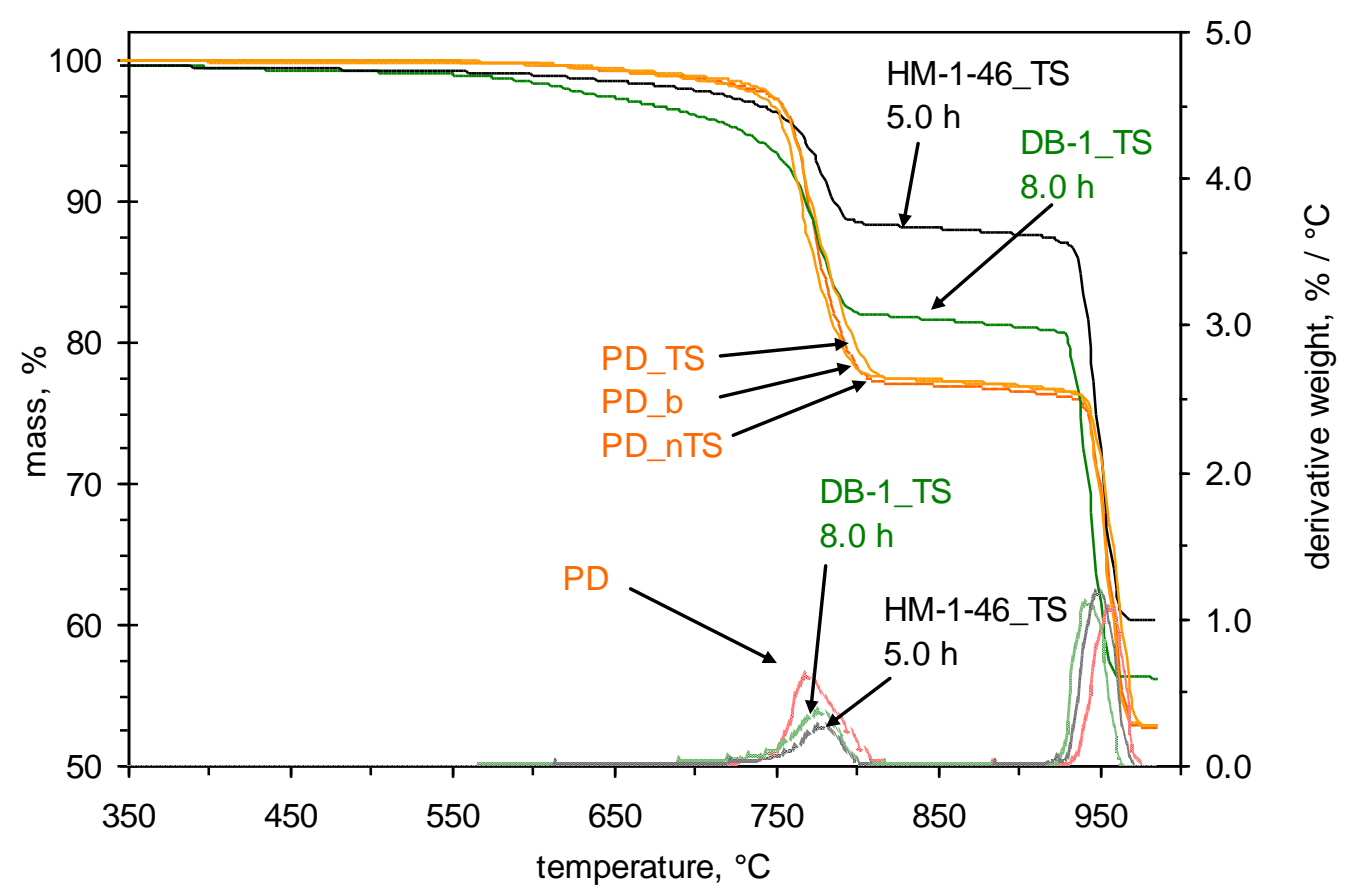

Figure 5.34. TG and DTG plots for pure dolomite (PD), dolomitic aggregate (DB-1) and dolomitic aggregate extracted from mixture (HM-1). 


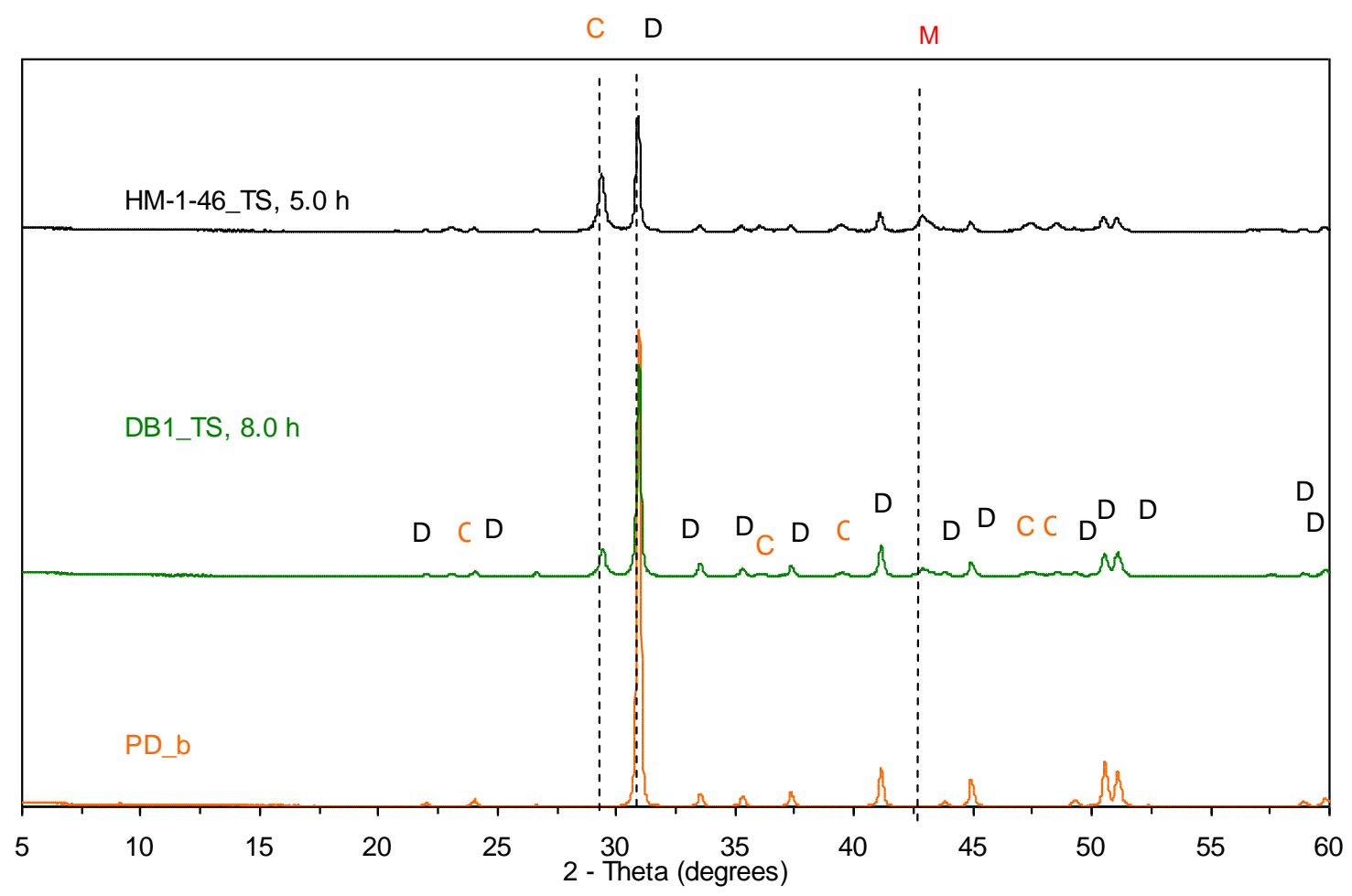

Figure 5.35. XRD patterns for pure dolomite (PD), dolomitic aggregate (DB-1) and dolomitic aggregate extracted from mix (HM-1).

A summary of the XRD identification and relative intensity of the peaks is shown in Appendix B, Table B-2; a summary of the TG data is shown in Table B-2.

These analysis techniques clearly demonstrate that dolomitic aggregates that have been subjected to the ignition oven have partially decomposed, producing calcite and periclase. This partial decomposition in the ignition oven means that there is less dolomite present to decompose during the TGA procedure, so less mass loss is observed in that test. 


\subsection{Task 12 - Pyritic Limestone Ignition Tests}

In Task 12, a limited number of tests were performed on mixture samples conforming to HM-1 but made with pyritic limestone aggregate instead of the problematic dolomite aggregate. Samples were tested at three test temperatures: $538^{\circ} \mathrm{C}$ $\left(1000^{\circ} \mathrm{F}\right), 483^{\circ} \mathrm{C}\left(900^{\circ} \mathrm{F}\right)$ and $427^{\circ} \mathrm{C}\left(800^{\circ} \mathrm{F}\right)$. The samples were heated in the ignition oven for 240 minutes. As shown in Figure 5.36, the samples with pyritic limestone exhibit much smaller mass losses than those with problematic dolomite. In addition, the influence of the test temperature on the sample mass is much smaller for the pyritic limestone than for the dolomite aggregate: for pyritic limestone in tests run at $538^{\circ} \mathrm{C}$ and $427^{\circ} \mathrm{C}$ only a $0.5 \%$ difference in mass loss was noticed; for dolomite this difference was $5.0 \%$.

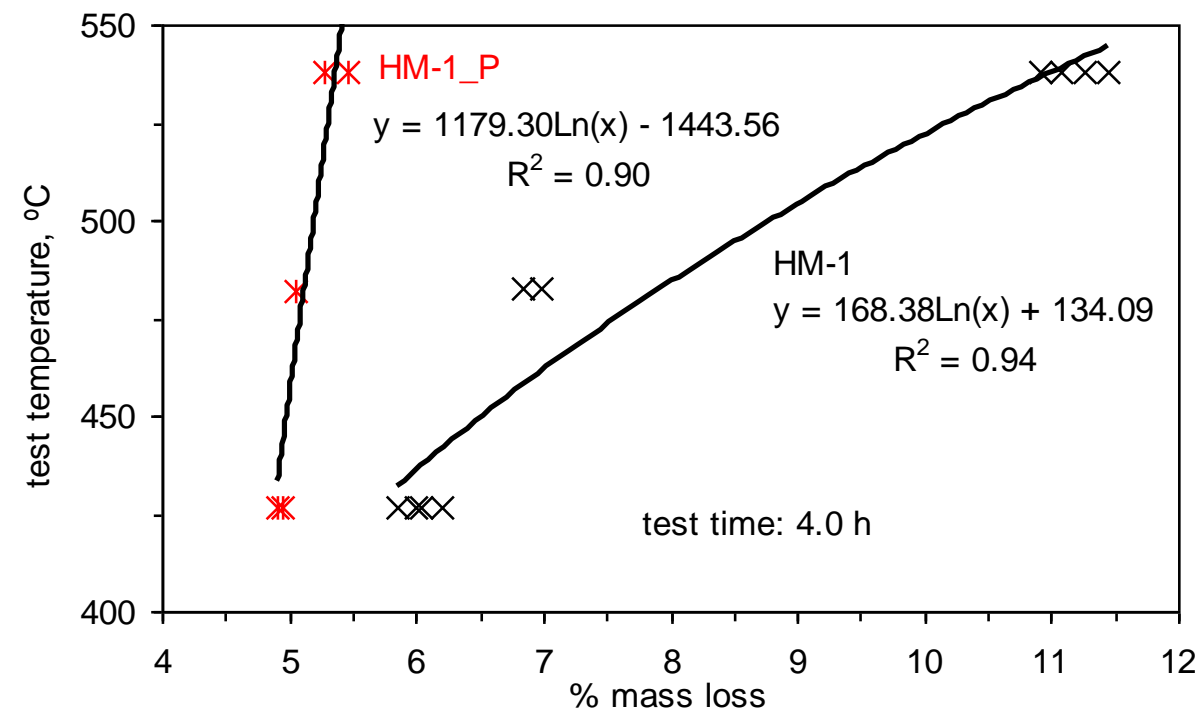

Figure 5.36. Comparison of the relationship between test temperature and mass loss measured after 4.0 hours ignition test for HM-1 with dolomite and HM-1_P with pyritic limestone. 
This task leads to the conclusion that the pyritic limestone is less susceptible to the test temperature than problematic dolomite.

\subsection{Phase One Conclusions and Phase Two Plan}

The results of Phase I lead to the following conclusions:

- When testing non-problematic mixtures in the ignition oven, the oven temperature drops when the door is opened, then overshoots the target temperature as it heats up again. After overshooting, the oven recovers and attains the target. The temperature increases again when the binder in the mix ignites. When the binder ignition ceases, the target temperature is again reached and the test terminates. The mass loss proceeds at a high rate as the oven temperature increases initially, then decreases and eventually levels off when all the binder has been removed.

- When testing problematic mixes, the oven temperature exhibits a similar pattern but the mass loss does not stabilize and the test does not automatically terminate.

- An unconventional non-thermal shock (nTS) method was compared to the standard thermal shock (TS) method and provided better temperature control; the oven temperature did not significantly exceed the target in the nTS method. The nTS method resulted in a lower mass loss for the problematic aggregate, presumably because the aggregate was not exposed to higher temperatures. The nTS method is more time consuming, however, making it less practical for routine testing. 
- The ignition oven procedure did result in changes in the specific gravities and absorption of the problematic dolomite but the differences between the thermal shock and the non-thermal shock methods were minimal.

- The gradations compared before and after the ignition oven test were not markedly different.

- Mixes with higher binder contents exhibit greater mass changes than mixes with lower binder contents, as expected. Higher binder contents also appear to lead to faster increases in the oven temperature and higher temperatures as the binder ignites.

- With problematic dolomite, mass losses occur in the aggregate even when binder is not present to ignite.

- High dolomite contents (as in pure dolomite) lead to higher mass losses when the aggregate is exposed to high temperatures.

- The length of time the problematic aggregate is exposed to high temperatures also affects the mass loss, with more loss as time progresses.

- Higher test temperatures lead to higher mass losses with problematic aggregates, so lower test temperatures are preferred.

- Temperatures as low as $427^{\circ} \mathrm{C}$ are sufficient to remove the binder from mixes and do result in significantly less mass loss than higher temperatures; the mass loss with problem aggregates, however, still may not stabilize.

- At higher test temperatures, the oven exceeded the target temperature more quickly.

- The temperature is not consistent throughout the oven chamber. The temperature in the vicinity of the upper basket is as much as $50^{\circ} \mathrm{C}$ higher than that in the lower 
basket. The temperature at the oven thermistor is between those at the upper and lower basket locations. The presence of binder to ignite yields even greater differences in the temperatures at these various locations.

- A two-step test procedure can be used whereby most of the binder can be removed at low temperature and the remaining soot can be burned off in a shorter time at a high temperature. The procedure offers few advantages, however, since the amount of soot present after the low temperature step did not significantly affect the measured binder content and the test is much more time consuming.

- The two-step test did verify that the binder can be effectively removed at a lower test temperature even if it appears that some soot remains on the aggregate.

- Cooling the sample after testing before determining the sample mass with an external balance does result in an increase in the sample mass due to the buoyancy effect of a hot sample. After the sample cools, its mass continues to increase, presumably through the absorption of moisture from the air. The cooling period should be consistent and limited to avoid these effects. With an internal balance, these effects are limited and masses are measured consistently.

- The glass-cleaning oven can be used to burn off the binder from a mix and does result in better temperature control, which can in turn result in less variable mass loss. This is not an ideal option, however, because not all labs have glass cleaning ovens and they do not have internal balances.

- Thermogravimetric analysis showed that samples of dolomitic aggregate that had been exposed to high temperatures in the ignition oven had partially decomposed and therefore exhibited less mass loss in the TGA. Samples of dolomitic aggregates 
recovered from hot mix samples after the ignition oven test had decomposed more than samples of aggregate only, due to the higher temperatures in the ignition oven when the binder ignited.

- X-ray diffraction testing confirmed the presence of calcite and periclase in aggregate samples that had been exposed to high temperatures in the ignition oven; these minerals were formed by the decomposition of dolomite in the ignition oven.

- Limited testing showed that the pyritic limestone tested here is less susceptible to the test temperature than problematic dolomite.

Based on the findings from Phase One, several changes to the standard IO test method were proposed, resulting in the "modified" IO test procedure. This modified test procedure calls for lowering the test temperature to $427^{\circ} \mathrm{C}$ and using the bottom basket only (with half the total sample mass). The lower temperature was shown in Phase One to result in less mass loss while still removing the binder. Since the temperature in the top basket was determined to be significantly higher than in the lower basket, placing mix in the lower basket only would reduce the exposure of the problematic aggregate to excessive temperatures. The proposed changes should minimize aggregate mass losses and provide more uniform temperature distribution during the IO test without significantly increasing the test time.

In Phase Two, then, the modified test method was evaluated. Results from the modified method were compared to results from the standard ignition oven method and to a solvent extraction for samples of plant produced mixes containing problematic and nonproblematic aggregates. 


\section{CHAPTER 6: TEST RESULTS AND DISCUSSIONS - PHASE II}

As mentioned earlier, the results of Phase One of this study resulted in the development of a modified ignition oven test protocol for HMA with high mass loss aggregates. Phase Two of this research involved the verification of the proposed modified test method. As explained in chapters 3 and 4, six different mixes (HM-A to HM-F) were tested.

\subsection{Task 13 - Comparison of Standard and Modified Ignition Oven Methods}

As described in Chapter 3, this task involved testing six plant-produced mixes containing various proportions of the same problematic dolomite as tested in Phase One, ranging from 14 to $94 \%$ of the total aggregate mass. (These mixes were summarized in Table 3.2.) Some mixes also contain less problematic or non-problematic aggregates. All of the mixes tested were $9.5 \mathrm{~mm}$ mixes except for HM-B, which was a $19 \mathrm{~mm}$ mix.

Each mix was tested using the standard and modified test methods at two or three test temperatures. The binder contents were also determined using solvent extraction for comparison. The results of all of these tests are summarized in Table 6.1. As expected, the ignition oven test results were dependent on both the test temperature and the test method used. 
Table 6. 1. Comparison of the results: mixes HM-A to HM-F.

\begin{tabular}{|c|c|c|c|c|c|c|}
\hline $\begin{array}{c}\text { Mix } \\
\text { (Binder \%) }\end{array}$ & $\begin{array}{c}\text { Test } \\
\text { method }\end{array}$ & $\underset{{ }^{\circ} \mathbf{C}}{\text { Temp. }}$ & $\begin{array}{c}\text { Test } \\
\text { time, } \\
\text { min. }\end{array}$ & $\begin{array}{c}\text { Mass loss, } \\
\%\end{array}$ & $\begin{array}{c}\text { St dev (mass } \\
\text { loss, \%) }\end{array}$ & $\begin{array}{c}\text { IO mass loss- } \\
\text { solvent extr., } \\
\%\end{array}$ \\
\hline \multirow{6}{*}{$\begin{array}{l}\text { HM-A } \\
(5.3 \%)\end{array}$} & standard & 427 & 41 & 6.50 & 0.18 & 1.48 \\
\hline & modified & 427 & 50 & 6.13 & 0.08 & 1.11 \\
\hline & standard & 483 & 55 & 7.22 & 0.10 & 2.20 \\
\hline & modified & 483 & 52 & 6.75 & 0.06 & 1.73 \\
\hline & \multicolumn{3}{|c|}{ solvent extraction } & 5.03 & & 0.06 \\
\hline & $\mathrm{CF}$ & 0.95 & 44 & & $0.08^{*}$ & \\
\hline \multirow{6}{*}{$\begin{array}{l}\text { HM-B } \\
(3.7 \%)\end{array}$} & standard & 427 & 64 & 4.75 & 0.33 & 1.67 \\
\hline & modified & 427 & 57 & 4.19 & 0.16 & 1.11 \\
\hline & standard & 483 & 98 & 5.58 & 0.21 & 2.50 \\
\hline & modified & 483 & 52 & 4.63 & 0.19 & 1.55 \\
\hline & \multicolumn{3}{|c|}{ solvent extraction } & 3.08 & & 0.08 \\
\hline & $\mathrm{CF}$ & 1.00 & 56 & & $0.13^{*}$ & \\
\hline \multirow{6}{*}{$\begin{array}{l}\text { HM-C } \\
(5.4 \%)\end{array}$} & standard & 427 & 42 & 6.51 & 0.19 & 0.93 \\
\hline & modified & 427 & 44 & 6.52 & 0.08 & 0.94 \\
\hline & standard & 483 & 42 & 6.80 & 0.09 & 1.22 \\
\hline & modified & 483 & 36 & 6.83 & 0.25 & 1.25 \\
\hline & \multicolumn{3}{|c|}{$\begin{array}{l} \\
\text { solvent extraction }\end{array}$} & 5.58 & & 0.06 \\
\hline & $\mathrm{CF}$ & 0.56 & 54 & & $0.14^{*}$ & \\
\hline \multirow{6}{*}{$\begin{array}{l}\text { HM-D } \\
(5.8 \%)\end{array}$} & standard & 427 & 42 & 7.03 & 0.02 & 1.62 \\
\hline & modified & 427 & 45 & 6.71 & 0.10 & 1.30 \\
\hline & standard & 483 & 66 & 7.42 & 0.07 & 2.01 \\
\hline & modified & 483 & 31 & 7.40 & 0.01 & 1.99 \\
\hline & \multicolumn{3}{|c|}{$\begin{array}{l} \\
\text { solvent extraction }\end{array}$} & 5.41 & & 0.06 \\
\hline & $\mathrm{CF}$ & 1.16 & 44 & & $0.25^{*}$ & \\
\hline \multirow{6}{*}{$\begin{array}{l}\text { HM-E } \\
(5.6 \%)\end{array}$} & standard & 427 & 46 & 6.56 & 0.30 & 1.29 \\
\hline & modified & 427 & 45 & 6.19 & 0.07 & 0.92 \\
\hline & standard & 483 & 39 & 6.95 & 0.05 & 1.68 \\
\hline & modified & 483 & 35 & 6.87 & 0.00 & 1.60 \\
\hline & \multicolumn{3}{|c|}{$\begin{array}{l} \\
\text { solvent extraction }\end{array}$} & 5.27 & & 0.06 \\
\hline & $\mathrm{CF}$ & 1.01 & 41 & & $0.26^{*}$ & \\
\hline \multirow{6}{*}{$\begin{array}{l}\text { HM-F } \\
(6.1 \%)\end{array}$} & standard & 427 & 46 & 6.76 & 0.21 & 0.52 \\
\hline & modified & 427 & 46 & 6.82 & 0.07 & 0.59 \\
\hline & standard & 483 & 47 & 7.06 & 0.06 & 0.82 \\
\hline & modified & 483 & 34 & 7.12 & 0.00 & 0.89 \\
\hline & \multicolumn{3}{|c|}{$\begin{array}{ll}\text { solvent extraction } \\
\end{array}$} & 6.24 & 0.12 & \\
\hline & $\mathrm{CF}$ & 0.35 & 44 & & $0.21 *$ & \\
\hline
\end{tabular}

*Standard deviation for calibration sample based on 4 tests; all other standard deviation based on 2 results. Calibration factor (CF) is the difference between ignition oven test result and known binder content; $\mathrm{CF}$ was determined based on the laboratory produced mixes, using job mix formula (JMF) and raw material provided by the HMA producer. 
In most cases, the modified test method results were lower than those for the standard protocol; the differences between both methods were observed to be around $0.3 \%$. The maximum differences between the methods were $0.56 \%$ and $0.96 \%$ for tests performed at $427^{\circ} \mathrm{C}$ and at $483^{\circ} \mathrm{C}$, respectively. The average differences between the methods were $0.26 \%$ and $0.24 \%$ for tests performed at $427^{\circ} \mathrm{C}$ and at $483^{\circ} \mathrm{C}$, respectively. In addition, it was observed that in most cases the proposed modified test method (performed at $427^{\circ} \mathrm{C}$ and using bottom basket only) yielded the smallest mass loss values and smallest standard deviation values.

Ignition tests conducted at $538^{\circ} \mathrm{C}$ (samples HM-A and HM-B) were terminated manually after 120 minutes as they did not reach the designated cut off level. Mass losses at the end of this time were $10.28 \%$ (HMA-A) and $8.04 \%$ (HMA-B) for the standard method and $9.31 \%$ and $6.92 \%$, respectively, for the modified method. (Note: the JMF binder contents for these mixes were only $5.3 \%$ and $3.7 \%$, respectively.) At the time of termination of these tests, the mass losses were still increasing. Due to this instability, tests at $538^{\circ} \mathrm{C}$ were not conducted for mixes HM-C to HM-F.

\subsection{Task 14 - Comparison of the Modified IO Method and Solvent Extraction}

For the typical usage of the ignition oven in mix production control, a calibration (or correction) factor (CF) is applied to the ignition test result to obtain the binder content. In this study, CFs for the laboratory produced mixes were obtained for the modified method conducted at $427^{\circ} \mathrm{C}$. Four calibration samples were fabricated in the lab from the raw materials for each of the six mixes. These samples were prepared using the same 
blended aggregate and binder as was used in the plant-produced mixes. The binder content was that called for in the Job Mix Formula. The calculated CFs were then applied to the plant-produced mixes tested using the same (modified) method and at the same test temperature $\left(427^{\circ} \mathrm{C}\right)$. As shown in Table 6.1, the CFs were high (around $1 \%$ ) in four cases. For two mixes, the CFs were found to be 0.56 and $0.35 \%$. However, for higher test temperatures or the standard test method, even higher calibration factors may be expected.

As shown in Figure 6.1, the differences between the binder contents determined by the solvent extractions and the modified ignition oven tests were small. (These differences are also summarized in the last column of Table 6.1.) In addition, the standard deviations (shown in Table 6.1) were similar for both binder content determination methods, though the solvent extraction variability was slightly smaller. This suggests that the reduced sample size in the modified procedure is still representative of the mixture properties since it compares well with the solvent extraction. 


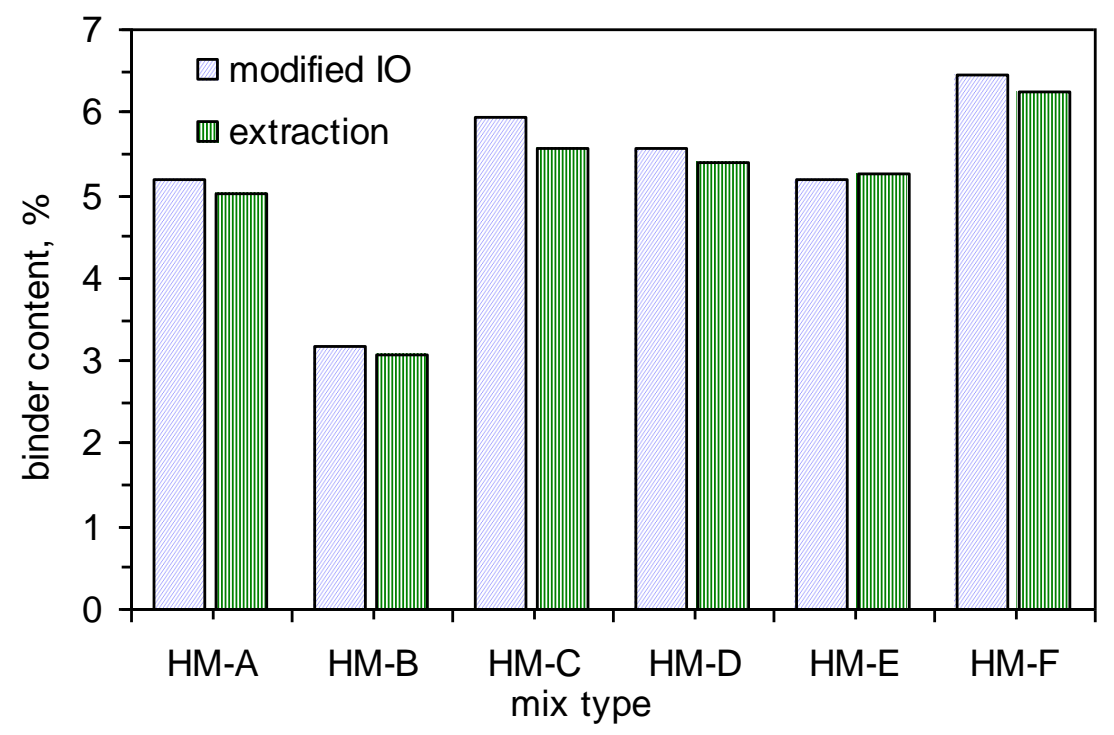

Figure 6.1. Comparison of the binder content determination: solvent extraction and corrected modified IO test procedure run at $427^{\circ} \mathrm{C}$.

The reduced size of sample, however, might not be adequate for determination of the gradation. If gradation is required, the ignition oven procedure could be run twice and the extracted aggregate combined for sieve analysis. Splitting the sample and recombining after two separate runs of the ignition oven procedure is allowed by AASHTO T308.

Examination of Table 6.1 also reveals that the differences between the mass loss results from the standard and modified methods were comparable when the calibration factors were significantly below 1.00. For mixes HM-C and HM-F, with CFs of 0.56 and 0.35 respectively, the standard method actually yielded slightly lower mass losses than the modified method and therefore compared slightly better with the solvent extraction.

Based on the results of Phase Two, the modified method is recommended for use with known problematic aggregates. The method could also be used with unknown 
aggregates when the calibration factor is determined to be greater than 1.0 or when the standard test method does not terminate after a pre-determined period of time; 90 minutes is the recommended maximum. New calibration factors should be determined for the modified method; these values may still be close to 1.0, but the mass loss results will be more accurate and will compare better with solvent extraction.

This proposed modified test method should be evaluated in a pilot study in one or two INDOT districts where problematic aggregates are common (such as Crawfordsville). The pilot study should explore the possibility of refining the recommended calibration factor level at which to change from the standard to the modified test method. It should also investigate whether the reduced sample size is adequate for gradation determination or if the modified ignition oven procedure must be run twice to collect enough aggregate for sieve analysis. 


\section{CHAPTER 7: CONCLUSIONS}

In addition to the task specific findings summarized in 5.13, the following, more general conclusions and recommendations resulted from this research.

The research results presented in this report proved that HMA mixtures containing dolomitic aggregate will experience additional mass loss during the ignition oven test above that expected from burning off the binder alone. That additional mass loss is the result of the decomposition of the dolomitic aggregate. Furthermore, research proved that for HMA containing dolomite the mass loss occurring during the ignition oven test is both temperature and time dependent. That additional mass loss may be reduced if the ignition oven test is conducted at a lower temperature or by shortening the length of the testing period. The use of a temperature as low as $427^{\circ} \mathrm{C}$ was shown to adequately remove the binder from the mix.

The temperature observed during the typical ignition oven test can be significantly $\left(40\right.$ to $60^{\circ} \mathrm{C}$ ) higher than the pre-set oven temperature, depending on the type of the mix. This increase in the temperature will lead to additional mass losses in mixes with susceptible aggregate.

The additional mass loss observed in the glass cleaning oven was lower than that observed in the traditional ignition oven, presumably due to differences in the heating process associated with these two types of ovens. While the glass cleaning oven was 
observed to be suitable for determination of the binder content, the lack of an internal balance and the relative scarcity of the ovens in INDOT labs lessen the value of implementing it for this use.

In this study, it was found that the temperature difference between the top and bottom baskets is significant, amounting to around $58^{\circ} \mathrm{C}$. In the vicinity of the dolomite decrepitation temperature, this temperature increase of $58^{\circ} \mathrm{C}$ in the top basket may result in increased mass loss and decomposition of the aggregate. If HMA were placed only in the bottom basket, the sample temperature would be more uniform and decomposition would be limited.

Based on these findings, a modified ignition oven test procedure was developed. The method involves placing half the total sample mass in the bottom basket only, then running the ignition oven procedure at a temperature of $427^{\circ} \mathrm{C}$. Comparisons between the binder content test methods (solvent extraction and modified ignition oven test run at $427^{\circ} \mathrm{C}$ or $800^{\circ} \mathrm{F}$ ) proved that both test methods yield similar results.

A modified ignition oven test method is therefore recommended for use with problematic aggregates. This method should be used with known problematic aggregates or unfamiliar aggregates when the calibration factor is determined to be greater than or equal to 1.0 or when the standard test does not automatically terminate in less than 90 minutes. 
APPENDICES 


\section{Appendix A: Temperature Distribution and Variation}

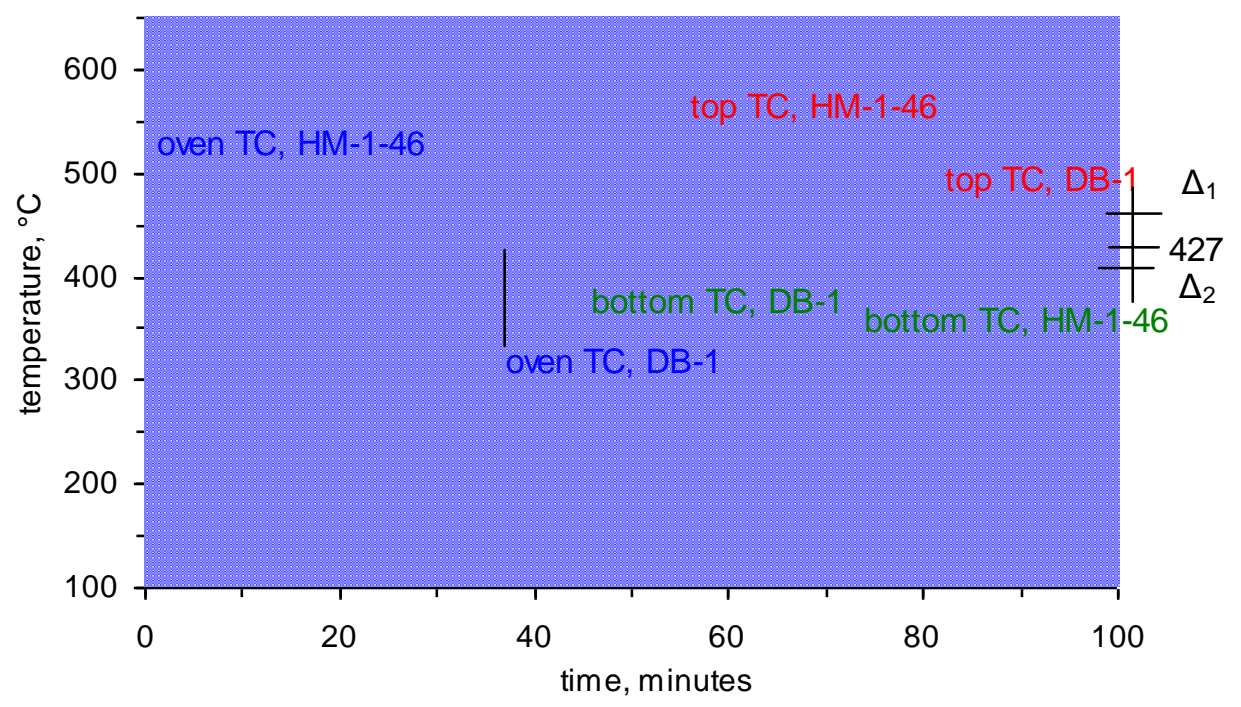

Figure A-1. Typical temperature distribution plot for HMA with 4.6\% asphalt (HM-1) and DB- 1 at $427^{\circ} \mathrm{C}$.

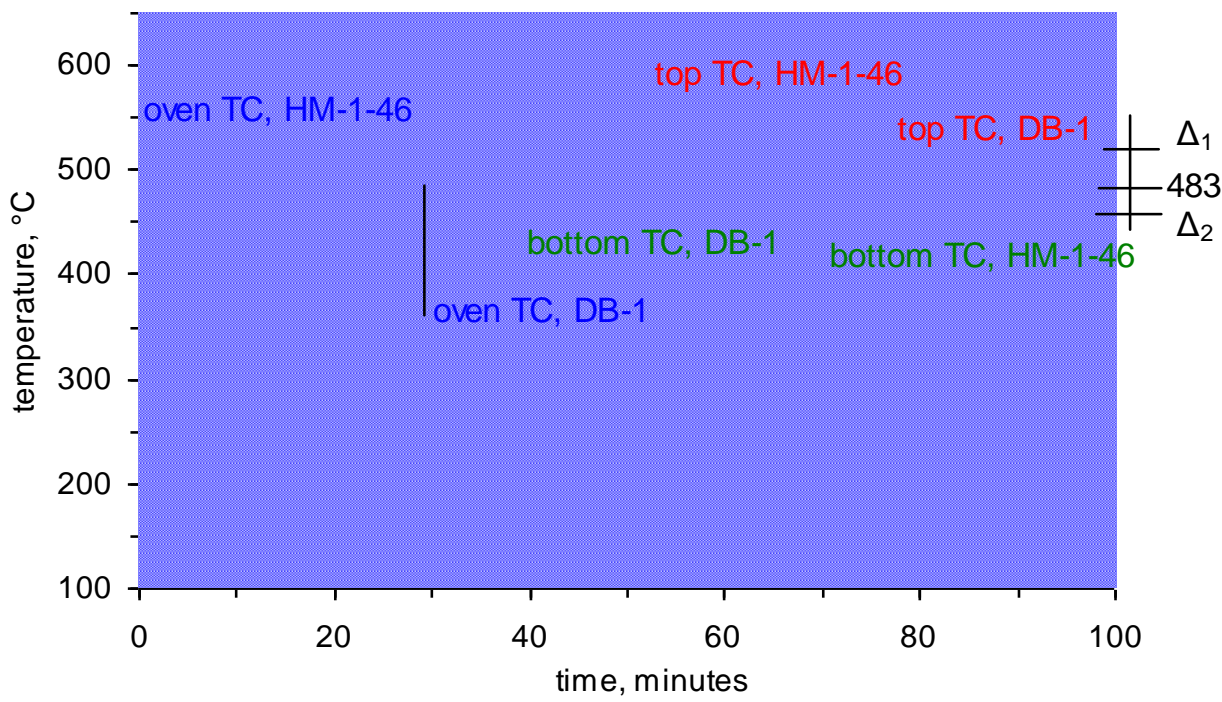

Figure A-2. Typical temperature distribution plot for HMA with 4.6\% asphalt (HM-1) and DB- 1 at $483^{\circ} \mathrm{C}$. 


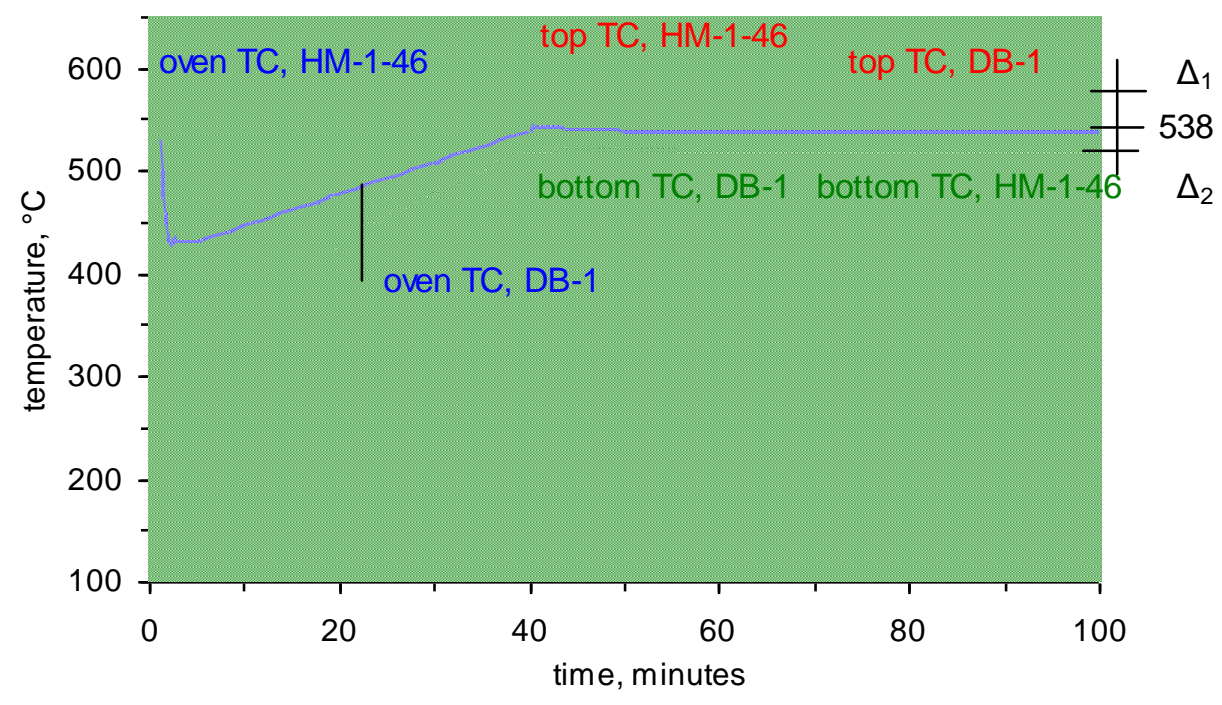

Figure A-3. Typical temperature distribution plot for HMA with 4.6\% asphalt (HM-1) and DB- 1 at $538^{\circ} \mathrm{C}$.

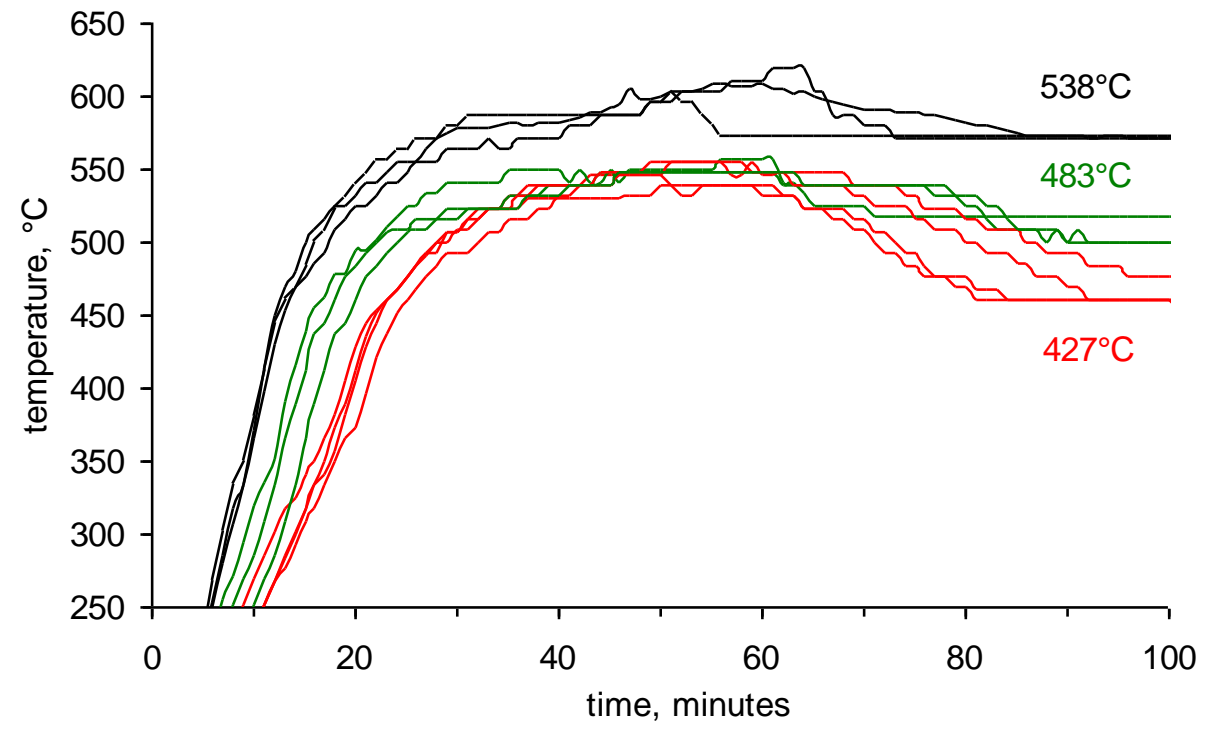

Figure A-4. --Temperature variation during ignition test with HM-1, 4.6\% binder. Top thermocouple reading. 


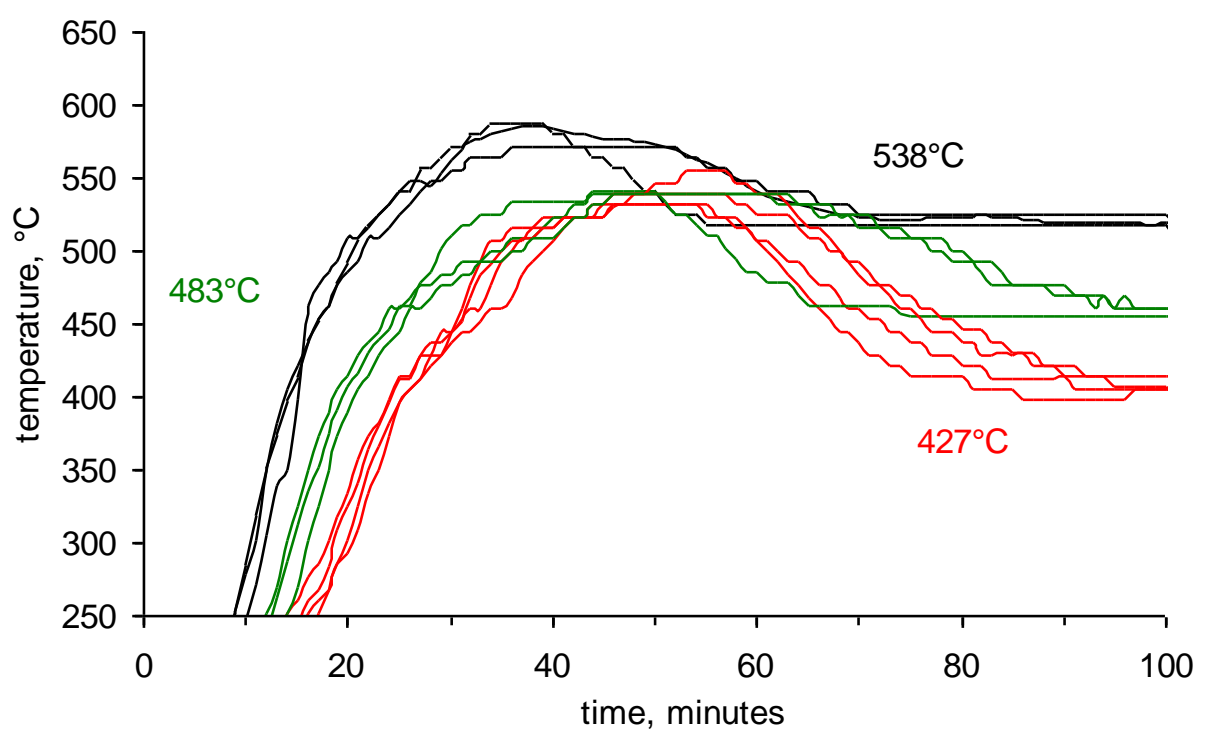

Figure A-5. Temperature variation during ignition test with HM-1, 4.6\% binder. Bottom thermocouple reading. 


\section{Appendix B: Compositional Analysis}

Table B-1. XRD test results.

\begin{tabular}{|c|c|c|c|c|c|c|c|c|c|}
\hline Sample & $\begin{array}{l}\text { Time of } \\
\text { Ignition, } \\
h\end{array}$ & $\begin{array}{l}\text { Main } \\
\text { Dolomite } \\
\text { Peak, } \\
\text { counts }\end{array}$ & Average & $\begin{array}{c}\text { Relative } \\
\text { Intensity - } \\
\text { Main Calcite } \\
\text { Peak, \% }\end{array}$ & $\begin{array}{c}\text { Average, } \\
\%\end{array}$ & $\begin{array}{l}\text { Relative Intensity - } \\
\text { Main Magnesium } \\
\text { Oxide Peak, \% }\end{array}$ & $\begin{array}{c}\text { Average, } \\
\%\end{array}$ & $\begin{array}{l}\text { Relative Intensity - } \\
\text { Main Calcium } \\
\text { Oxide Peak, \% }\end{array}$ & $\begin{array}{l}\text { average, } \\
\%\end{array}$ \\
\hline DB-1_b-R1 & --- & 22777 & 21158 & 0.3 & 0.3 & 0.3 & 0.3 & 2.7 & 1.4 \\
\hline DB-1_b-R2 & --- & 23804 & & 0.2 & & 0.3 & & 0.5 & \\
\hline DB-1-nTSa-R1 & 6.3 & 17320.0 & 17044.3 & 9.5 & 13.5 & 2.5 & 3.3 & 1 & 3.2 \\
\hline DB-1-nTSa-R2 & 10.0 & 18264.0 & & 10.9 & & 2.9 & & 3.3 & \\
\hline DB-1-TSa-R2 & 8.1 & 18282.0 & & 12.4 & & 3.3 & & 1.7 & \\
\hline HM-1-36-nTSa-R1 & 6.4 & 16077.0 & 14591.5 & 15.8 & 19.0 & 4.1 & 5.1 & 3.2 & 2.1 \\
\hline HM-1-36-nTSa-R2 & 10.0 & 13106.0 & & 22.1 & & 6.1 & & 0.9 & \\
\hline HM-1-46-nTSa-R2 & 9.1 & 14802.0 & 16265.5 & 28.4 & 21.7 & 7.8 & 6.0 & 1.3 & 1.5 \\
\hline HM-1-46-nTSa-R3 & 10.0 & 17729.0 & & 14.9 & & 4.1 & & 1.6 & \\
\hline HM-1-56-nTSa-R1 & 10.0 & 15306.0 & 14958.0 & 19.4 & 22.7 & 5 & 5.9 & 2.8 & 2.1 \\
\hline HM-1-56-nTSa-R2 & 10.0 & 14610.0 & & 25.9 & & 6.8 & & 1.4 & \\
\hline HM-1-46-TSa-R1 & 1.5 & 23524.0 & 16539.5 & 6.4 & 28.3 & 1.5 & 7.6 & 2.7 & 1.8 \\
\hline HM-1-46-TSa-R2 & 5.0 & 9555.0 & & 50.2 & & 13.6 & & 0.8 & \\
\hline pD_b & --- & 42381.5 & & & & & & 0.15 & \\
\hline pD_nTSa & 8.4 & 40000.0 & 41520.0 & & & & & 0.4 & \\
\hline pD_TSa & 8.0 & 42178.5 & & & & & & 0.15 & \\
\hline
\end{tabular}


Table B-2. TGA results, $\mathrm{CO}_{2}$ purge gas.

\begin{tabular}{|c|c|c|c|c|c|c|c|c|c|}
\hline \multirow[t]{2}{*}{ Sample } & \multirow{2}{*}{$\begin{array}{l}\text { Stage } 0 \\
\text { Temp }\end{array}$} & \multicolumn{2}{|c|}{ Stage 1} & \multicolumn{2}{|c|}{ Stage 2} & \multicolumn{2}{|c|}{ Stage 3} & \multicolumn{2}{|c|}{ Stage 4} \\
\hline & & Temp & $\%$ Mass & Temp & $\%$ Mass & Temp & $\%$ Mass & Temp & $\%$ Mass \\
\hline DB-1_b-R1 & 567 & 745 & 93.0 & 815 & 77.1 & 929 & 75.7 & 979 & 52.8 \\
\hline DB-1_b-R2 & 554 & 739 & 93.0 & 813 & 76.7 & 926 & 75.7 & 975 & 52.3 \\
\hline DB-1-nTSa-R1 & 578 & 731 & 95.8 & 812 & 81.1 & 929 & 79.9 & 977 & 55.4 \\
\hline DB-1-nTSa-R2 & 575 & 745 & 95.7 & 813 & 81.5 & 926 & 80.6 & 977 & 56.1 \\
\hline DB-1-TSa-R2 & 560 & 710 & 96.0 & 809 & 81.9 & 922 & 80.9 & 966 & 56.3 \\
\hline HM-1-36-nTSa-R1 & 573 & 747 & 95.8 & 810 & 83.2 & 926 & 82.0 & 972 & 57.4 \\
\hline HM-1-36-nTSa-R2 & 572 & 740 & 96.4 & 813 & 83.8 & 926 & 82.9 & 979 & 57.4 \\
\hline HM-1-46-nTSa-R2 & 550 & 744 & 96.2 & 809 & 86.6 & 925 & 85.5 & 974 & 59.3 \\
\hline HM-1-46-nTSa-R3 & 589 & 744 & 96.2 & 813 & 83.1 & 926 & 82.2 & 972 & 57.0 \\
\hline HM-1-56-nTSa-R1 & 592 & 745 & 96.2 & 815 & 83.6 & 925 & 82.4 & 977 & 57.4 \\
\hline HM-1-56-nTSa-R2 & 592 & 745 & 96.5 & 815 & 85.5 & 928 & 84.3 & 979 & 58.6 \\
\hline HM-1-46-TSa-R1 & 570 & 747 & 95.3 & 817 & 79.7 & 928 & 78.7 & 972 & 54.4 \\
\hline HM-1-46-TSa-R2 & 580 & 742 & 96.7 & 809 & 88.3 & 925 & 87.3 & 974 & 60.3 \\
\hline pD_b & 566 & 736 & 97.9 & 823 & 77.1 & 931 & 76.1 & 979 & 52.8 \\
\hline pD_nTSa & 569 & 732 & 97.9 & 823 & 77.6 & 926 & 76.7 & 977 & 53.0 \\
\hline pD_Tsa & 566 & 727 & 98.6 & 835 & 77.4 & 933 & 76.5 & 978 & 52.9 \\
\hline $\min$ & 550 & 727 & 93 & 809 & 77 & 925 & 76 & 972 & 52 \\
\hline $\max$ & 592 & 747 & 99 & 835 & 88 & 933 & 87 & 979 & 60 \\
\hline
\end{tabular}




\section{Appendix C: Proposed Changes to ITM 586}

In order to provide the modified test method as an alternate to be used with problematic aggregate, the following changes/additions to the current ITM 586-10T are proposed.

Add 6.11:

6.11 If the calibration factor is equal to or greater than 1.00 or if the test does not automatically terminate at the pre-set shut-off limit, follow 9.0.

\section{Add 9.0 (and renumber existing sections 9.0 and 10.0 accordingly):}

\subsection{ALTERNATE ASPHALT CONTENT PROCEDURE}

This alternate method is used with aggregates exhibiting excessive mass loss in the ignition oven. It may be used with known problematic aggregates (including some dolomites), aggregates with calibration factors greater than 1.00 or with aggregates whose mass does not stabilize at the shut-off limit to terminate the test automatically.

9.1 Determine a new calibration factor by following the 6.0 except use half the recommended sample mass and place it in the bottom basket only. Use a temperature of $800^{\circ} \mathrm{F}\left(427^{\circ} \mathrm{C}\right)$.

9.2 Determine the asphalt content according to 8.0 except use half the recommended sample mass and place it in the bottom basket only. Use a test temperature of $800^{\circ} \mathrm{F}$ $\left(427^{\circ} \mathrm{C}\right)$. 
9.3 If the aggregate gradation is required, run a second sample according to 9.2 and combine the two resulting aggregate samples then test according to 10.0.

\section{Add 11.3 to renumbered section on Report:}

11.3 If the alternate produced in 9.0 was used, note this in the report. 


\section{REFERENCES}




\section{List of Specifications and Standards}

ASTM D 6307 (2005), “Standard Test Method for Asphalt Content of Hot-Mix Asphalt by Ignition Method"

AASHTO R 30 (2002), "Standard Practice for Mixture Conditioning of Hot-Mix Asphalt (HMA)"

AASHTO T 27 (1999), "Standard Method of Test for Sieve Analysis of Fine and Coarse Aggregates" -Twentieth Edition; ASTM C136-96a

AASHTO T 85 (1991), "Standard Method of Test for Specific Gravity and Absorption of Coarse Aggregate" - ASTM Designation: C 127-88 (1993)

AASHTO T 228 (2004), "Standard Method of Test for Specific Gravity of Semi-Solid Bituminous Materials” - ASTM Designation: D 70-03

AASHTO T 308 (2005), "Standard Method of Test for Determining the Asphalt Binder Content of Hot-Mix Asphalt (HMA) by the Ignition Method"

AASHTO T 319 (2003), "Standard Method of Test for Quantitative Extraction and Recovery of Asphalt Binder from Asphalt Mixtures." 


\section{List of References}

1. Brown, E. R., Murphy N. E., Yu L. and Mager S., "Historical Development of Asphalt Content by the Ignition Method," Asphalt Paving Technology, Association of Asphalt Paving Technologists, St. Paul, MN, 1995, pp. 1-35.

2. Behrens, M. L., Dvorak B. I. and Woldt W. E., "Comparison of Asphalt Extraction Procedures: Implications of Hidden Environmental and Liability Costs," Transportation Research Record 1661, Transportation Research Board, Washington, DC, 1999, pp. 46-53.

3. Brown, E. R. and Mager S., “Asphalt Content by Ignition Round Robin Study,” Report No. 95-3, National Center for Asphalt Technology, Auburn, AL, 1995.

4. McKeen, R. G., “Asphalt Content by Ignition: Round Robin Experiment,” New Mexico State Highway and Transportation Department, Santa Fe, NM, December 1997, pp. 13-14.

5. Burati, J.L. and Connell J., "Study of Alternative Procedures for Controlling and Accepting Asphalt Mixtures," FHWA-SC-96-05, Washington, DC, 1996.

6. Howard, C. P. and Burati J. L., "Study of the NCAT Ignition Oven for Control of Asphalt Mixtures," FHWA-SC-96-06, Washington, DC, 1996.

7. Lee, R. E. and Tahmoressi M., "Using Ignition Ovens to Determine Asphalt Content and to Prepare Aggregates for Sieve Analysis," Texas DOT, Austin, TX, 1996.

8. Mallick, R. and Brown E. R., "Limited Round Robin Asphalt Content Test Using Troxler Furnace," Report No. 99-6, National Center for Asphalt Technology, Auburn, AL, 1999.

9. Schroer J., "Asphalt Content of Dolomite Mixtures Using the Troxler NTO," Missouri DOT, August 21, 2002.

10. Prowell B. D. and Schreck R., "Asphalt Content by the Ignition Method: Virginia's Experience," Eight International Conference on Asphalt Pavements, University of Washington, Seatle, August 10-14, 1997.

11. "Asphalt Content by the Ignition Method, VTM 102" Orientation School, Virginia DOT, Virginia Transportation Research Council (VTRC), Virginia Asphalt Association (VAA), Virginia, April 1995.

12. Hurley G. C. and Prowell B. D., "Evaluation of Infrared Ignition Furnance for Determination of Asphalt Content," Transportation Research Record no. 1861, 2003, pp. 44-50. 
13. Prowell B. D., "Evaluation of Infrared Ignition Furnace for Determination of Asphalt Content," Report No. 02-05, National Center for Asphalt Technology, Auburn, AL, 2002, pp. $5-10$.

14. Williams S. G. and Hall K. D., "A Comparison of Ovens Used in Determination Binder Content by the Ignition Method," Journal of Association of Asphalt Paving Technologists, Proceedings of the technical Sessions, Vol. 70, 2002, pp. 712-728.

15. Mallick R., Brown E. R. and McCauley N., "Effect of Ignition Test for Asphalt Concrete on Aggregate Properties," presented at Transportation Research Board $77^{\text {th }}$ Annual Meeting, Washington D.C.,1998, pp. 1-15.

16. Prowell B. D. and Carter C. B., "Evaluation of the Effect on Aggregate Properties of Samples Extracted Using the Ignition Furnance," Virginia DOT, Interim Report, VTRC 00-IR1, April 2000, pp. 14-17.

17. Rogers C., Williams D., Gorman B., Sahsuvar H., Greenbury B. and Masliwec T., "Ignition Oven - Problems with Quartz Rich Aggregates Materials," International Center for Aggregates Research, Twelfth Annual Symposium Proceedings, Denver, CO, April 4-7, 2004.

18. ITM No. 586-06T - "Binder Content by Ignition,” Indiana Department of Transportation, Materials and Test Division, 2006.

19. Ignition Oven Aggregate Mass Loss Procedure, Effective May 1, 2005, Illinois Department of Transportation.

20 . Hinrichsen J. A., Iowa DOT Research on Dolomite Breakdown in the Ignition Oven, Iowa DOT, 2004.

21. Prowell B. D. and Hurley G. C., "Refinement of the Hot Mix Asphalt Ignition Method for High Loss Aggregates," Report No. 05-05, National Center for Asphalt Technology, Auburn, AL, 2005, pp. 4-19.

22. Prowell B. D. and Youtcheff J., "Effect of Lime on Ignition Furnace Calibration," Transportation Research Record no. 1712, 2000, pp. 74-78.

23. Rogers C. W. and Woodhead J. A., "Earth Materials and Earth Resources, vol. III, Earth Science," $1^{\text {st }}$ ed., Salem Press, Inc., Pasadena, CA, Hackensack, NJ, 2001, pp. 1567-1572.

24. Neuendorf K. K. E., Mehl J. P. Jr. and Jackson J. A., "Glossary of Geology,” $5^{\text {th }}$ ed., American Geological Insitute, Alexandria, Virginia, 2005, pp. 166-167. 
25. Schieferdecker A. A. G., "Geological Nomenclature," $1^{\text {st }}$ ed., Royal Geological and Mining Society of the Netherlands, 1959, pp. 0089 and 5383.

26. Bates R. L., Jackson j. A., "Dictionary of Geological Terms," $3^{\text {rd }}$ ed., Anchor Press / Doubleday, Garden City, New York, 1984, pp. 129-130 and 147.

27. Sharp J. H., Wilburn F. W. and McIntosh R. M., "The Effect of Procedural Variables on TG, DTG and DTA Curves of Magnesite and Dolomite," Journal of Thermal Analysis,Vol. 37, 1991, pp.2021-2029.

28. Wilburn F. W. and Sharp J. H., "The Bed-Depth Effect in the Thermal Decomposition of Carbonates," Journal of Thermal Analysis,Vol. 40, 1993, pp. 133-140.

29. Tams C. and Garrabe G., "Characterization of Clay Minerals Using the Diamond TG/DTA," Application Note from PerkinElmer Life and Analytical Sciences company, www.perkinelmer.com.

30. Weast R. C., "Handbook of Chemistry and Physics," $54^{\text {th }}$ ed., CRC Press, Cleveland, Ohio, 1973-74, pp. F-89.

31. McIntosh R. M., Sharp J. H. and Wilburn F. W., "The Thermal Decomposition of Dolomite," Thermochemica Acta, vol. 165, 1990, pp. 281-296.

32. Boynton R. S., "Chemistry and Technology of Lime and Limestone," Second Ed., Wiley Interscience Publisher, New York, 1980, pp. 133-164.

33. Lamar J. E., "Handbook on Limestone and Dolomite for Illinois Quarry Operators," Illinois State Geological Survey, Urbana, Illinois, Bulletin 91, 1967, pp. 84-87.

34. Lamar J. E., "Handbook on Limestone and Dolomite for Illinois Quarry Operators," Illinois State Geological Survey, Urbana, Illinois, Bulletin 91, 1967, pp. 84-87

35. McCauley R. A. and Johnson L. A., "Decrepitation and Thermal Decomposition of Dolomite," Themochimica Acta, vol. 185, 1991, pp. 271-282.

36. Dollimore D., Dunn J. G., Lee Y. F. and Penrod B. M., "The Decrepitation off Dolomite and Limestone," Thermochemica Acta, vol. 237, 1994, pp. 125-131.

37. Samtani M., Dollimore D. and Alexander K.," Thermal Decomposition of Dolomite in an Atmosphere of Carbon Dioxide - the Effect of Procedural Variables in Thermal Analysis," Journal of Thermal Analysis and Calorimetry, vol. 65, 2001, pp. 93-101 
38. Bandi W. R. and Krapf G., "The Effect of $\mathrm{CO}_{2}$ Pressure and Alkali Salt on the Mechanism of Decomposition of Dolomite," Thermochimica Acta, vol. 14, 1976, pp.221-243.

39. McIntosh R. M., Sharp J. H. and Wilburn F. W., "The Thermal Decomposition of Dolomite," Thermochemica Acta, vol. 165, 1990, pp. 281-296.

40. "Unpublished Data," Indiana Department of Transportation and Indiana hot mix asphalt producers, 2002.

41. Indiana Department of Transportation, “2006 Standard Specifications Book,” Section 900 Materials Details, 2005.

42. Operation Manual and Parts List, Series 1087, NCAT Asphalt Content Tester, Barnestead Thermolyne Corporation, 1998.

43. Technical information form Tempyrox Company Pyro-Clean® web page, http://www. pyroclean.com.

44. Prowell B. D., Hurley G. C., "Refinement of the Hot Mix Asphalt Ignition Method for High Loss Aggregates," Report No. 05-05, National Center for Asphalt Technology, Auburn, AL, 2005, pp. 7-8.

45. Search Manual (Hannawalt) and Alphabetical Index (Chemical and Mineral Name), Powder Diffraction File, Inorganic Phases, JCPDS, International Centre for Diffraction Data, Swarthmore, Pa, USA, 1987.

46. Search Manual (Hannawalt) and Alphabetical Index (Chemical and Mineral Name), Powder Diffraction File, Inorganic Phases, JCPDS, International Centre for Diffraction Data, Swarthmore, Pa, USA, 1987. 